\title{
MATERIALS SCIENCE DIVISION \\ COAL TECHNOLOGY NINTH QUARTERLY REPORT,
}

October-December 1976 


\section{DISCLAIMER}

This report was prepared as an account of work sponsored by an agency of the United States Government. Neither the United States Government nor any agency Thereof, nor any of their employees, makes any warranty, express or implied, or assumes any legal liability or responsibility for the accuracy, completeness, or usefulness of any information, apparatus, product, or process disclosed, or represents that its use would not infringe privately owned rights. Reference herein to any specific commercial product, process, or service by trade name, trademark, manufacturer, or otherwise does not necessarily constitute or imply its endorsement, recommendation, or favoring by the United States Government or any agency thereof. The views and opinions of authors expressed herein do not necessarily state or reflect those of the United States Government or any agency thereof. 


\section{DISCLAIMER}

Portions of this document may be illegible in electronic image products. Images are produced from the best available original document. 
The facilities of Argonne National Laboratory are owned by the United States Government. Under the terms of a contract (W-31-109-Eng-38) between the U. S. Energy Research and Development Administration, Argonne Universities Association and The University of Chicago, the University employs the staff and operates the Laboratory in accordance with policies and programs formulated, approved and reviewed by the Association.

\section{MEMBERS OF ARGONNE UNIVERSITIES ASSOCIATION}

The University of Arizona Carnegie-Mellon University Case Western Reserve University

The University of Chicago

University of Cincinnati

Illinois Institute of Technology

University of Illinois

Indiana University

Iowa State University

The University of Iowa
Kansas State University The University of Kansas Loyola University Marquette University Michigan State University The University of Michigan University of Minnesota University of Missouri Northwestern. University University of Notre Dame

\author{
The Ohio State University \\ Ohio University \\ The Pennsylvania State University \\ Purdue University \\ Saint Louis University \\ Southern Illinois University \\ The University of Texas at Austin \\ Washingtun University \\ Wayne State University \\ The University of Wisconsin
}

\section{NOTICE}

This report was prepared as an account of work sponsored by the United States Government. Neither the United States nor the United States Energy Research and Development Administration, nor any of their employees, nor any of their contractors, subcontractors, or their employees, makes any warranty, express or implied, or assumes any legal liability or responsibility for the accuracy, completeness or usefulness of any information, apparatus, product or process disclosed, or represents that its use would not infringe privately-owned rights. Mention of commercial products, their manufacturers, or their suppliers in this publication does not imply or connote approval or disapproval of the product by Argonne National Laboratory or the U. S. Energy Research and Development Administration.

Printed in the United States of America Available from

National Technical Information Service

U. S. Department of Commerce 5285 Port Royal Road

Springfield, Virginia 22161

Price: Printed Copy $\$ 4.50$; Microfiche $\$ 3.00$ 
Distribution Category:

Coal Conversion and Utilization--

Materials and Components (UC-90h)

ANL $-77-5$

ARGONNE NATIONAL LABORATORY

9700 South Cass Avenue

Argonne, Illinois 60439

MATERIALS SCIENCE DIVISION

COAL TECHNOLOGY NINTH QUARTERLY REPORT, OCTOBER-DECEMBER 1976

\section{Persons in Charge}

W. A. Ellingson

Project Leader

R. W. Weeks

Associate Division Director

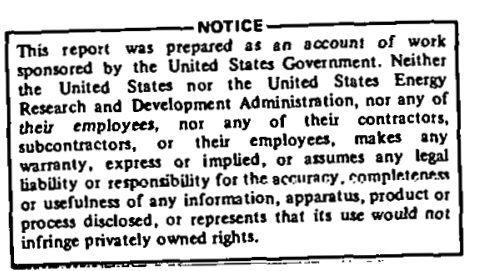

Previous reports in this series

$\begin{array}{lrr}\text { ANL-76-7 } & \text { July-September } & 1975 \\ \text { ANL-76-22 } & \text { October-December } & 1975 \\ \text { ANL-76-60 } & \text { January-March } & 1976 \\ \text { ANL-76-111 } & \Lambda \text { pril-June } & 1976 \\ \text { ANL-76-125 } & \text { July-September } & 1976\end{array}$


THIS PAGE

\section{WAS INTENTIONALLY LEFT BLANK}


HIGHLIGHTS . . . . . . . . . . . . . . . . . . . . . viii

ABSTRACT . . . . . . . . . . . . . . . . . . . . 1

INTRODUCTION . . . . . . . . . . . . . . . . . 1

Task A - Evaluation of Ceramic Refractories for Slagging Gasifiers . . 1

Task C -- Application and Development of Nondestructive Evaluation 3 Methods for Coal-conversion Processes . . . . . . . . .

1. Erosive-wear Detection and Monitoring . . . . ..... 3

a. Metallic Transfer Lines . . . . . . ...... 3

b. Refractory-lined Transfer Lines........... 12

2. Refractory-installation Practices -- Acoustic Emission . . 20

Task D -- Corrosion Behavior of Materials in Coal-conversion Processes . . . . . . . . . . . . . . 26

1. Coal-gasification Processes . . . . . . . . . . 27

2. Alloy Behavior in Process Environments . . . . . . . . . 30

3. Experimental Program . . . . . . . . . . . . . . 31

Task E -- Erosion Behavior of Materials in Coal-conversion Processes . 38

Task F -- Component Performance and Failure Analysis . . . . . . . 48

1. Synthane Weld-neck Flange . . . . . . . . . . . 49

2. Synthane EBV Ball-valve Stem Failure . . . . . . . . . . 51

3. HYGAS $\mathrm{N}_{2}$ Purge Line (322 Line) . . . . . . . . . . . . 53

4. HYGAS Thermocouple Protection Tube Failure . . . . . . . 53

5. GFERC Cracked Gate Valve . . . . . . . . . . . . 54

REFERENCES ........................ . . 55 
1 . Sintered $\mathrm{MgO}-\mathrm{Cr}_{2} \mathrm{O}_{3}$ Bricks After Exposure to Slag . . . . . . . 4

2 Sintered $\mathrm{Al}_{2} \mathrm{O}_{3}-\mathrm{Cr}_{2} \mathrm{O}_{3}$ Bricks after Exposure to. Slag . . . . . 5

3 Various Refractory Bricks after Exposure to Slag . . . . . . . 6

4 Fusion-cast Brick after Exposure to Slag. . . . . . . . . 7

5 Schematic Diagram of Bi-Gas Coal-conversion Process Showing Location of In-situ Erosion-measurement Systems . . . . . . . 9

6 Photograph of Insulation Removal . . . . . . . . . . . . 9

7 Flictegraph of "Tnp Tee" Showing Waveguides with 5-MHz Longitudinal-wave U1trasonic Transducers Attached for Iu-situ Erosion Measurement ................. 10

8 Photograph of Bi-Gas Coal-teed Line Sliviwing Ewcop Ang1es and "Top Tee" ......................... 10

9 Schematic Representation of Erosion-measurement Positions for Bi-Gas Coal-feed Transfer Line . . . . . . . . . . 10

10 Schematic Diagram Showing Monitoring Puints on "Top Tee" . . . . 11

11 Photograph of Installation . . . . . . . . . . . 12

12 Photograph of Installed velay Llues at Lower Sweep Pnsition Prior to Allichment of 5-MHz Transducers . . . . . . . .

13 Schematic of Laboratory Test Arrangement Used to Study Thermal Patterns of Defects .....................

14 Analog-tu-digital Conversion of Fround-level Energles of Thermal Pattern ...................... 14

15 Analog-to-digital Conversion of Thermal Pattern of Sample with Enlarged Cavity vefect . . . . . . . . . . . . . . .

16 Analog-to-digital Conversion of Thermal Pattern of Sample with Enlarged Cavity Defect . . . . . . . . . . . . . . .

.17 Results Obtained from Fig. 15 for Selected Parameters Using Present System for Data Analysic (Cavity Defect) . . . . . . .

18 Results Obtained from Fig. 16 for Selected Parameters Using Present System for Data Analysis (Enlarged Cavity Defect) . . • 
19 Plan View of Ful1-scale Refractory Test Panel . . . . . .

20 Cross-section of Full-scale Refractory Test Panel Showing Hanger and Throughwall Position of Thermocouples . . . . . .

21 Schematic of Automatic Control System for Thermal Curing of Full-scale Refractory Test Panels . . . . . . . . . . .

22 Schematic of Acoustic-emission Data-acquisition System . . •

23 Time-temperature Diagram for Thermocouple Positions 10 and 7 for Curing Cycle ................... 23

24 Total Acoustic-emission Counts as a Function of Time for Acoustic Transducer Location 1 . . . . . . . . . . 24

25 Comparison of Time-temperature Plot with Total Counts-Time Plot. . . . . . . . . . . . . . . . . 24

26 Total Counts vs Temperature for Refractory Curing Cycle . . .

27. Time-Temperature Plots for All Thermocouples at the Two Throughwall Locations . . . . . . . . . . . . . . . . . •

29 Variation of Oxygen Partial Pressure as a Function of Temperature Calculated for Different Coal-gasification Processes .

30 Variation of Sulfur Partial Pressure as a Function of Temperature Calculated for Different Coal-gasification Processes.

31 Variation of Carbon Activity as a Function of Temperature Calculated for Different Coal-gasification Processes . . . .

32 Oxygen-Sulfur Thermochemical Diagram for Type 304 Stainless Steel at 1000,1200 , and $1400 \mathrm{~K}$. . . . . . . . . .

33 Oxygen-Sulfur Thermochemical Diagram for Incoloy 800 at 1000 , 1200 , and $1400 \mathrm{~K}$. . . . . . . . . . . . . .

34 Oxygen-Sulfur Thermochemical Diagram for Inconel 671 at 1000 ,

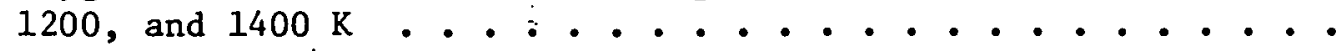

35 Thermodynami.c Stability of Different Phases in U. S. Steel Alloy (Fe-18.5 wt\% $\mathrm{Cr}-18 \mathrm{wt} \% \mathrm{Ni}$ ) and Inconel 671 (50 wt\% Ni$49 \mathrm{wt} \% \mathrm{Cr}-2 \mathrm{wt} \% \mathrm{FC})$ at $1089 \mathrm{~K}\left(1500^{\circ} \mathrm{F}\right)$.......... 
36 Thermodynamic Stability of Different Phases in U. S. Steel. Alloy ( $\mathrm{F}-18.5 \mathrm{wt} \% \mathrm{Cr}-18 \mathrm{wt} \% \mathrm{Ni}$ ) and Inconel 671. (50 wt\% $\mathrm{Ni}-48 \mathrm{wt} \% \mathrm{Cr}-2 \mathrm{wt} \% \mathrm{Fe})$ at $13 \mathrm{~K}\left(2000^{\circ} \mathrm{F}\right) . . . . . . .$. posure at $810^{\circ} \mathrm{C}\left(1500^{\circ} \mathrm{F}\right)$ to the Gas Environment Listed in Table X . Exposure at $816^{\circ} \mathrm{C}\left(1500^{\circ} \mathrm{F}\right)$ to the Gas Environment Listed in Tablc X..........................

39 Optical Micrograph of Incoloy 800 after a 25-h Exposure at $816^{\circ} \mathrm{C}\left(1500^{\circ} \mathrm{F}\right)$ to the Gas Environment Listed in Table X . . . .

40 Optical Micrograph of Inconel 671 after a 25-h Exposure at $816^{\circ} \mathrm{C}\left(1500^{\circ} \mathrm{F}\right)$ to the Gas Environment Listed in Table X . . .

$41 \mathrm{X}$-ray Photograph and $\mathrm{Cr}, \mathrm{Ni}, \mathrm{Fe}$, and $\mathrm{S}$ Distribution in Incoloy 800 Specimen Shown in Fig. 39 . . . . . . . . . . .

42. X-ray Photograph and $\mathrm{Cr}$ and $\mathrm{S}$ Distribution in Type 310 Stainless Steel Specimen Shown in Fig. $38 . . . . . . . . .$.

43 X-ray thotograph and Cr and NL Dislsibution in Inconel 671 Specimen Shown in Fig. 40 ...............

45 Erosive. Wear as a Function of Velocity for. Type 310 Stainless steel .......................

46 Erosive Wear as a Function of Velocity for Type 304 Stainless

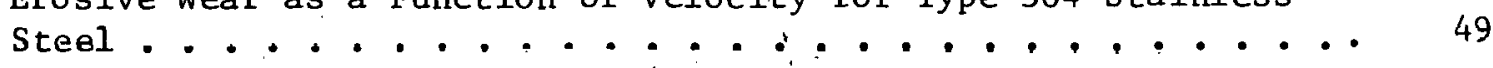

47 Isometric Drawlng of the Preheat Line . . . . . . . . . . 50

48 Isometric Drawing and Photograph of the Weld-neck Flange . . . 51

49 Synthane Coal-gasification Pilot-plant Process . . . . . . 52

50 Ball Valve, Fractured Valve Stem, and Top and Bottom Ballvalve seats . . . . . . . . . . . . . . . . .

51 Photograph and Schematic of Fracture Surface of Gate-valve Guide........................... 


\section{LIST OF TABLES}

No.

I Slag Composition (wt\%) during Abrasion-Corrosion Test

Run 3...........................

II Relative Resistance of Refractories Exposed to Slag in Run 3......................... 8

III Base-line Wall Thickness of Top Tee Points . . . . . . . 11

IV : Base-line Wall-thickness Values for $30^{\circ}$ Sweep Positions : . . 13

V Estimated Gas Compositions (vol\%) and Temperature and Pressure Conditions in Various Coal-gasification Processes with Lowsulfur Coal Feedstock ${ }^{2}$. . . . . . . . . . 28

VI Chemical Composition (wt\%) of Alloys Used in Present Work . . 30

VII Experimental Parameters Proposed. for Preexposure of Mechanical Test Specimens ................ 35

VIII Calculated Oxygen, Sulfur, and Carbon Potentials for Gas Mixtures 1 and 2 in Table $\operatorname{VII}^{\mathrm{a}}$. . . . . . . . . . . 36

IX Phases Expected under Different Experimental Conditions Proposed . . . . . . . . . . . . . . 39

X Gas Composition and Oxygen, Sulfur, and Carbon Potentials Established in the Preliminary Corrosion Experiment . . . . . 40

XI Particle Velocity Dependence $\left(V^{n}\right)$ for High-velocity Erosive Wear ...................... 


\author{
MATERIALS SCIENCE DIVISION \\ COAL TECHNOLOGY NINTH QUARTERLY REPORT, \\ - OCTOBER-DECEMBER 1976
}

\begin{abstract}
HIGHLIGHTS
Task A -- Evaluation of Ceramic Refractories for Slagging Gasifiers (C. R. Kennedy and R. B. Poeppe Z)

The analysis of specimens from 500-h run 3 was completed. Although the base-to-acid ratio varied from 1.25 to 0.65 during the test, the results are in substantial agreement wllh those of carlier tests. Construction of a new furnace buttom that will provide temperature gradients consistent with water-ronled cold faces has begun.
\end{abstract}

Task B -- Evaluation of Ceramic Coatings for Coal-conversion Plants (R. B. Poeppel)

No progress was made during this quarter.

Task C -- Application and Development of Nondestructive Evaluation Methods. for Coal-conversion Processes (W. A. Ellingson, W. J. Shack, and C. L. Johnson)

Continuous in-situ erosive-wear detection systems developed for determining erosion rates of the Bi-Gas process development unit were installed at three locations un lle main cool-clurry fepd line this quarter. Two of the systems were installed on $30^{\circ}$ sweep lines, and one was placed on a $90^{\circ}$ "blocked tee." All are on 254-mm Al06B Schedule 120 carbon steel.

Thermal-pattern recognition studies for determining erosive wear of refractorylined transfer lines were continued by development of ground-level energy subtractive routines. Two cavities were studied for thermal prufile dif... ferences. In addition, a second full-scale refractory test panel was cast, and acoustic-emission data were obtained during thermal curing. Initial results show that acoustic emission can be monitored to track internal wall temperature, which indicates that a potential exists for shrinkage crack control.

Task D -- Corrosion Behavior of Materials in Coal-conversion Processes (K. Natesan and O. K. Chopra)

A thermodynamic analysis has been performed to examine the mullicomponent gas environment as a function of temperature and pressure in different pilot-plant coal-gasification processes. The results are used to evaluate the stability of phases in Incoloy 800, Type 304 stainless stee1, and Inconel 671 dlluys in the process envirnnments. The construction of a corrosion test rig for the exposure of uniaxial tensile and corrosion specimens is completed, and preliminary experiments are being conducted. Four selected alloys, namely, U.S. Steel 18-18-2 alloy, Type 310 stainless steel, Incoloy 800, and Inconel 671, were exposed to a multicomponent gas environment 
at $816^{\circ} \mathrm{C}$ for $25 \mathrm{~h}$. The specimens were subsequently analyzed by optical metallography and scanning-electron microscopy. The results show that all the alloys developed chromium-rich oxide scales with some degree of internaloxidation, -sulfidation, and-carburization.

Task E -- Erosion Behavior of Materials in Coal-conversion Processes (W. J. Shack)

The basic assumptions of the analytical model developed for highangle impact are reviewed. Numerical. results are calculated for Types 304 and 310 stainless steels and compared with experimental results. The agreement is good at room temperatures but not good at high temperatures. The disagreement at high temperatures is attributed to the development of a protective oxide film.

Task F -- Component Performance and Failure Analysis (S. Dany Zuk, G. M. Dragel, M. D. Gorman, W. J. Shack, and W. A. Ellingson)

Failed components from the Synthane pilot plant (weld-neck flange and ball-valve stem), HYGAS pilot plant [ $\mathrm{N}_{2}$ purge line (322 line) and thermocouple protection tube], and Grand Forks Energy Research Center (gate valve) were examined during this quarter. The results have been communicated to the respective pilot plants. The following failure analysis reports have been issued: "Analysis of the HYGAS Ash Agglomerating Gasifier Internal Cyclone Dipleg Failure," "Synthane Weld Neck Flange Failure," and "Synthane Gasifier Distribulur Cone Thermocouple Sheath. (TE-268) Failures." 
MATERIALS SCIENCE DIVISION

COAL TECHNOLOGY NINTH QUARTERLY REPORT, OCTOBER-DECEMBER 1976

\section{ABSTRACT}

This broad-base materials program, begun in October 1974 , includes studies on both ceramic (refractory) and metallic materials. Appropriate laboratory and field experiments are integrated. This quarterly report, for the period octoberDecember 1976, presents the technical accomplishments in Tasks $\mathrm{A}$ and $\mathrm{C}-\mathrm{F}$.

\section{INTRODUCTION}

The economical conversion of coal into cleaner and more usable fuels will be facilitated through use of the most durable materials systems. The present report is the ninth quarterly progress report submitted by Argonne National Laboratory to the Fossil Energy Research Division of ERDA under project Number 7106, "Materials Technology for Coal Conversion Processes."

The project includes six tasks: (A) evaluation of ceramic refractories exposed to abrasion-corrosion caused by coal slag encountered in slagging gasifiers, (B) evaluation of ceramic coatings and refractories exposed to erosive environments, (C) development, evaluation, and application of nondestructive evaluation methods applicable to coal-conversion systems, such as in-situ erosive-wear detection/monitoring, (D) development of analytical models to predict corrosion behavior, e.g., phase transformations, of iron- and nickel-base alloys in gaseous environments, (E) development of analytical models to predict the erosive-wear behavior of materials used in coal-gasification plants, and (F) analysis of failed coal-gasification plant components. Progress in Tasks $\mathrm{A}$ and $\mathrm{C}-\mathrm{F}$ is discussed in the present report.*

Task A -- Evaluation of Ceramic Refractories for Slagging Gasifiers (C. R. K'eriviedy and R. B. Posppoz)

A third, 500-h run that exposed refractory specimens to slag attack at $1500^{\circ} \mathrm{C}$ and oxygen partial pressures of $\sim 10^{-3} \mathrm{~Pa}$ has been completed. Table I 1ists the slag chemistry (determined by wet chemical analysis) as a function of time throughout the test. As initially formulated, the slag was basic, with a base-to-acid (B/A) ratio of 1.25 . As the test proceeded, substantial amounts of $\mathrm{Al}_{2} \mathrm{O}_{3}$, apparently from the furnace bottom (and several chunks of hish $\mathrm{Al}_{2} \mathrm{O}_{3}$ refractory that spalled from the roof), dissolved into the slag and caused the slag to become acidic in naturc between 3 and $188 \mathrm{~h}$ $(B / A=0.79)$. Slow dissolution of $\mathrm{Al}_{2} \mathrm{O}_{3}$ continued through the test until the $\mathrm{B} / \mathrm{A}$ ratio was 0.65 at $532 \mathrm{~h}$.

*Progress in Task $B$ will be presented in the next quarterly report. 
TABLE I. Slag Composition ( $w t \%$ ) during Abrasion-Corrosion Test Run 3

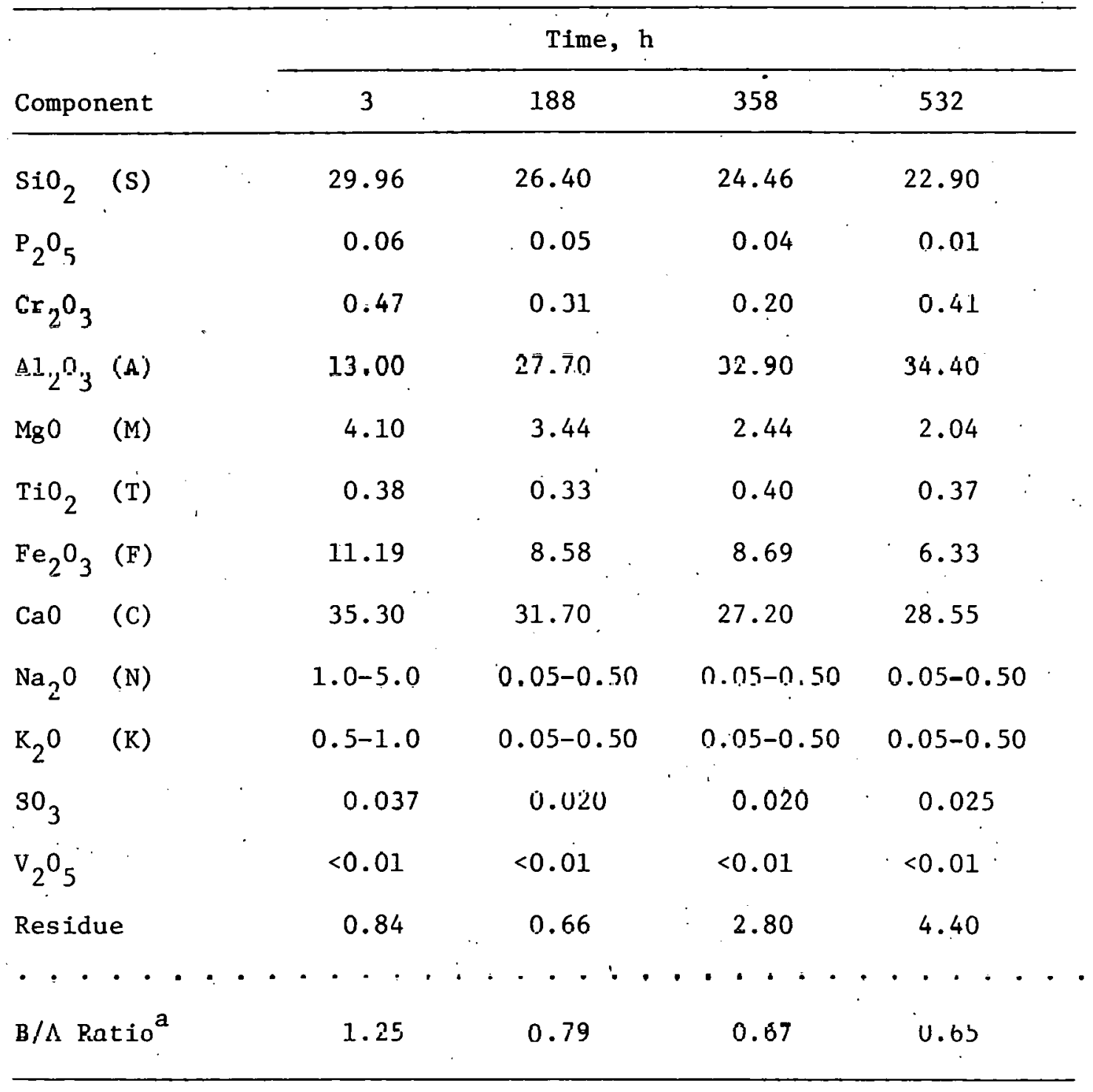

a ${ }_{\text {Baoc to acid ratio }} \mathrm{B} / \mathrm{A}=(\mathrm{F}+\overline{\mathrm{C}}+\mathrm{M}+\mathrm{N}+\mathrm{K} / \overline{\mathrm{S}}+\mathrm{A}+\mathrm{I})$. 
Figures 1-4 show the 16 refractory bricks as they appeared after exposure to the slag. The bricks are identified in Table II, and their relative corrosion resistance is summarized.

The sintered magnesia-chrome spinel specimens (Fig. 1) and sintered alumina-chrome specimens (Fig. 2) exhibited relatively small volume losses and depths of removal despite significant slag penetration. The $\mathrm{Al}_{2} \mathrm{O}_{3}-\mathrm{SiO}_{2}$ and $\mathrm{Al}_{2} \mathrm{O}_{3}-\mathrm{SiO}_{2}-\mathrm{Z}_{\mathrm{r}} \mathrm{O}_{2}$ bricks performed poorly (Fig. 3) as did a siliconoxynitride brick. The fusion-cast $\mathrm{Cr}_{2} \mathrm{O}_{3}-\mathrm{Fe}_{2} \mathrm{O}_{3}-\mathrm{MgO}$ spinel specimen (Fig. 4) exhibited negligible interaction, as in runs 1 and 2.

Comparison between the results of runs 2 and 3 for the four bricks tested in both runs $(19,20,22$, and 24) indicates that the volume losses and depths or removal (abrasion) are similar despite a wide variation in final slag chemistry, e.g., run $2 \mathrm{~B} / \mathrm{A}=1.5$ and run $3 \mathrm{~B} / \mathrm{A}=0.65$.

Redesign of the bottom section of the furnace to provide prototypic temperature profiles has been completed and construction has begun. The new refractory lining will consist of full-length $(228.6 \mathrm{~mm}), 3 / 4-1$ ength, and 1/2-length bricks backed by water-coolant cans. Each can will cool three bricks of the same length and composition, with four compositions being tested simultaneously (total of 12 cans and 36 bricks). Thermocouples will be installed at regular intervals so that heat-flow calculations can be performed.

Compositions scheduled for testing in the next two 500-h tests under prototypic thermal profiles include silicon carbide, silicon oxynitride, $\mathrm{MgO}-\mathrm{Cr}_{2} \mathrm{O}_{3}$ spinel, and $\mathrm{Al}_{2} \mathrm{O}_{3}-\mathrm{Cr}_{2} \mathrm{O}_{3}$ bricks.

Task C -- Application and Development of Nondestructive Evaluation Methods for Coal-conversion Processes (W. A. Ellingson, W. J. Shack, and C. L. Johnson)

Major portions of the field installation for the Bi-Gas in-situ erosivewear measurement system were completed this quarter. Data will be obtained on A106B Schedule 120, 250-mm-diam piping. Control of refractory heatup through use of acoustic emission was investigated by laboratory studies on a fullscale monolithic refractory test panel.

\section{Erosive-wear Detection and Monitoring}

\section{a. Metallic Transfer Lines}

The field installations of the in-situ erosive-wear measurement system at the Bi-Gas coal-gasification facility were completed. Acoustic waveguides, described in a previnus report, 1 were attached at three areas shown schematically in Fig. 5 as locations 2-4. A11 waveguides are attached to 250-mm A106B Schedule 120 carbon steel piping. The waveguides at location 1 , which are not installed, will be on Type 316 stainless steel.

Installation required that the transfer-line insulation be removed in the regions for which wall-thickness data were to be obtained. This was accomplished by manually sawing the aluminum outer skin and insulation away as shown in Fig. 6 . 


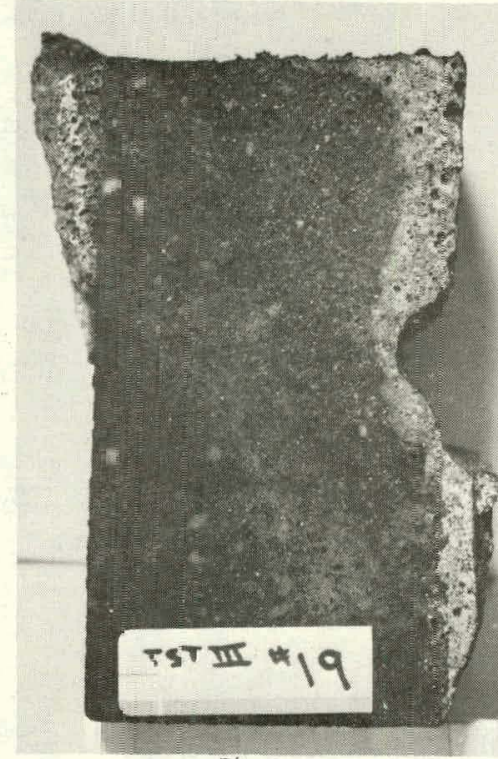

(a)

$+$

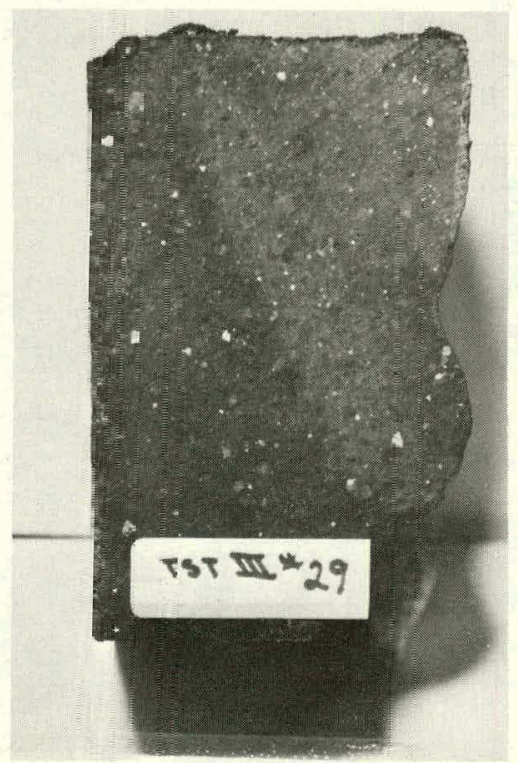

(d)

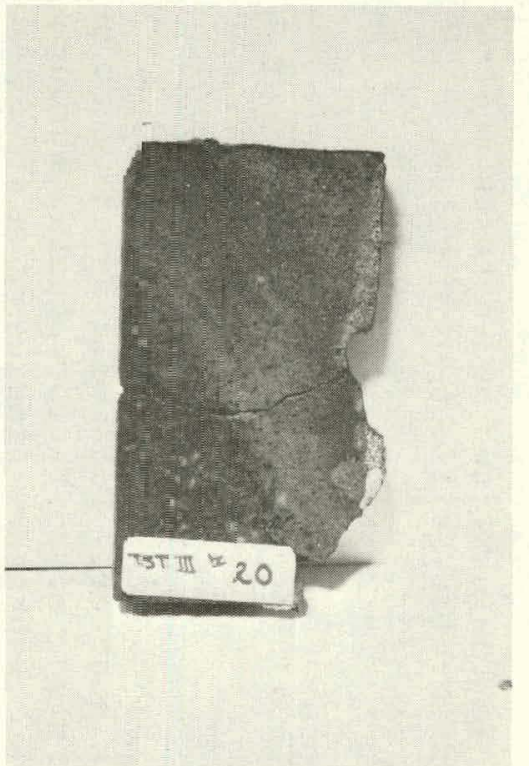

(b)

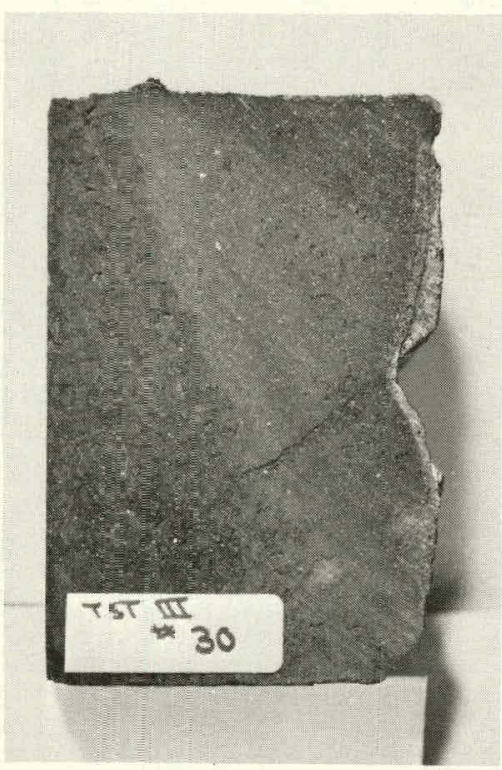

(e)

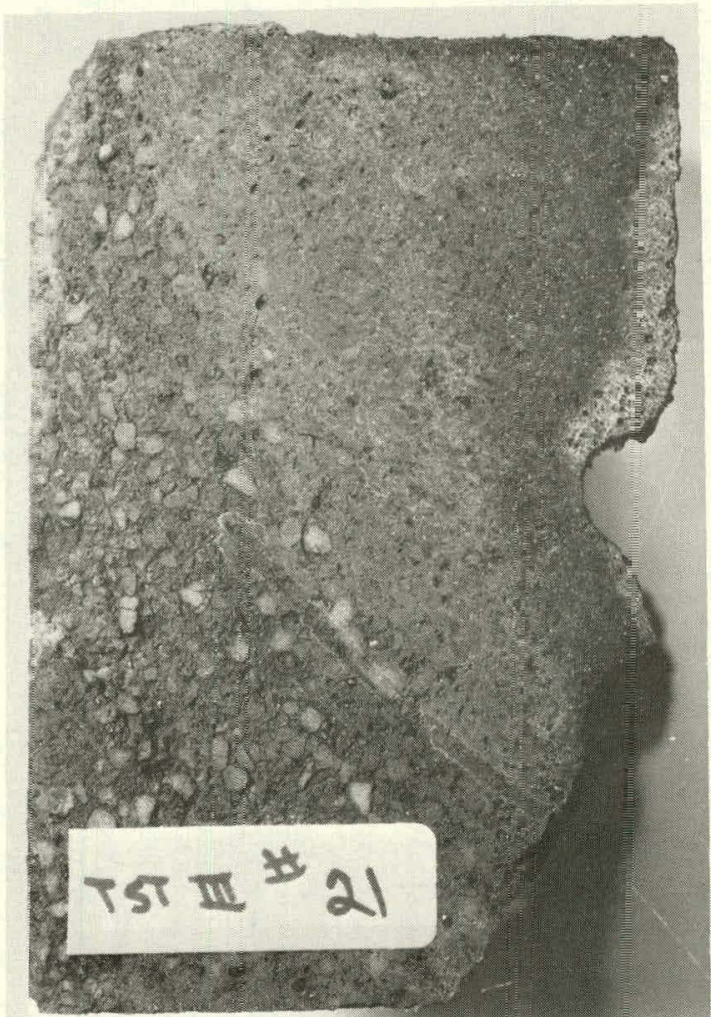

(c)

Fig. 1. Sintered $\mathrm{Mg} 0-\mathrm{Cr}_{2} \mathrm{O}_{3}$ Briaks azter Exposure to Slag. (a) 19 , (b) 20 , (c) 21 , (d) 29 , and (e) 30. Neg. No. MSD-63798. 


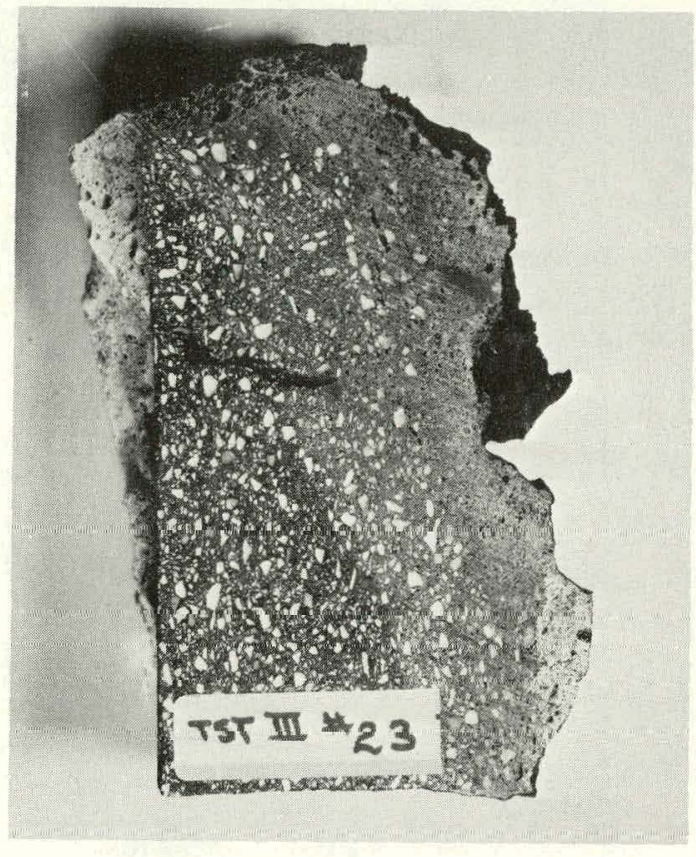

(a)

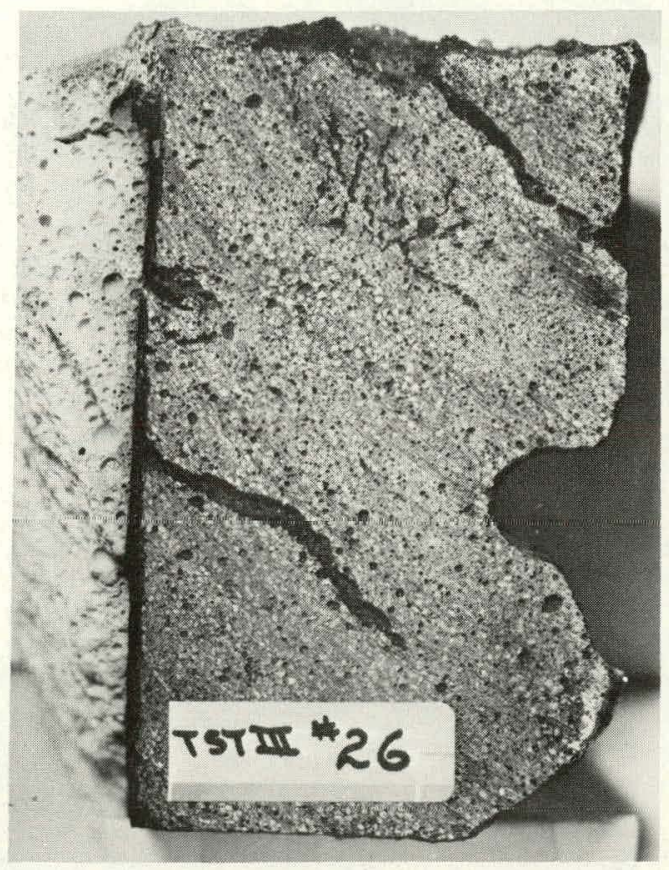

(c)

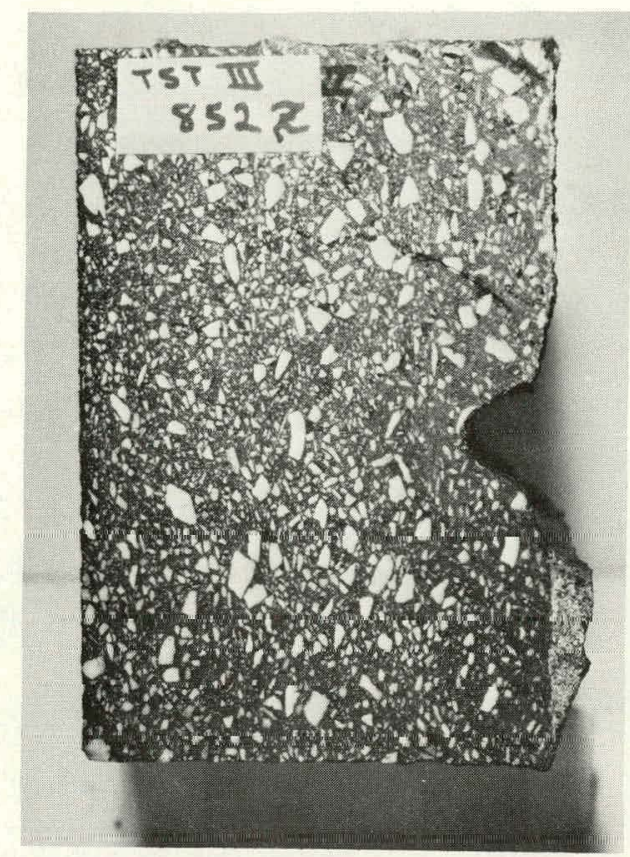

(b)

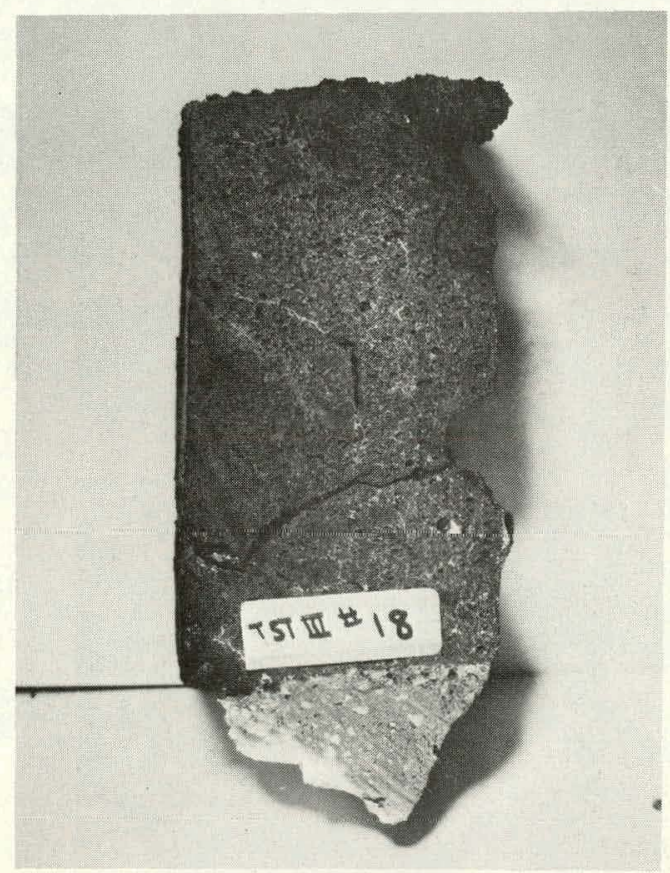

(d)

Fig. 2. Sintered $\mathrm{Al}_{2} \mathrm{O}_{3}-\mathrm{Cr}_{2} \mathrm{O}_{3}$ Bricks after Exposure to Slag. (a) 23, (b) 852 , (c) 26 , and (d) 18 (castable). Neg. No. MSD-63799. 


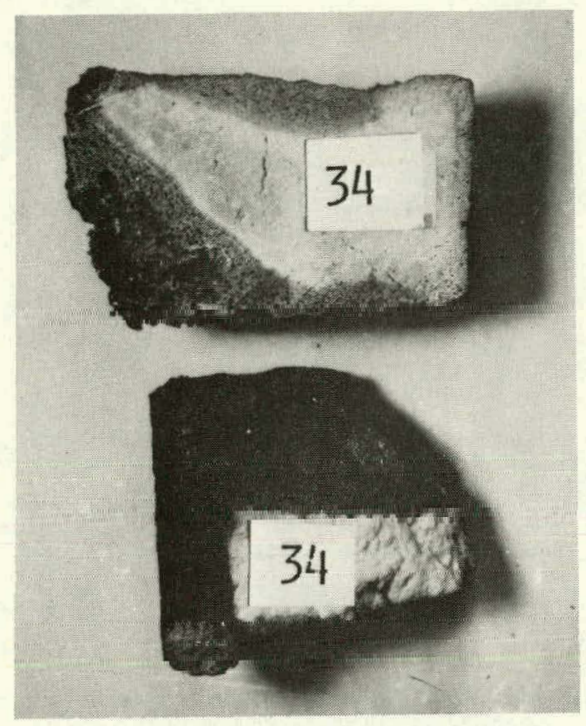

(a)

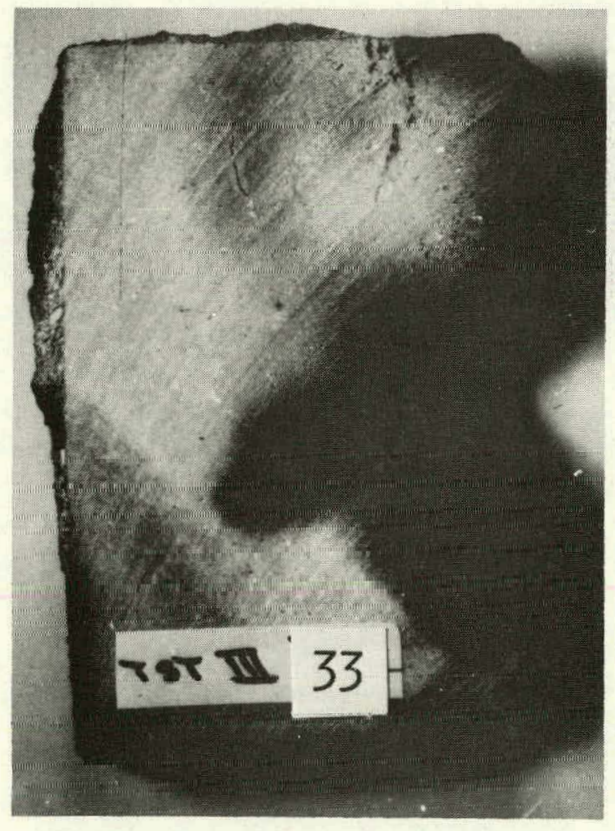

(c)

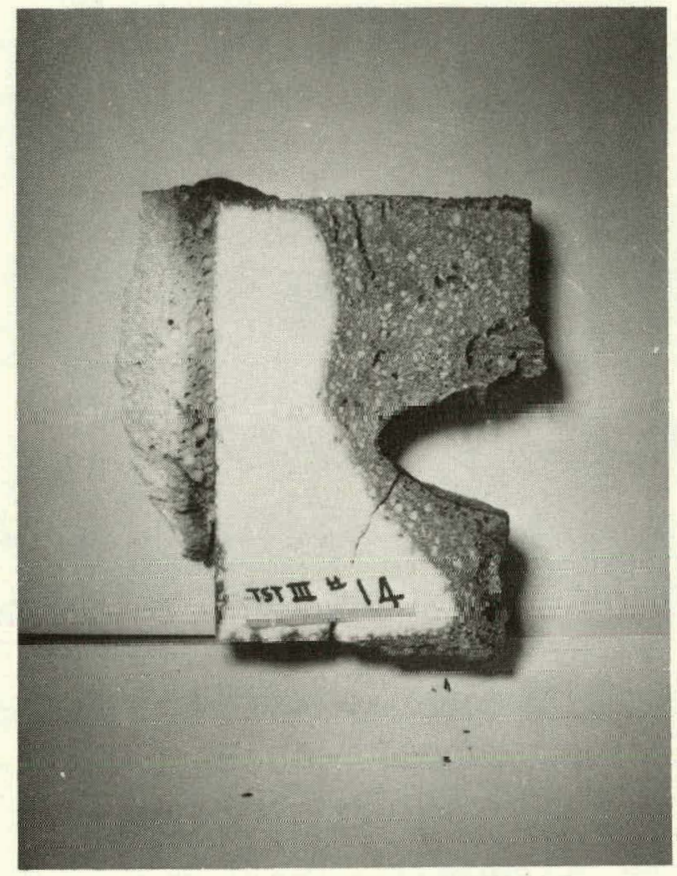

(b)

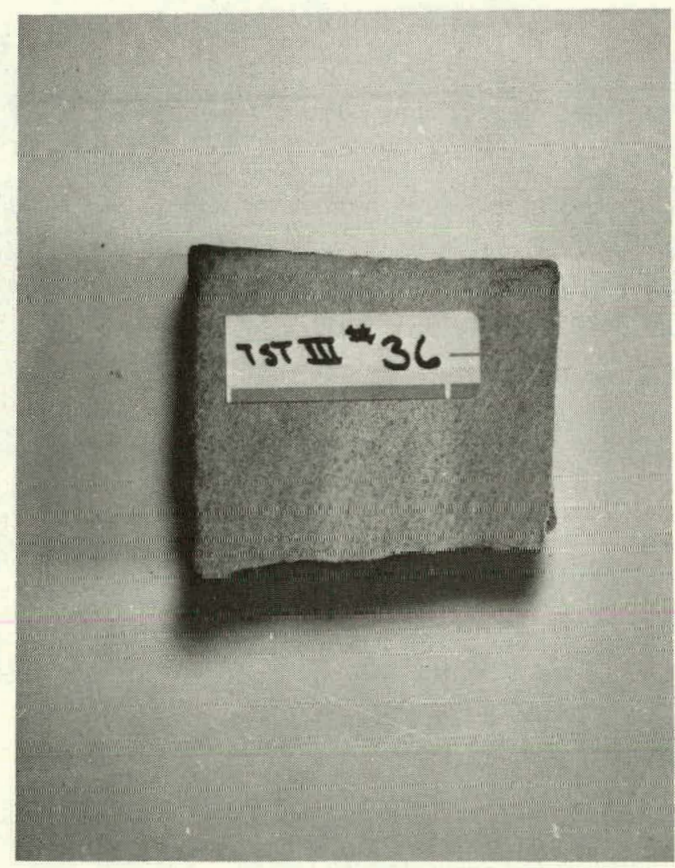

(d)

Fig. 3. Various Refractory Bricks after Exposure to Slag. (a) 34 , (b) 14, (c) 33 , and (d) 36 (note that the entire bottom half of this brick has dissolved). Neg. No. MSD-63800. 


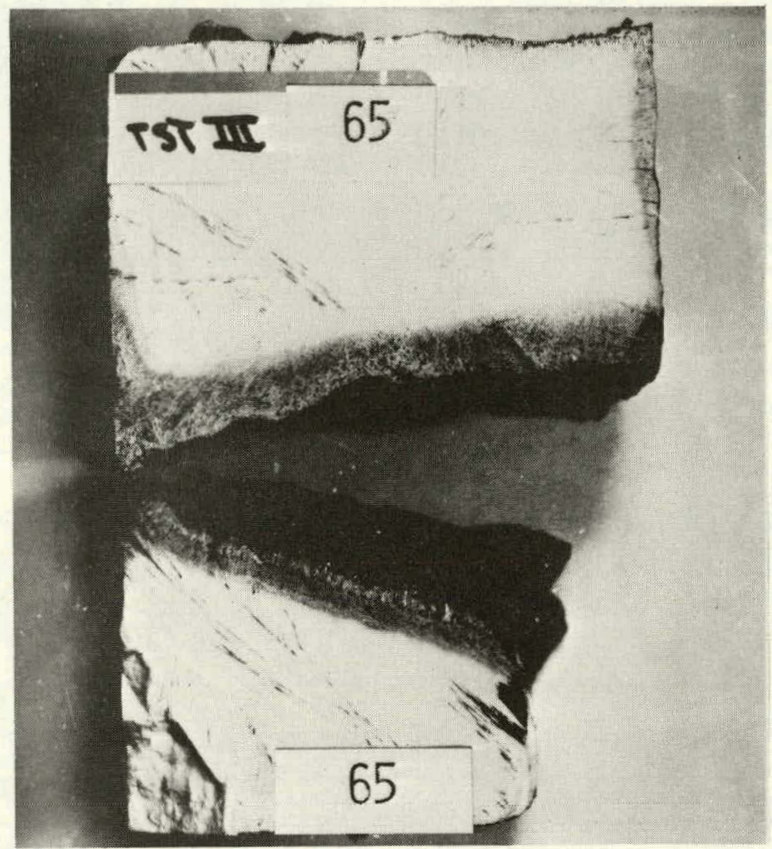

(a)

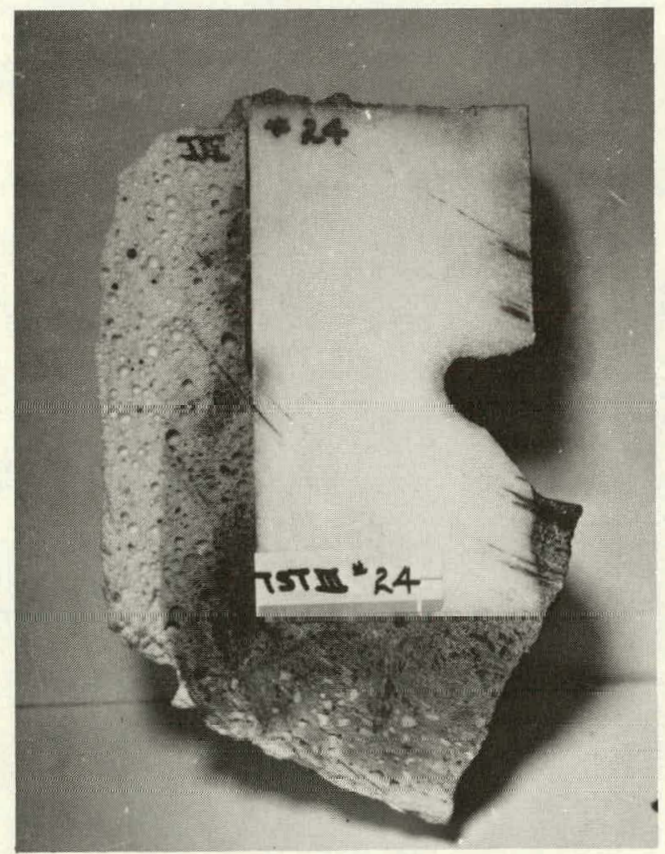

(b)

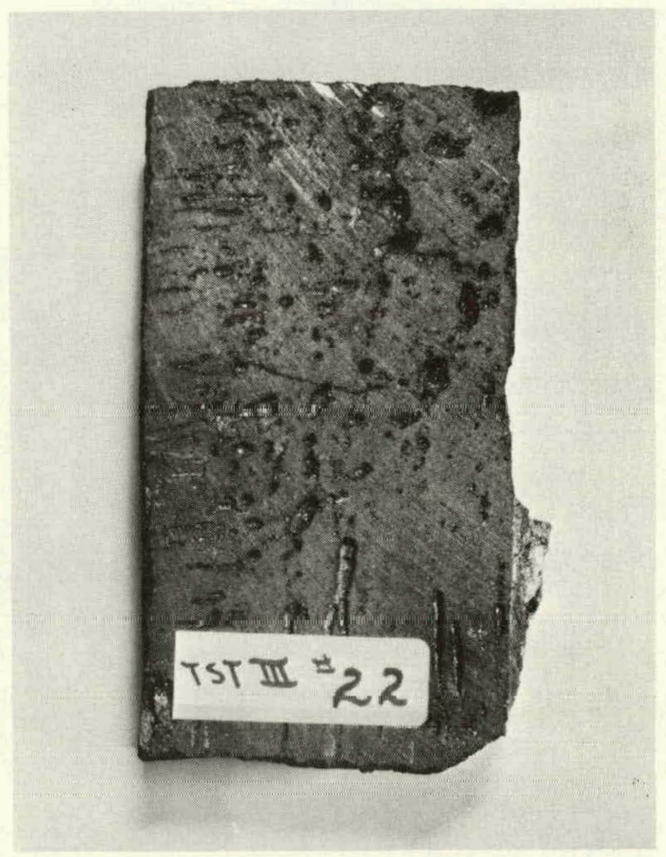

(c)

Fig. 4. Fusion-cast Brick after Exposure to Slag. (a) 65, (b) 24, and (c) 22 (note negligible attack). Neg. No. MSD-63801. 
TABLE II. Relative Resistance cf Refractories Exposed to Slag in Run 3

\begin{tabular}{|c|c|c|c|c|c|}
\hline $\begin{array}{l}\text { Identi- } \\
\text { fication } \\
\text { Number }\end{array}$ & Compositicn & Bond & $\begin{array}{c}\text { Normalized } \\
\text { Materia1 } \\
\text { Lost, } \\
\text { vol\% }\end{array}$ & $\begin{array}{l}\text { Maximum } \\
\text { Depth of } \\
\text { Penetra- } \\
\text { tion, mm }\end{array}$ & $\begin{array}{l}\text { Maximum } \\
\text { Depth of } \\
\text { Remova1, } \\
\mathrm{mm}\end{array}$ \\
\hline 19 & $\operatorname{Mg} 0 \quad(53 \%)-\mathrm{Cr}_{2} \mathrm{O}_{3}(19 \%)$ & \multirow[t]{12}{*}{ Sintered } & 3.2 & 35.6 & 11.4 \\
\hline 20 & $\operatorname{MgO}(59 \%)-\mathrm{Cr}_{2} \mathrm{O}_{3} \quad(19 \%)$ & & 1.5 & 38.1 & 8.1 \\
\hline 21 & $\operatorname{Mg} 0(59 \%)-\mathrm{Cr}_{2} 0_{3}(14.5 \%)$ & & 2.3 & 40.6 & 11.4 \\
\hline 29 & $\operatorname{MgO}(62.7 \%)-\mathrm{Cr}_{2} \mathrm{O}_{3}(18.1 \%)$ & & 1.4 & 38.1 & 5.8 \\
\hline 30 & $\mathrm{M}_{\mathrm{g}} \mathrm{O}(62.6 \%)-\mathrm{Cr}_{2} \mathrm{O}_{3}(16.8 \%)$ & & 1.5 & 40.6 & 8.9 \\
\hline 23 & $\mathrm{Al}_{2} \mathrm{O}_{3}(89.7 \%)-\mathrm{Cr}_{2} \mathrm{O}_{3}(10 \%)$ & & 5.8 & 48.3 & 10.7 \\
\hline 852 & $\mathrm{Al}_{2} \mathrm{O}_{3}(81.1 \%)-\mathrm{Cr}_{2} \mathrm{O}_{3} \quad(16.6 \%)$ & & 2.7 & 27.9 & 14.5 \\
\hline 26 & $\mathrm{Al}_{2} \mathrm{O}_{3}(67.5 \%)-\mathrm{Cr}_{2} \mathrm{O}_{3} \quad(32.0 \%)$ & & 2.8 & 58.4 & 16.0 \\
\hline 36 & $\mathrm{Si}(56 \%) 0(15 \%) \mathrm{N}(28 \%)$ & & 45.5 & $62.7^{a}$ & $62.7^{a}$ \\
\hline 14 & $\mathrm{Al}_{2} \mathrm{O}_{3}(91.6 \%)-\mathrm{SiJ}_{2} \quad(8 \%)$ & & 10.3 & 45.7 & 35.6 \\
\hline 34 & $\mathrm{Al}_{2} \mathrm{O}_{3}(55.7 \%)-\mathrm{SiO}_{2}(26.8 \%)-\mathrm{ZrO}_{2} \quad(16.1 \%)$ & & 59.0 & $73.7^{\mathrm{a}}$ & $73.7^{a}$ \\
\hline 33 & $\mathrm{Mg} 0, \mathrm{Al}_{2} \mathrm{O}_{3}$ & & $\therefore 0$ & $73.7^{\mathrm{a}}$ & 22.9 \\
\hline 18 & $\begin{array}{l}\mathrm{Al}_{2} \mathrm{O}_{3}(21.4 \%)-\mathrm{Fe}_{2} \mathrm{O}_{3}(22.6 \%)-\mathrm{-r}_{2} \mathrm{O}_{3}(39.6 \%) \\
\text { Castable }\end{array}$ & Chemical & 5.8 & 53.3 & 11.4 \\
\hline 24 & $\mathrm{Al}_{2} \mathrm{O}_{3}(97.6 \%)$ & \multirow[t]{3}{*}{ Fusion Cast } & 4.0 & 22.9 & 19.6 \\
\hline 22 & 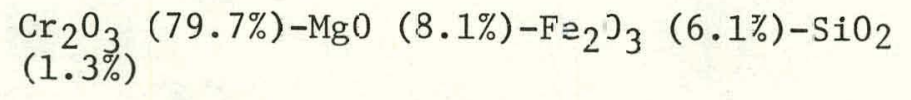 & & C. 3 & 5.1 & 1.9 \\
\hline 65 & $\mathrm{Al}_{2} \mathrm{O}_{3}(50 \%)-\mathrm{ZrO}_{2}(34 \%)-\mathrm{SiO}_{2}(1 \% \%)$ & & 33.4 & $73.7^{\mathrm{a}}$ & $73.7^{\mathrm{a}}$ \\
\hline
\end{tabular}

${ }^{\mathrm{a}}$ Complete attack. 


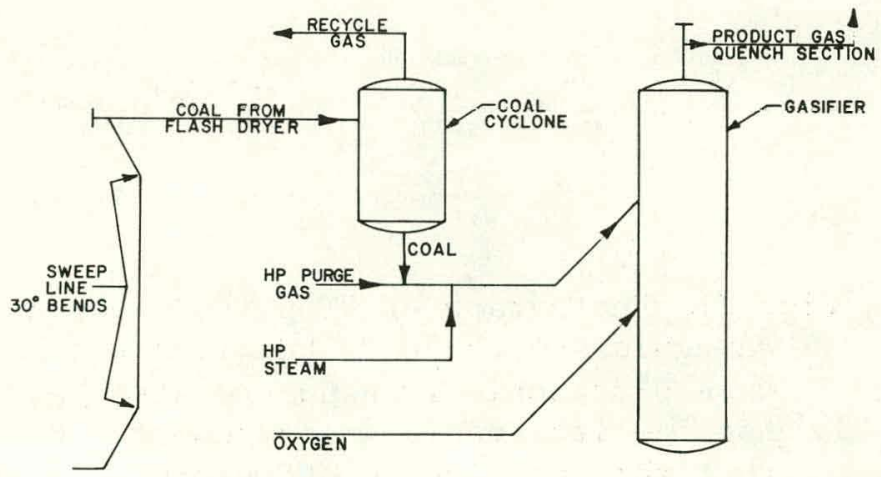

Fig. 5. Schematic Diagram of BiGas Coa1-conversion Process Showing Location of In-situ Erosion-measurement Systems. Neg. No. MSD-63393.

Fig. 6. Photograph of Insulation Removal. Note dual thickness at the cap end of "top tee." Neg. №, MSTm 63857 .

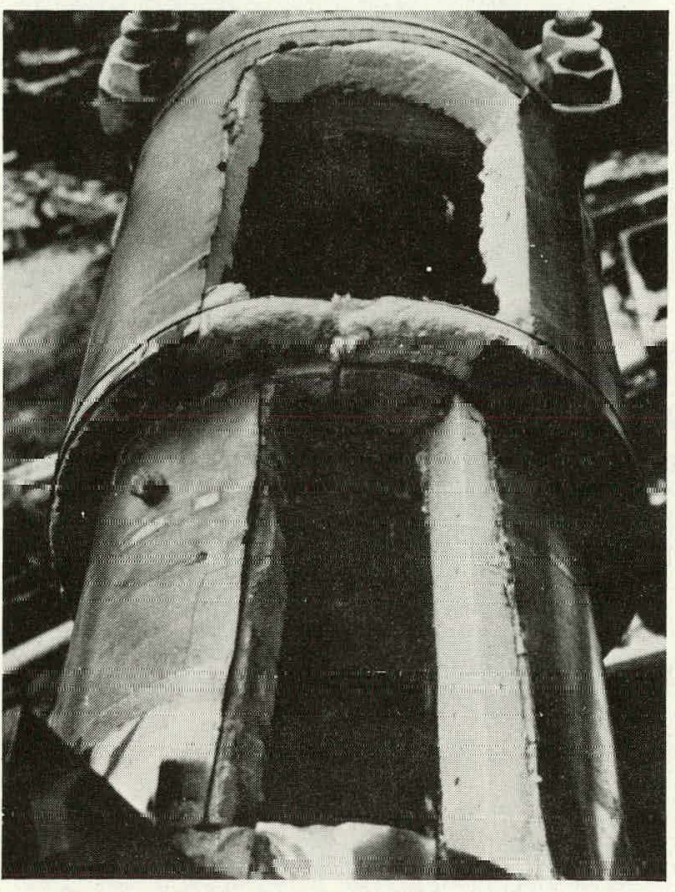

Longitudinal-wave transducers (5-MHz) are attached to the waveguides as shown in Fig. 7. Because the incoming flow line is $\sim 30^{\circ}$ off the vertical (as shown in Figs. 8 and 9), the measurement system is located off vertical. Figure 8 is a photograph of the coal-feed line configuration, and Fig. 9 is a schematic that shows details of the sweep-line geometry.

The measurement points on the "top tee" (location 2) are shown schematically in Fig. 10. The hub has a specification that calls for a nominal wall thickness of $31.75 \mathrm{~mm}$; the incoming and outgoing piping were welded to the hub as shown in Fig. 10. Base-line wall-thickness measurements are listed in Table III. The increase in wall thickness between position 25 and 26 is a result of the weld between the hub and outgoing piping.

Installation at the two $30^{\circ}$ sweep positions (locations 3 and 4 ) was accomplished using techniques similar to those employed on the top tee. Figure 11 shows a perspective of the assembly. Figure 12 shows one of the 

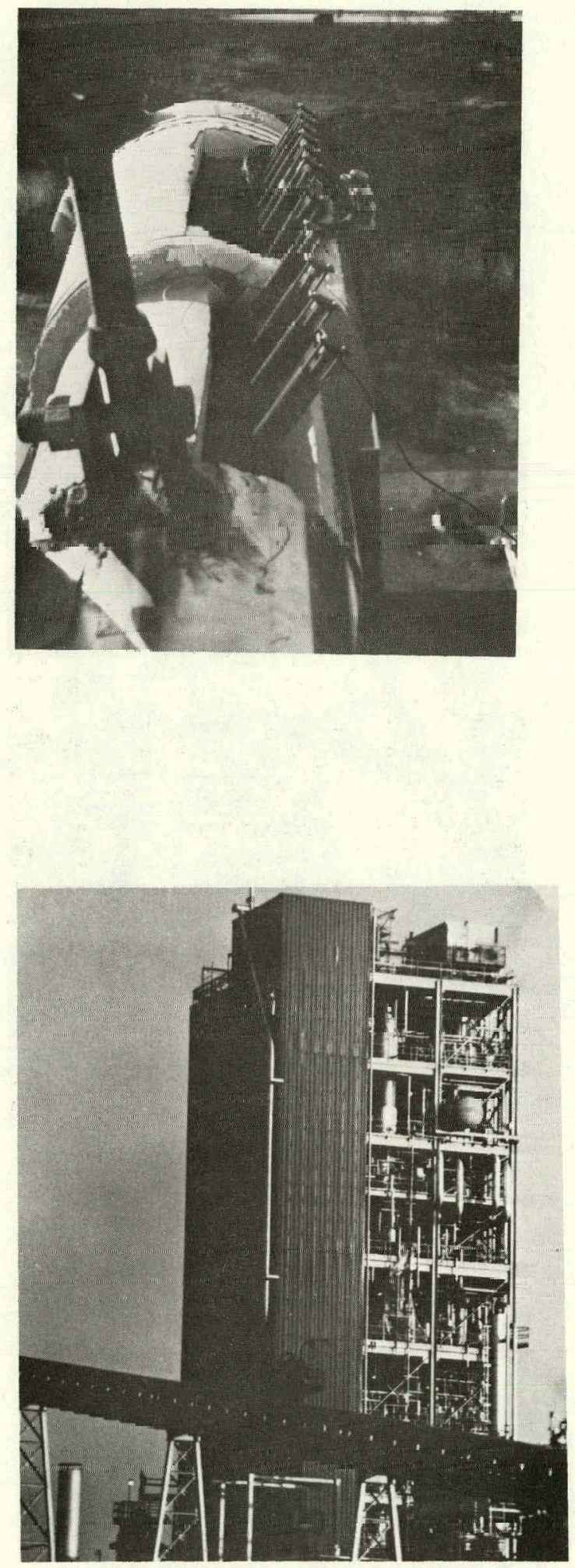

Fig. 8. Photograph of Bi-Gas Coa1feed Line Showing Sweep Angles and "Top Tee." Neg. No. MSD63856.
Tig. 7. Pliobugtaph of "Tnp Tep" showing Waveguides with 5-MHz Longitudinalwave Ultrasonic Transducers Attached for In-s1tu Erosion Measurement. Note that the position is off vertical such that the measurement is directly in line with incoming flow. Neg. No. MSD-63854 .

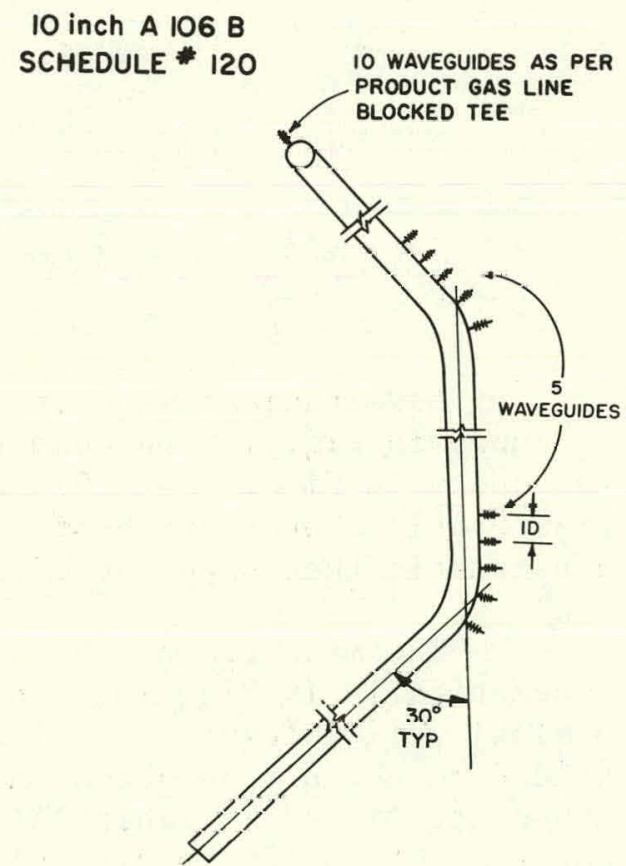

Fig. 9. Schematic Representation of Erosion-measurement Positions for Bi-Gas Coal-feed Transfer Line. Neg. No. MSD62999 . 


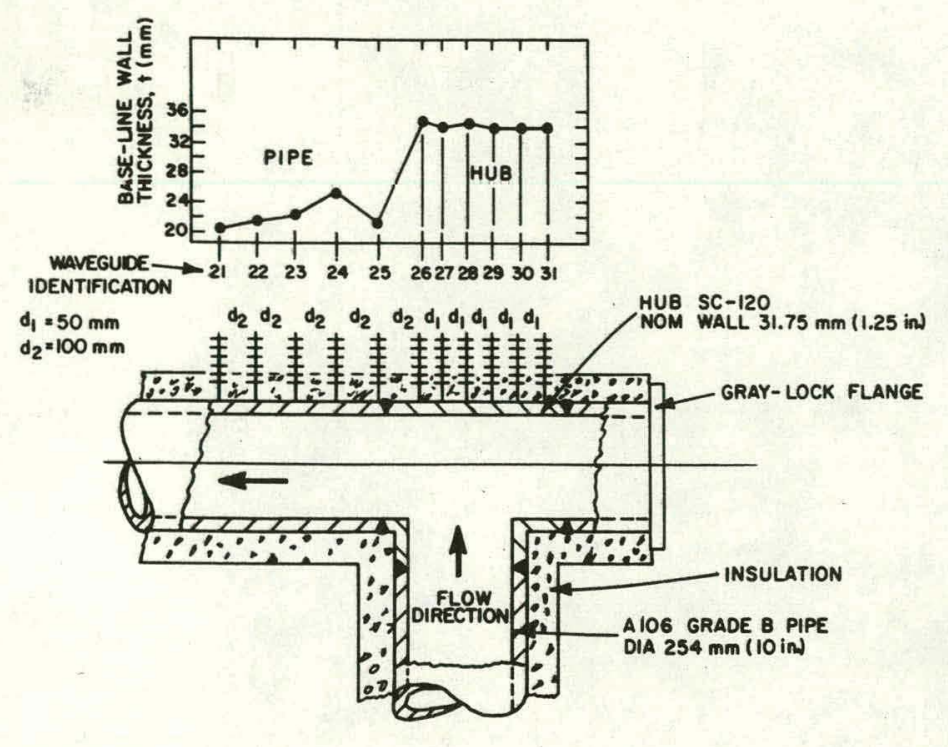

Fig. 10. Schematic Diagram Showing Monitoring Points on "Top Tee." Neg. No. MSD63831 .

TABLE III. Base-line Wa11 Thickness of Top Tee Points

\begin{tabular}{cc}
\hline Erosion Point & $\begin{array}{c}\text { Wall } \text { Thickness }^{\mathrm{a}} \\
\mathrm{mm}\end{array}$ \\
\hline 21 & 20.92 \\
22 & 20.75 \\
23 & - \\
24 & $21.41^{\mathrm{b}}$ \\
25 & $35.10^{\mathrm{b}}$ \\
26 & 34.65 \\
27 & 35.00 \\
28 & 34.75 \\
29 & 34.85 \\
30 & 34.90 \\
\hline 31 & \\
astM specification permits manufactured wal1 thickness \\
to vary up to 12.5\% under nominal (21.41 mm), i.e., \\
minimum wall thickness of 18.75 mm. \\
b Approximated by subtracting known waveguide length from \\
length determined by initial pulse to backwal1 echo.
\end{tabular}




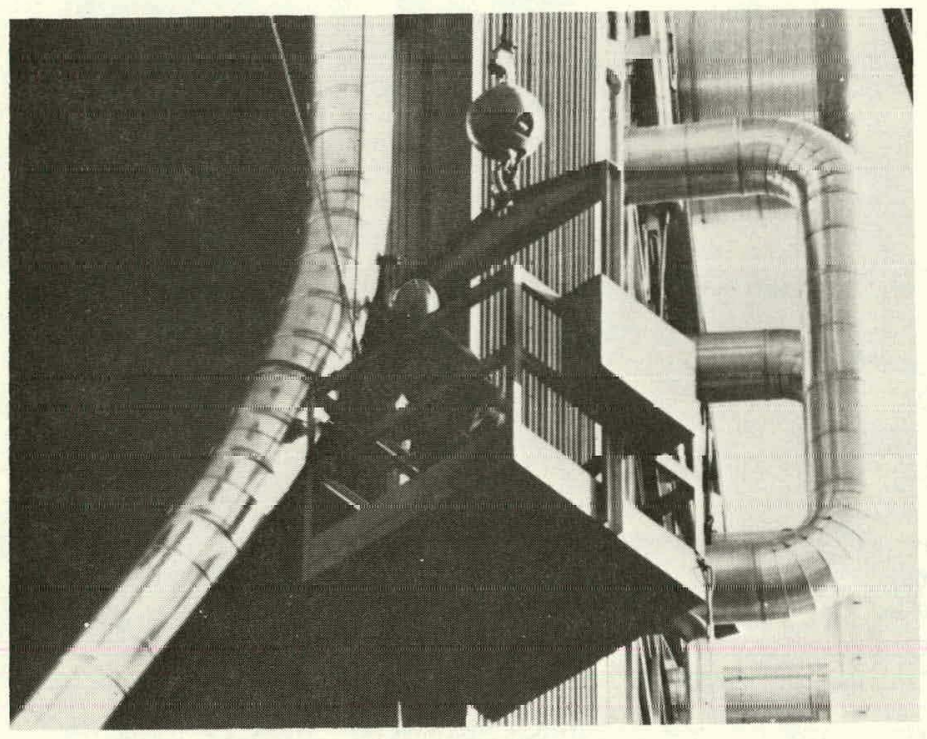

Fig. 11. Photograph of Installation. Neg. No. MSD63858.

Fig. 12. Photograph of Installed Delay Lines at Lower Sweep Position Prior to Attachment of $5-\mathrm{MHz}$ Transducers. Neg. No. MSD-63855.

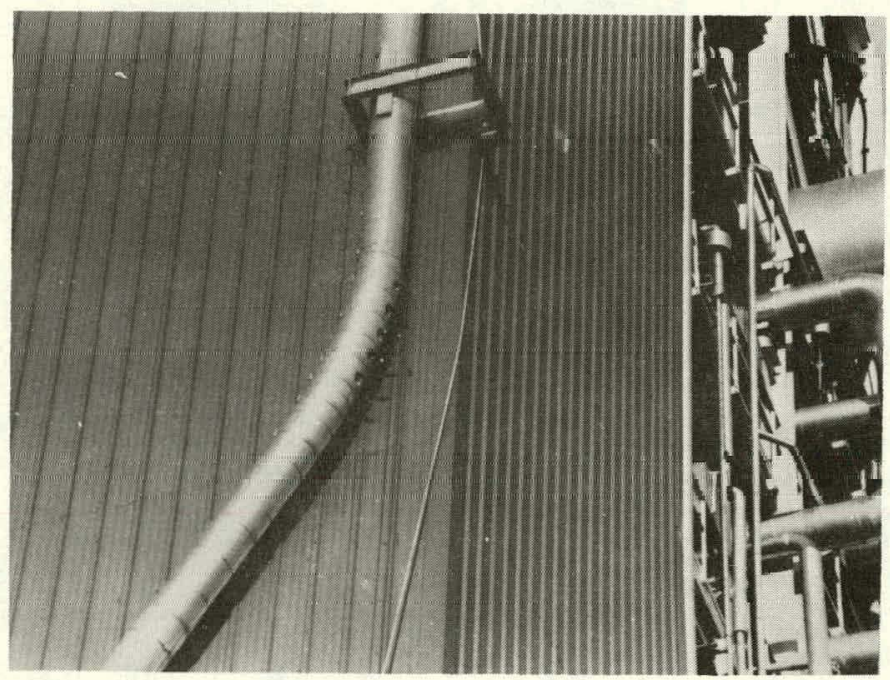

installations completed except for transducer attachment. Numerical identification of the individual positions is indicated in Fig. 9. Table IV lists the measured base-line wall-thickness values for the sweep positions. No data were obtained at position 16 because the echo contained a significant noise level and the desired signal could not be discriminated.

\section{b. Refractory-lined Transfer Lines}

During this quarter, the study of using infrared images for quantitative prediction of defects in refractory linings was continued. In the present experiments, a GREENLITE 28 refractory tile* was arbitrarily chosen as the test sample; the setup is shown in Fig. 13. A hot plate was

*Manufactured by A. P. Green Refractories Company. Contains primary alumina $(60-63 \%)$ and silica $(33-36 \%)$. 
TABLE IV. Base-line Wa11-thickness Values for $30^{\circ}$ Sweep Positions

\begin{tabular}{ccc}
\hline Sweep & Erosion Point & $\begin{array}{c}\text { Wa11 } \\
\text { Thickness } \\
\text { mm }\end{array}$ \\
\hline Upper & 20 & 19.58 \\
& 19 & 18.99 \\
& 18 & 21.21 \\
& 17 & 19.76 \\
$\downarrow$ & 16 & - \\
& 15 & 18.47 \\
& 14 & 18.42 \\
& 13 & 19.02 \\
& 12 & 17.50 \\
\end{tabular}

${ }^{a}$ ASTM specification permits manufactured wall thickness to vary up to $12.5 \%$ under nominal (21.41), i.e., minimum wall thickness of $18.75 \mathrm{~mm}$.

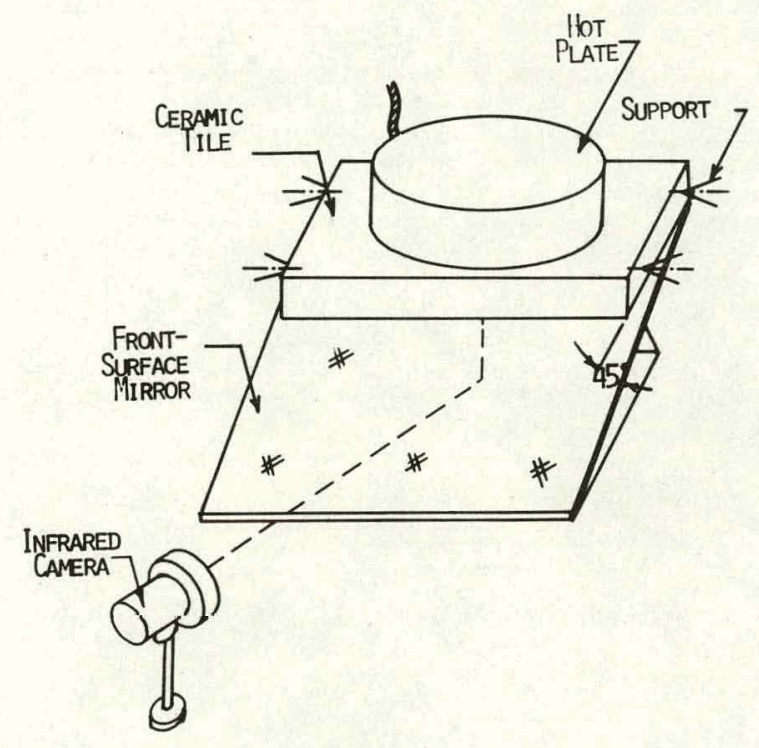

Fig. 13. Schematic of Laboratory Test Arrangement Used to Study Therma1 Patterns of Defects. Neg. No. MSD- 63830. used as the heat source. To minimize lateral heat dissipation in the sample, a nichrome wire was impregnated into a narrow groove cut around the front surface of the tile. Currents through the wire were adjusted to ensure an isothermal surface condition when the bottom of the tile was heated and the system reached steady state. To minimize reflection caused by the ambient irradiation, the front surface of the tile was painted black using $3 \mathrm{M}$ Nextel Velvet coating.

In the experiment, first a black and white pirture was taken from the infrared display to establish the ground-1evel energies* (Fig. 14). In Fig. 14a, the white region represents hot spots; the hot spots near the lower edge result from the heat liberated from the nichrome (guard) heater. The rest of the picture shows nearly uniform gray tone, which signifies that the surface has reached the isothermal state.

To additionally enhance the visual perception as well as prepare for later data analysis, the black and white picture was image processed and digitized over the region shown, and the two-dimensional array was plotted in

*Defined herein as the energy output from a good (or no-faull) sample. 


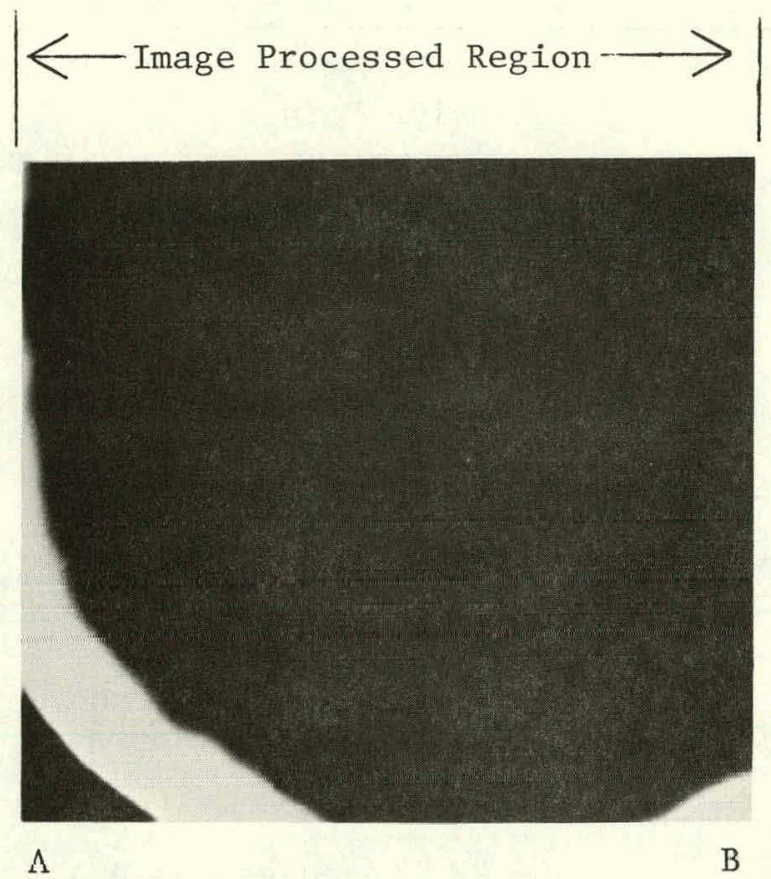

(a)

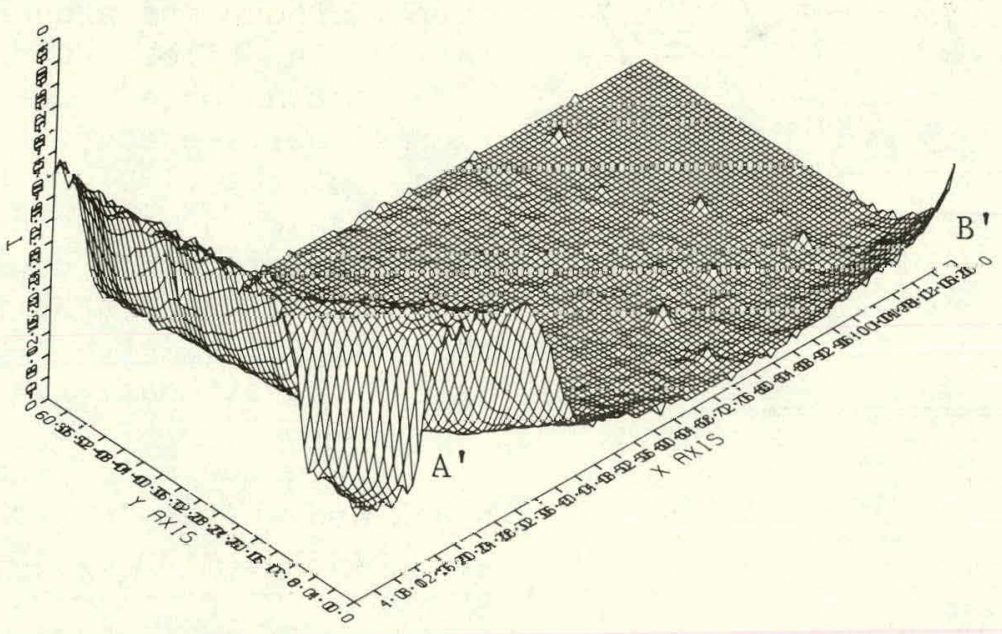

(b)

Fig. 14. Analng-tn-digital Comversion of Cround-level Energies of Thermal Pattern. (a) Initial black and white image and (b) isometric display of resultant digitized image. Neg. Nos. MSD63865 and MSD-63865-1. 
a three-dimensional display as shown in Fig. 14b. The temperature (T) axis in the figure denotes the infrared energy levels and local spikes on the $T$ surface can be attributed to small dimples which appear on the refractory surface.

Following this preparation work, a cavity (12 mm in diameter and $6 \mathrm{~mm}$ deep) was drilled on the back side of the refractory and the infrared picture was again taken, digitized, and displayed as shown in Fig. 15. Because of the presence of the cavity, hot spots appeared.

The cavity was deepened from 6 to $14 \mathrm{~mm}$, and the same procedures were repeated; this yielded another set of data as shown in Fig. 16. As expected, the sharp ridges in Fig. 15b are rounded off in Fig. $16 \mathrm{~b}$ because of the spread of the hot spots.

As noted earlier, the first picture (Fig. 14) was used to establish ground-level energies. To study the net effect due to material defects, the data in Figs. 15 and 16 must be "cleaned" by subtracting out the ground-1evel energies. This operation also removes from the view field the misleading signals, which, in the present case, are caused by those hot spots that result from the nichrome heater. This cleaned data set is entered into the computer memory and used for analysis.

It is quite obvious that, with the infrared image digitized in a twodimensional array, the data available for analysis are plentiful. Many criteria can be used for feature extraction, but only six were selected for test purposes. During this quarter, the extraction method used was that of passing a constant $\mathrm{T}$ plane through the $\mathrm{T}$ surface. This generates isotherm contours at selected T levels; in Fig. 15, for example, the area enclosed by the isotherm contours can thus be evaluated and plotted versus $T$ as shown in Fig. 17a.

C $T$ dxdy Additional use of these isotherm contours can be made by calculating $\int_{A} \mathrm{~T}$ dxdy over the area A enclosed by the contour. The integrated value can again be plotted versus $\mathrm{T}$, thus yielding another feature plot (Fig. 17b).*

Figure $17 \mathrm{c}$ was constructed by dividing the ordinates of the curve in Fig. 17b by those in Fig. 1/a and plotting the division versus $\mathrm{T}$. On the other hand, Fig. 17d-f shows the slope of the curves in the aforementioned plots. A repeat of the above procedure using Fig. 16 yields a second set of feature plots as shown in Fig. 18. (Figure 18a-c and e also shows the data from Fig. $17 \mathrm{a}-\mathrm{c}$ and e.) Since the total feature extraction portion of the analysis is complete, the thermal-pattern recognition process can be performed.

The utility of comparing the curves in Fig. 18b is readily observed. Not only are they smooth, but a marked upward curve shift can be observed when the cavity is deepened. Thus, this curve shift can be used for identifying defects.

Note that the curves in Fig 18a, c, and e also characterize a curve shift. The curves in these three plots are less smooth; a cross-over point

\footnotetext{
*In the figure, the integrated value was designated integrated "volume" from a geometrical standpoint.
} 


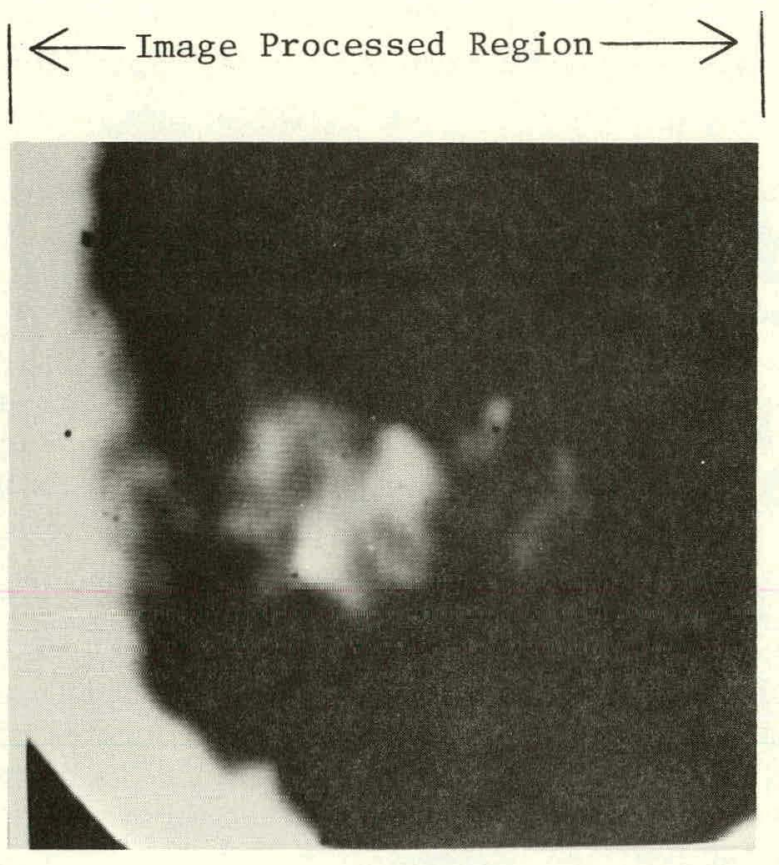

A

B

(a)

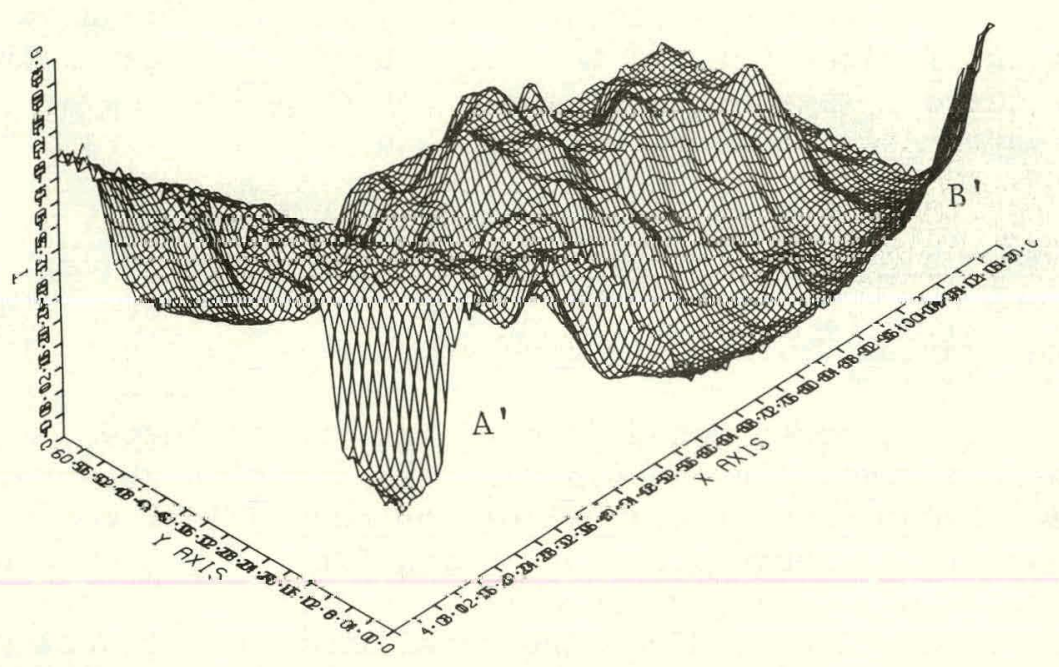

(b)

Fig. 15. Analog-to-digital Conversion of Thermal Pattern of Sample with Enlarged Cavity Defect. (a) Initial steady-state black and white image and (b) isometric display of resultant digitized image. Neg. Nos. MSD-63864-1 and MSD-63866. 


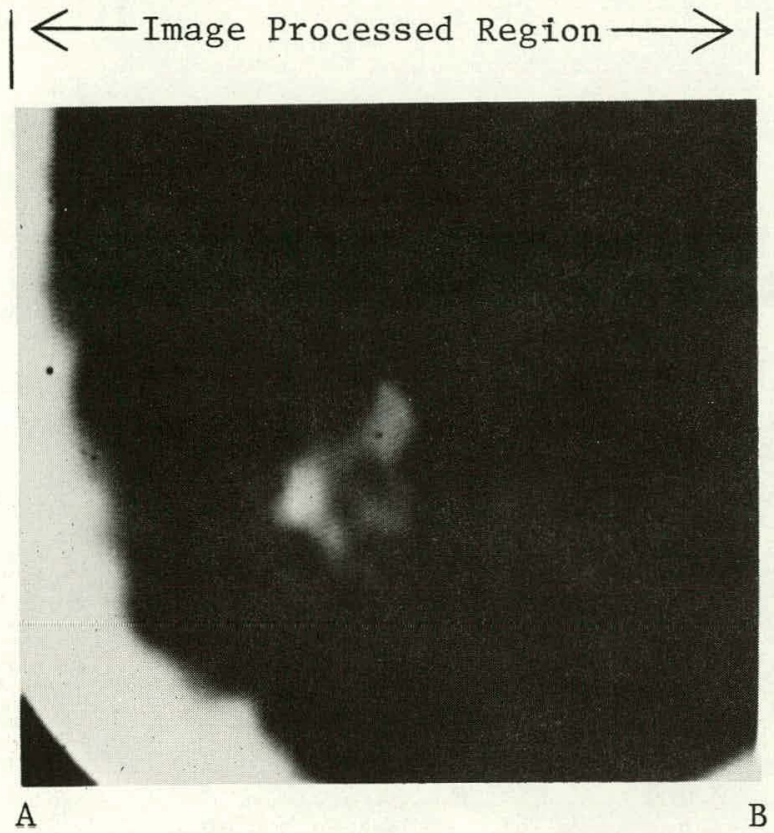

(a)

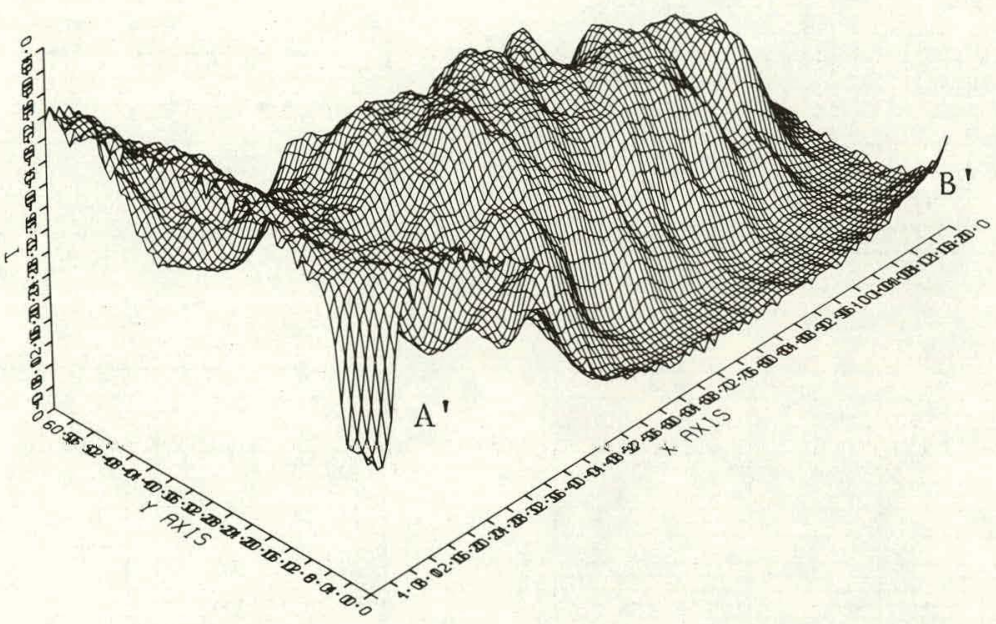

(b)

Fig. 16. Analog-to-digital Conversion of Thermal Pattern of Sample with Enlarged Cavity Defect. (a) Initial steady-state black and white image and (b) isometric display of resultant digitized image. Neg. Nos. MSD-63866-1 and MSD-63864. 
AREA ENCLCSED INSIDE ISOTHERM LOOP

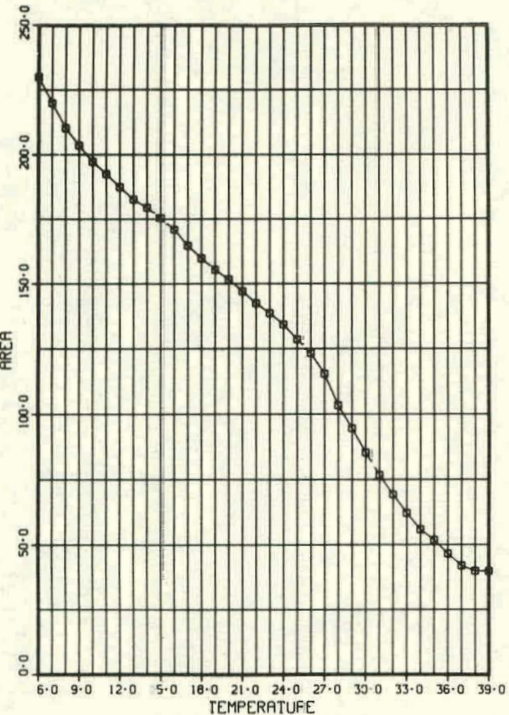

(a)

CHANGE IN ENCLOSED AREA

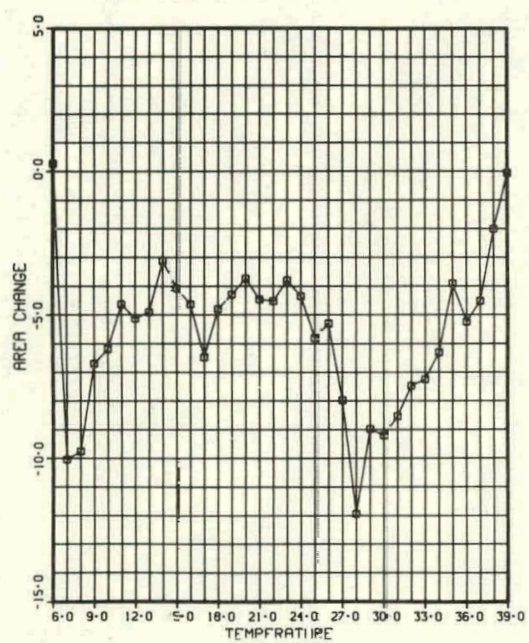

(d)

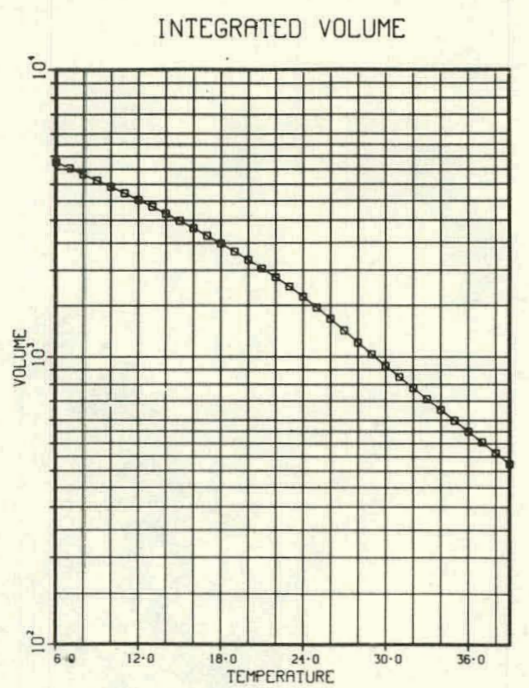

(b)

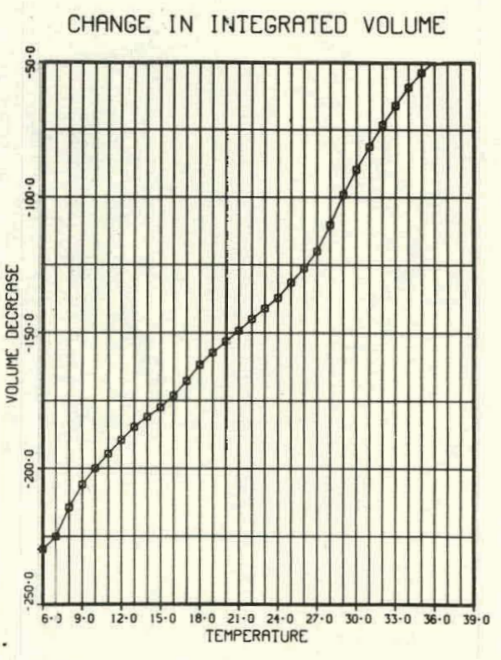

(e)

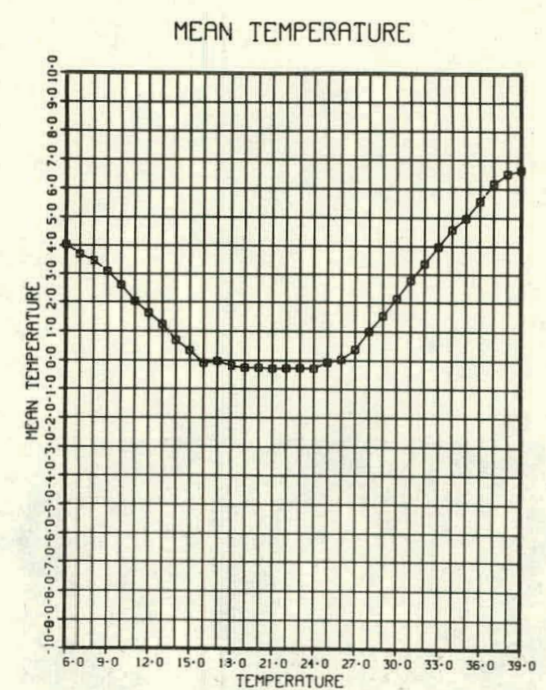

(c)

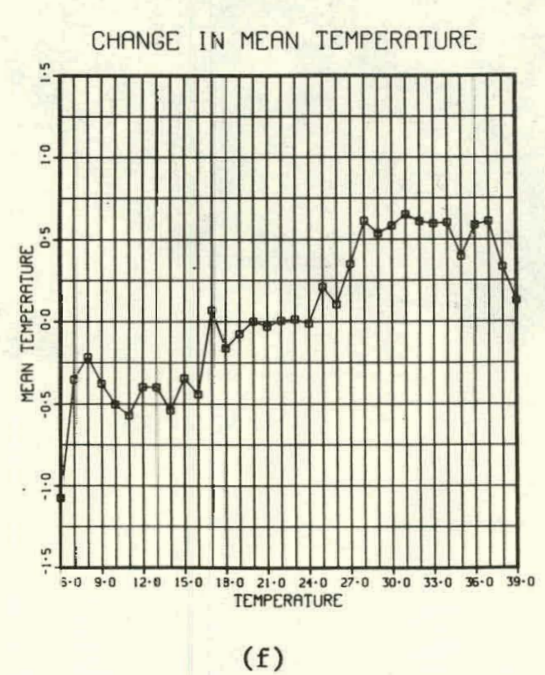

(f)

Fig. 17. Results Obtained from Fig. 15 for Selected Parameters Using Present System for Data Analysis (Cavity Defect). Neg. Nos. MSD-63905 through MSD-63910. 
AREA ENCLOSED INSIDE ISOTHERM LOOP

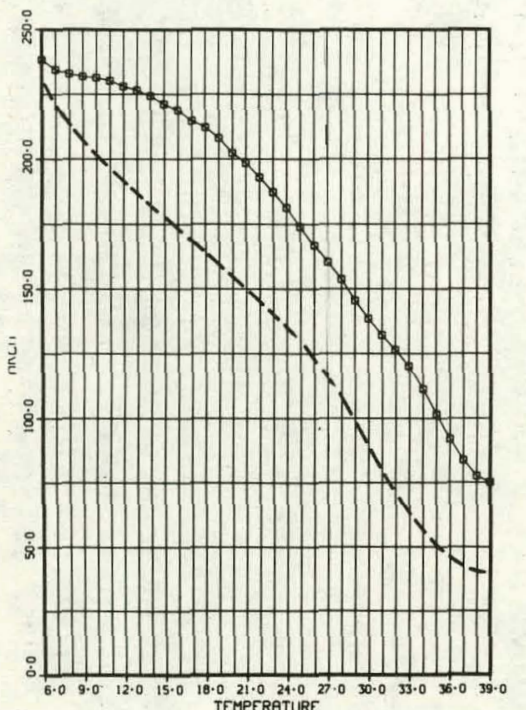

(a)
INTEGRATED VOLUME

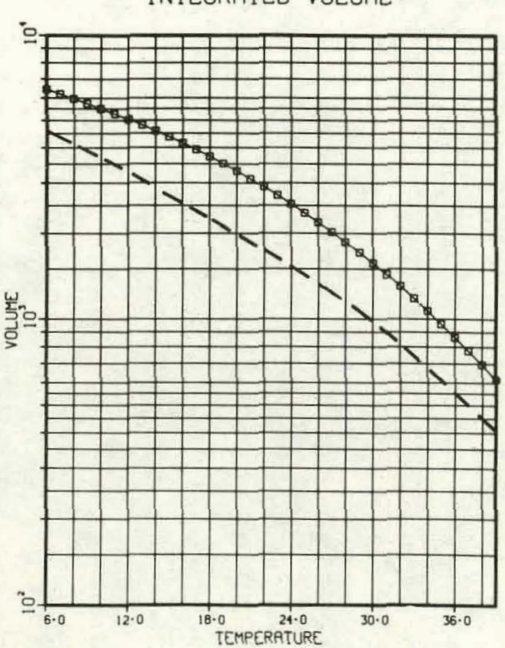

(b)

CHANGE IN INTEGRATEC VOLUME

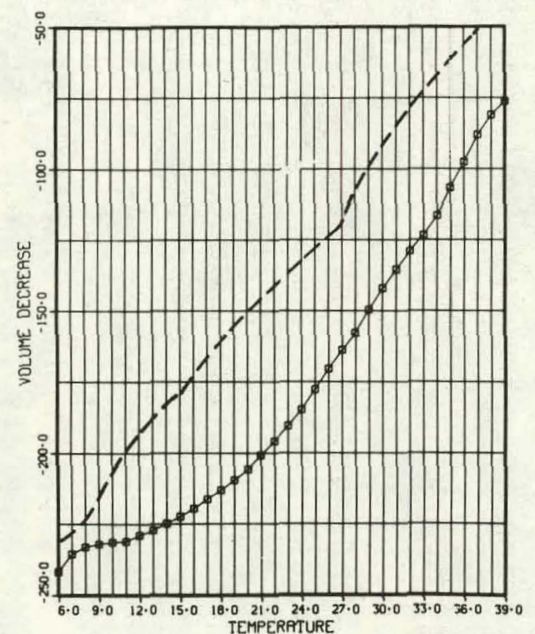

(e)
MEAN TEMPERATURE

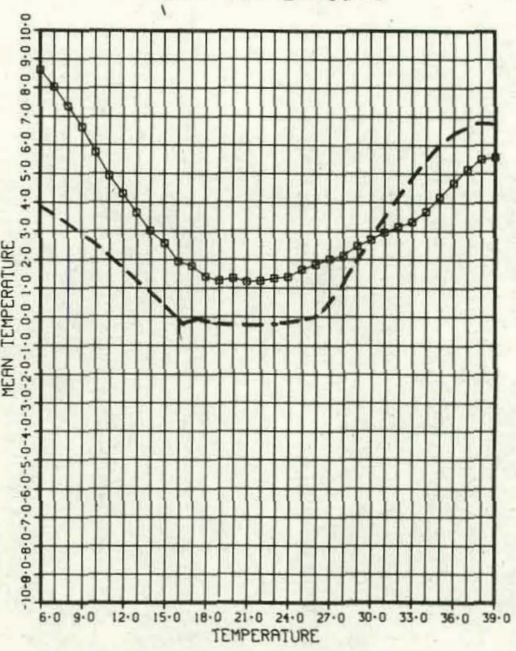

(c)

CHANGE IN MEAN TEMPERATURE

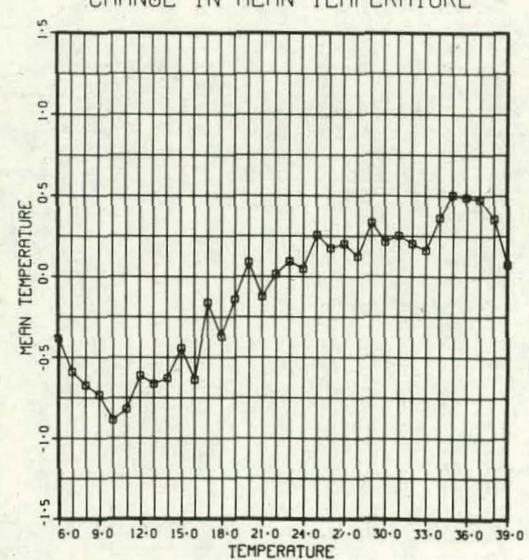

(f)

(d)

Fig. 18. Results Obtained from Fig. 16 for Selected Parameters Using Present System for Data Analysis (Enlarged Cavity Defect). Results from Fig. 17 are shown by dashed lines in (a)-(c) and (e). Neg. Nos. MSD-63911 through MSD-63916. 
even appears in Fig. 18c, which signifies that caution must be exercised when this feature is used for analysis. Other feature curves (Figs. 17d and f and $18 \mathrm{~d}$ and $\mathrm{f}$ ) are quite irregular and therefore useless for pattern recognition.

Interior materials discontinuities will affect the observed surface temperature pattern. However, when using thermal-pattern recognition to identify interior flaws, the resolution depends on the surface boundary conditions applied as well as thermophysical properties of the material that comprises the test system. The method is additionally complicated by the fact that the temperature resolution capability of the infrared camera is $0.2^{\circ} \mathrm{C}$ at a $30^{\circ} \mathrm{C}$ object temperature. ${ }^{2}$ Hence, an instrumentation limit to identification of flaws exists.

'l'he need exists fur a model analycis that permits study of the effects of individual parameters, which is economically infeasible with laboratory experiments. In the model dualysis, one can conduct synthesized tests of specimens with simple material defects and analyze the results. Hence, this model analysis will reveal the strength and limitation of the patternrecognition method unperturbed by the instrumenl ersul that cannot be icolated in experiments. This analysis will be the main task during the next quarter.

\section{Refractory-installation Practices -- Acoustic Emission}

Thermomechanical failure of refractories exposed to high pressure and temperature could present a highly undesirable operational condition. This type of failure is anticipated in coal-gasification plants (especially high Btu) because of (a) expected large vessel size, (b) high operating pressures, (c) high operating temperature, and (d) exposure to severe erosive-corrosive environmenls.

Cracks in the refractory lining can lead to local hot spots on the pressure-boundary plate, and heat losses through a cracked lining can be sub stantially higher than through a sound lining. If a sound refractory lining can be produced, the lining thickness can be reduced, which may result in an increase in the net capacity of the conversion system or a decrease in vessel size. Thus, control of the extent of cracking during heatup should aid in development of a strong, longer-1ife component.

The sensitivity of acoustic-emisston melluds for detection of cracking is being studied so that cracking of refractory linings during curing can be monitored and thus controlled. This quarter a full-scale test panel was cured and continuously monitored for acoustic emission during the entire temperature cycle. The full-scale panel tested consists of a 19-mm steel plate, which simulates the pressure boundary with a 229-mm-Lhick monolithic refractory lining. The test panel was $1.01 \times 1.27 \mathrm{~m}$, and anchors were spaced at 229-mm intervals as shown in Fig. 19. These were standard " $Y$ " anchors (hangers), which were welded to the steel shell as shown in Fig. 20. The anchors were made entirely of Type 304 stainless steel. Thermocouples (copper-constantan) were attached to the anchors at 25-mm intervals through the refractory thickness at two locations, one near the center of the refractory and the other $178 \mathrm{~mm}$ from one edge (Fig. 19). The array of thermocouples at these two positions enabled establishment of the temperature pro- 


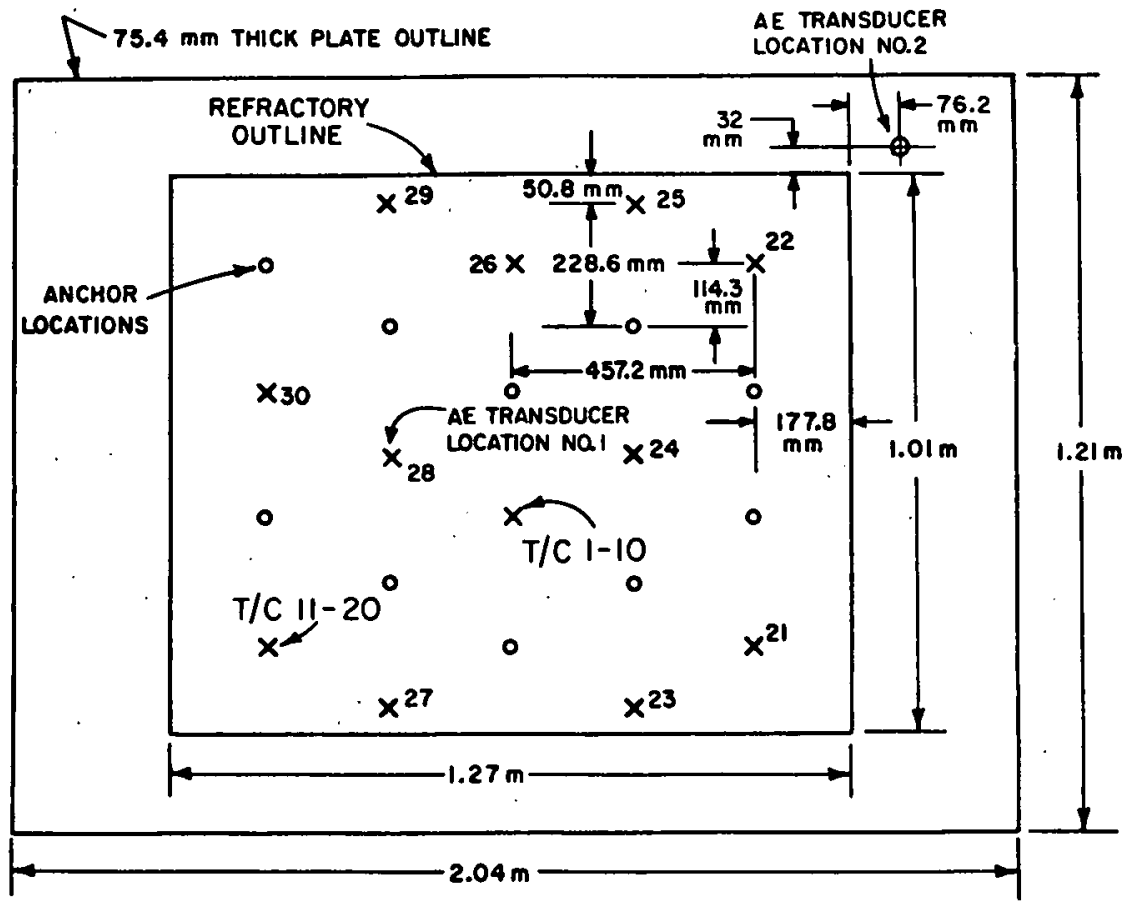

Fig. 19. Plan View of Full-scale Refractory Test Panel. Neg. No. MSD-63823.

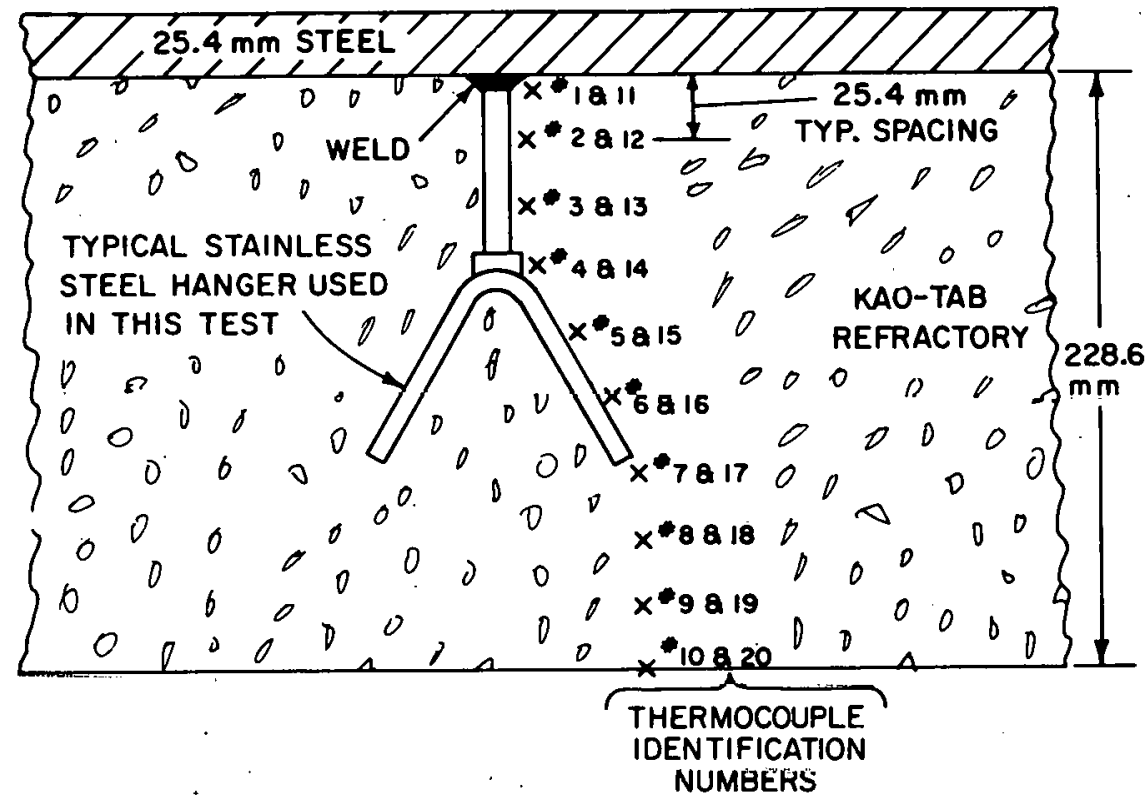

Fig. 20. Cross-section of Full-scale Refractory Test Panel Showing Hanger and Throughwall Position of Thermocouples. Neg. No. MSD-63826. 
file through the refractory. Additional thermocouples were placed such that the temperature distribution of the refractory surface that faces the heating elements could be determined (Fig. 19).

The refractory used for this test panel was Babcock and Wilcox $\mathrm{KAOTAB}$, which is a $93 \%$ alumina refractory with a nominal density of $2400 \mathrm{~kg} / \mathrm{m}^{3}$. The refractory was cast using the "ball-in-hand" consistency test and vibrated using a portable eccentric vibrator. Mixing was accomplished through use of a standard "paddle wheel" mixer, which has a capacity of two bags per mix. Some problems occurred in the casting process; the "ball-in-hand" consistency tended to dry rapidly, and fast work was required to avoid initial "set" before addition of the next batch of material. After casting, the refractory was allowed to air dry for 14 days at room temperature.

Two nondestructive examinations were conducted on the test pane1: acoustic emission, to investigate the relation between refractory shrinkagc cracking and acoustic emission, and gamma radiography, to establish crackpattern detection capability before and after curing.

The test-panel heat-up cycle was regulated by an automatic temperature controller system, shown schematically in Fig. 21 .

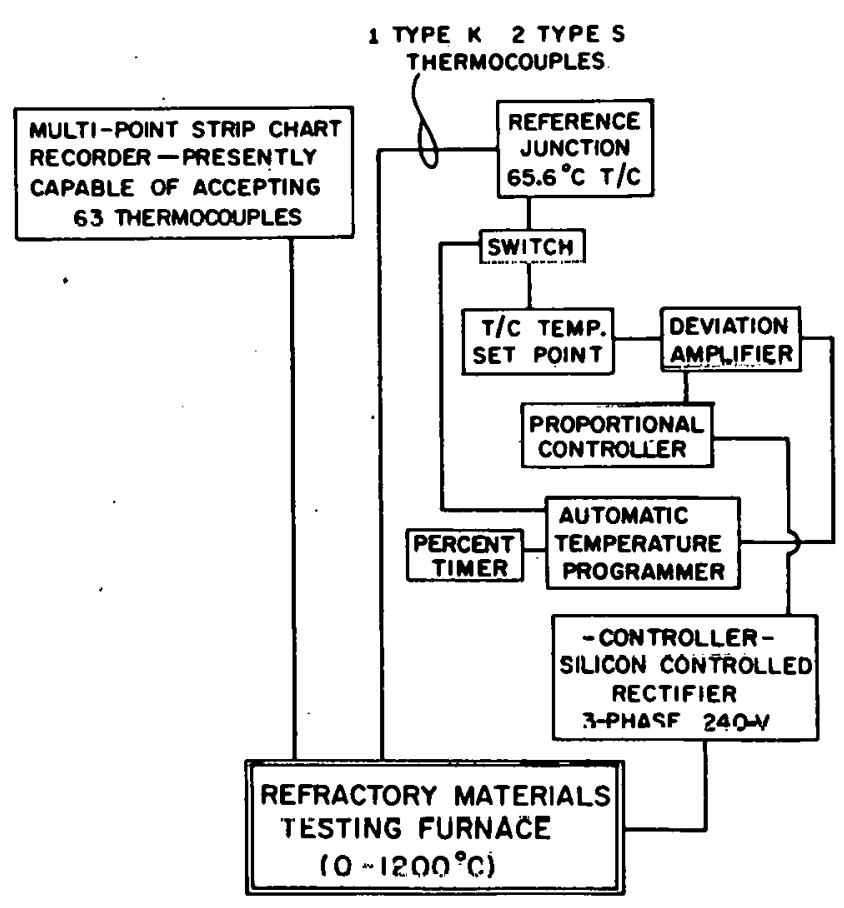

Fig. 21. Schematic of Automatic Control System for Thermal Curing of Ful1-scale Refractory Test Panels. Neg. No. MSD-63821.
Resonant frequency (center frequency $175 \mathrm{kHz}$ ) acoustic-emission transducers were placed at two locations. Location 1 , near the center of the test panel, was selected to be directly over a hanger (same position as thermocouple 28 ), and location 2 , was chosen such that no refractory would be directly. below it. Figurc 19 shows the placement of thcsc transducers. The surface near the center of the steel plate was estimated to reach a temperature in excess of that which the transducer could withstand (i.e., $>200^{\circ} \mathrm{C}$ ). To permit data to be obtained at this 1ocation, a quartz waveguide $32 \mathrm{~mm}$ in diameter and $64 \mathrm{~mm}$ in length was coupled to the stee $\perp$ she $\perp$ using a commercialiy available high-temperature couplant. The acousc1c-em1ssion data-acquisition system is shown in Fig. 22. The acoustic-emission data processor was set for a fixed voltage threshold of $1.95 \mathrm{~V}$. The output, in total acousticemission counts, was recorded on a Hewlett-Packard Mode1 7045A X-Y Recorder. schedule:

The refractory was intended to be cured using the following heat-up 


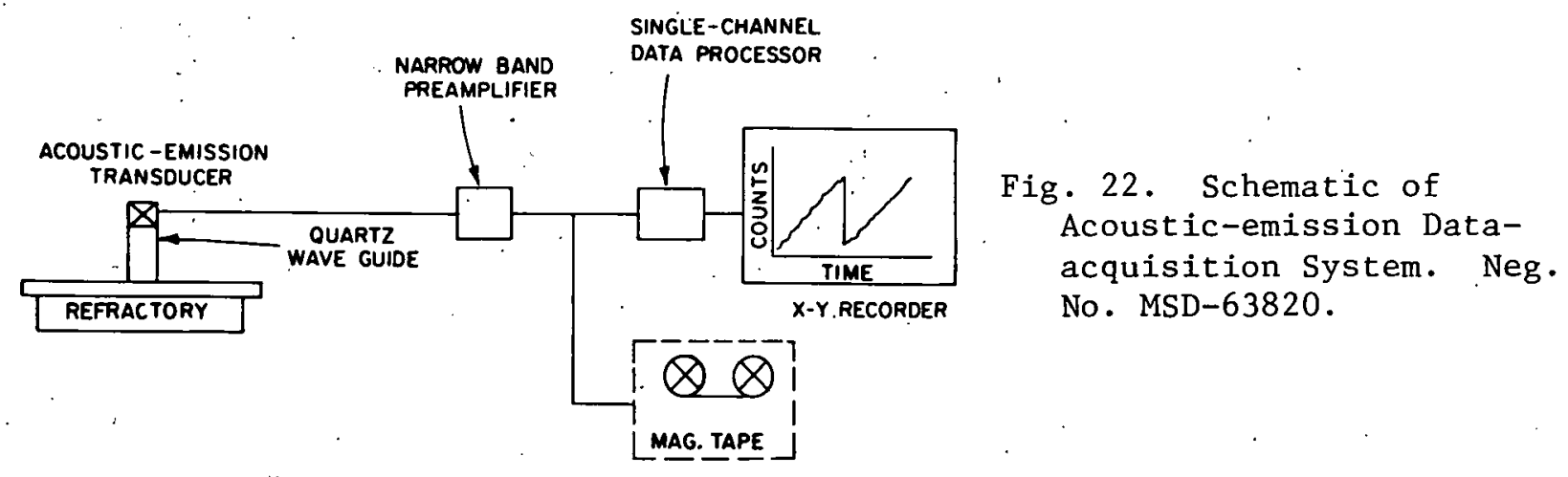
A. A $5.76 \times 10^{-4} \mathrm{~s}$ hold at $93-204^{\circ} \mathrm{C}$
B. Heat up at $1.06 \times 10^{-2}{ }^{\circ} \mathrm{C} / \mathrm{s}$ to $538^{\circ} \mathrm{C}$
C. Hold at $538^{\circ} \mathrm{C}$ for $2.88 \times 10^{4} \mathrm{~s}$
D. Heat up at $1.06 \times 10^{-2}{ }^{\circ} \mathrm{C} / \mathrm{s}$ to $1093^{\circ} \mathrm{C}$
E. Hold at $1093^{\circ} \mathrm{C}$ for $1.80 \times 10^{4} \mathrm{~s}$.

The actual heat-up schedule (using surface thermocouple data) was as follows (Fig. 23):
A. A $5.76 \times 10^{4} \mathrm{~s}$ hold between 190 and $220^{\circ} \mathrm{C}$
B. Heat up at $1.28 \times 10^{-2}{ }^{\circ} \mathrm{C} / \mathrm{s}$ to $450^{\circ} \mathrm{C}$
C. Hold for $3.96 \times 10^{4} \mathrm{~s}$ at $450^{\circ} \mathrm{C}$
D. Heat up to $930^{\circ} \mathrm{C}$ at $1.75 \times 10^{-2}{ }^{\circ} \mathrm{C} / \mathrm{s}$ for $1.08 \times 10^{4} \mathrm{~s}, 5.8 \times 10^{-3}{ }^{\circ} \mathrm{C} / \mathrm{s}$ for
$3.24 \times 10^{4} \mathrm{~s}$, and $4.17 \times 10^{-3}{ }^{\circ} \mathrm{C} / \mathrm{s}$ for
$2.16 \times 10^{4} \mathrm{~s}$
E. Hold at $930^{\circ} \mathrm{C}$ for $5.04 \times 10^{4} \mathrm{~s}$.

Fig. 23. Time-temperature Diagram for Thermocouple Positions 10 and 7 for curing Cycle. Neg. No. MSD-63828.

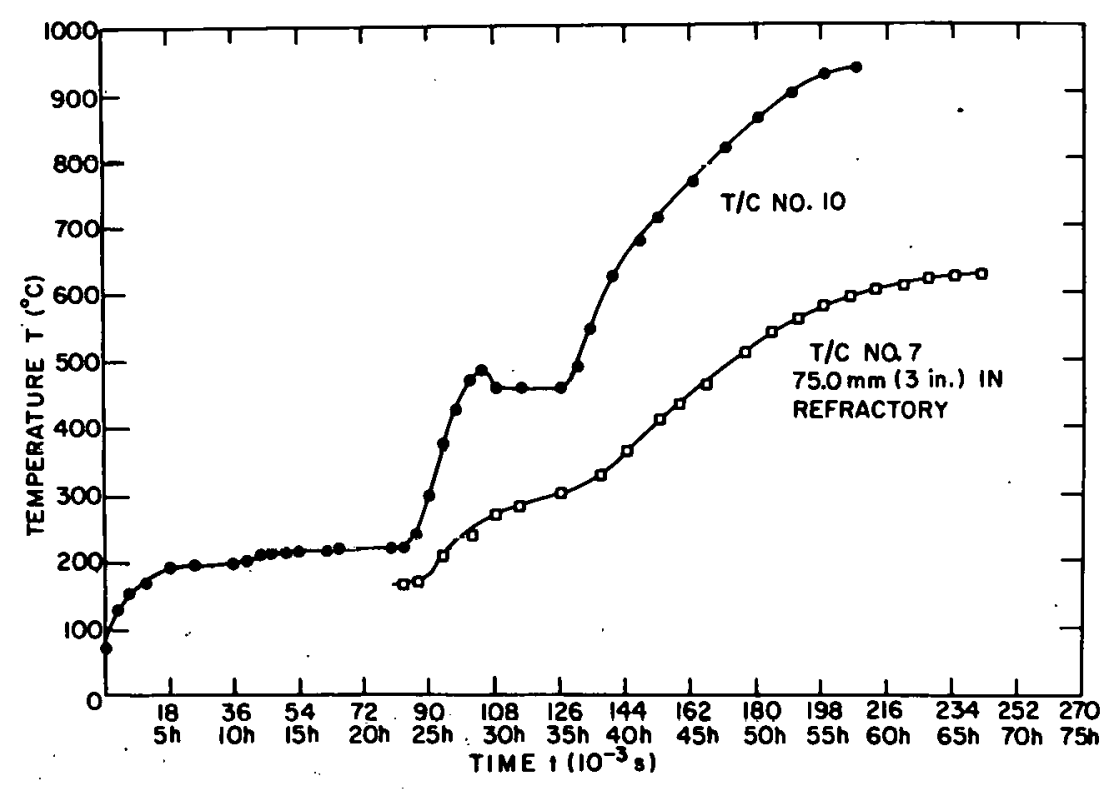


The resultant plot of total acoustic-emission counts versus time is shown in Fig. 24 for transducer location 1. Comparing the total counts versus time with the temperature of a thermocouple located on the inside of the refractory, e.g., thermocouple 7 (75 $\mathrm{mm}$ deep), indicates that the acousticemission total counts track the temperature closely (Fig. 25). This is additionally established by observing total counts versus temperature (Fig. 26). Note in Fig. 26 that the total counts increase significantly with increasing temperature but the count rate is reduced after holding at temperature.

Similar results were obtained at acoustic-emission location 2 , although the absolute value of the total count was somewhat less than at location 1 . This experiment gives rise to the following question relative to the source

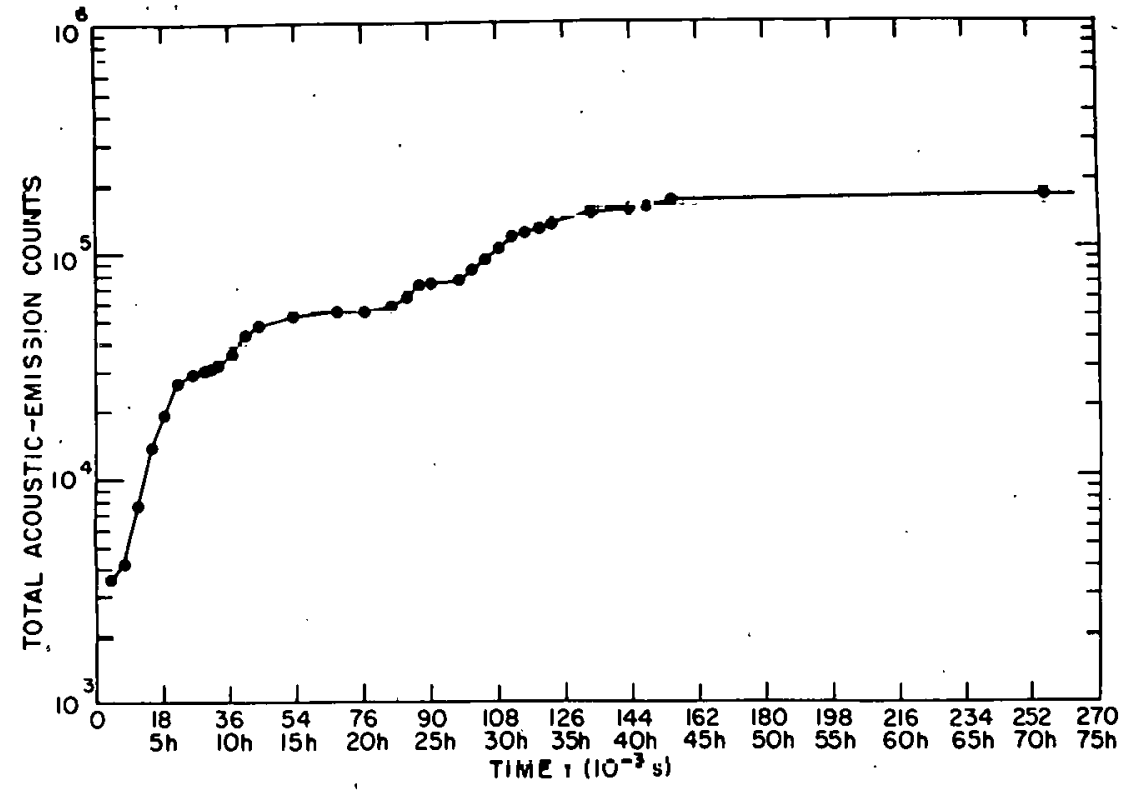

Fig. 24. Total Acousticemission Counts as a Function of Time for Acoustic Transducer Location 1. Neg. No. MSD-63833.

Fig. 25. Comparison of Time-Temperature Plot with Total CountsTime Plot. Neg. No. MSD-63877.

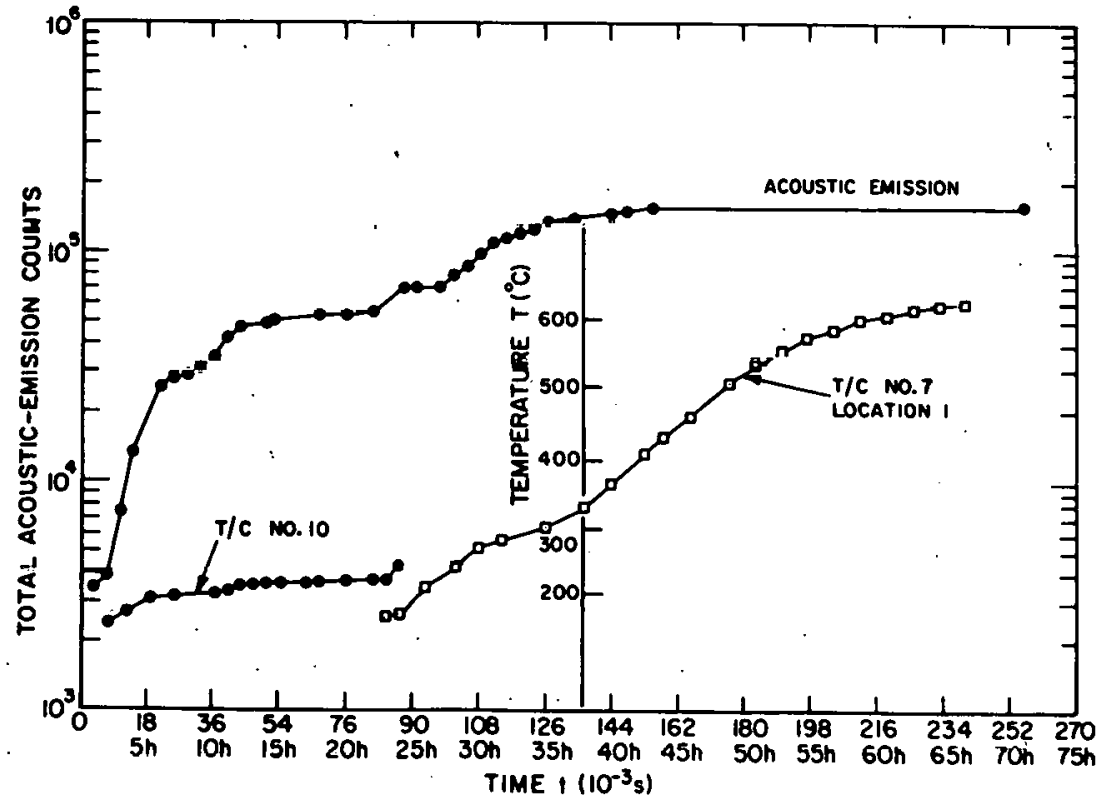




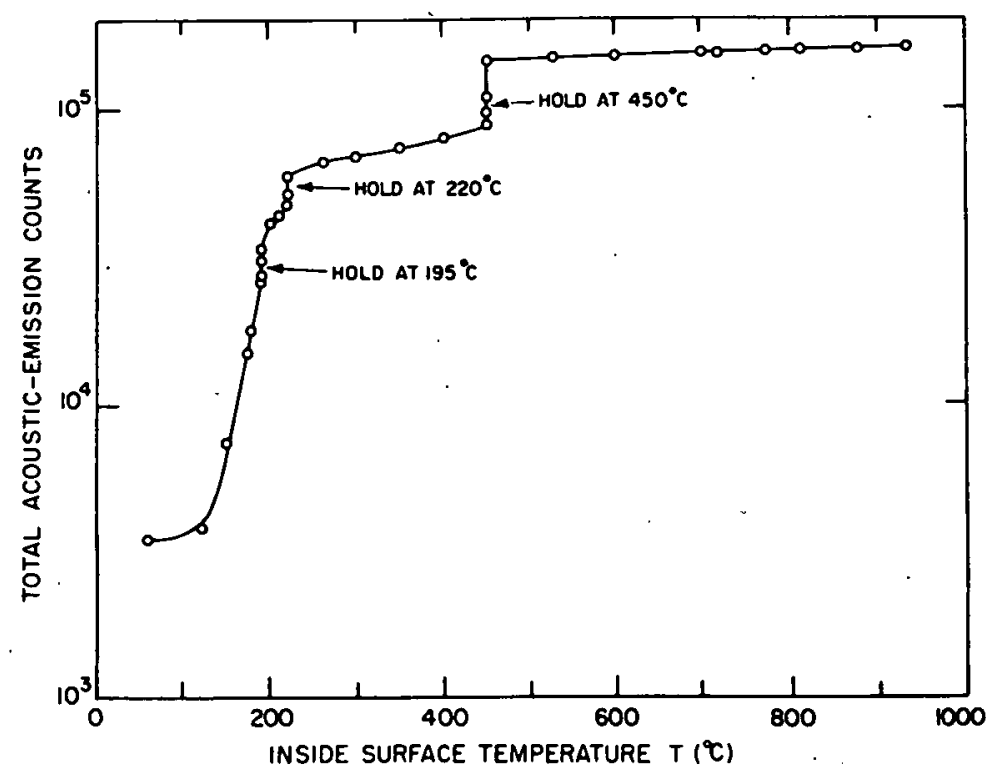

Fig. 26. Total Counts vs Temperature for Refractory Curing Cycle. Neg. No. MSD-63819.

of the emission: are the emissions caused by (a) expansion of the steel plate or (b) the difference in the thermal expansion between the refractory and steel (which results in rubbing)? In future work, if possible, a unique frequency window for the refractory cracking emissions will be determined. The present results are promising, however, and future curring will be at a much slower temperature rate to determine whether the cracking is less severe.

Gamma radiographs were taken before and after curing the test panel, but the results are still being tabulated and present indications show that few cracks were detected. Cores $100 \mathrm{~mm}$ in diameter will be obtained from the refractory, and tests will be conducted to determine the physical properties of the material as well as extent of the cracking that occurred during the curing.

Throughwall temperature distributions were obtained as a function of time. The time-temperature distribution for the curing cycle is shown in Fig. 27. The surface thermocouple at location 2 reads higher at all times than the one at location 1 , which is near the center of the refractory. This difference is attributed to the fact that some heating elements near the center failed during the cycle, and, thus, the edge wall temperature is slightly higher. The thermal conductivity of the refractory is obtained by plotting the temperature distribution through the wall for steady-state conditions. Figure 28 is a plot of the temperature distribution through the wall at the two locations where thermocouples were distributed every $25 \mathrm{~mm}$. Note that the throughwall temperature distribution for thermocouples 11-20 is discontinuous. This probably resulis from the thermocouples belng shaken loose by the vibrator, which was necessary to remove the air from the refractory during casting.

The slope of the first $180 \mathrm{~mm}$ is $n 2.05^{\circ} \mathrm{C} / \mathrm{mm}$. The slope of the second portion is $44.8{ }^{\circ} \mathrm{C} / \mathrm{mm}$. This difference is perhaps attributable to the fact that the monolithic refractory layer was actually cast as a two-component liner. The first $178 \mathrm{~mm}$ were poured with KAOTAB, which has a thermal conductivity of $51.7 \mathrm{~W} /\left(\mathrm{m}^{2}-{ }^{\circ} \mathrm{K}\right)$, and the top $50 \mathrm{~mm}$ were poured with KAOTUFF, which has a thermal conductivity of $42.6 \mathrm{~W} /\left(\mathrm{m}^{2}-{ }^{\circ} \mathrm{K}\right)$. 


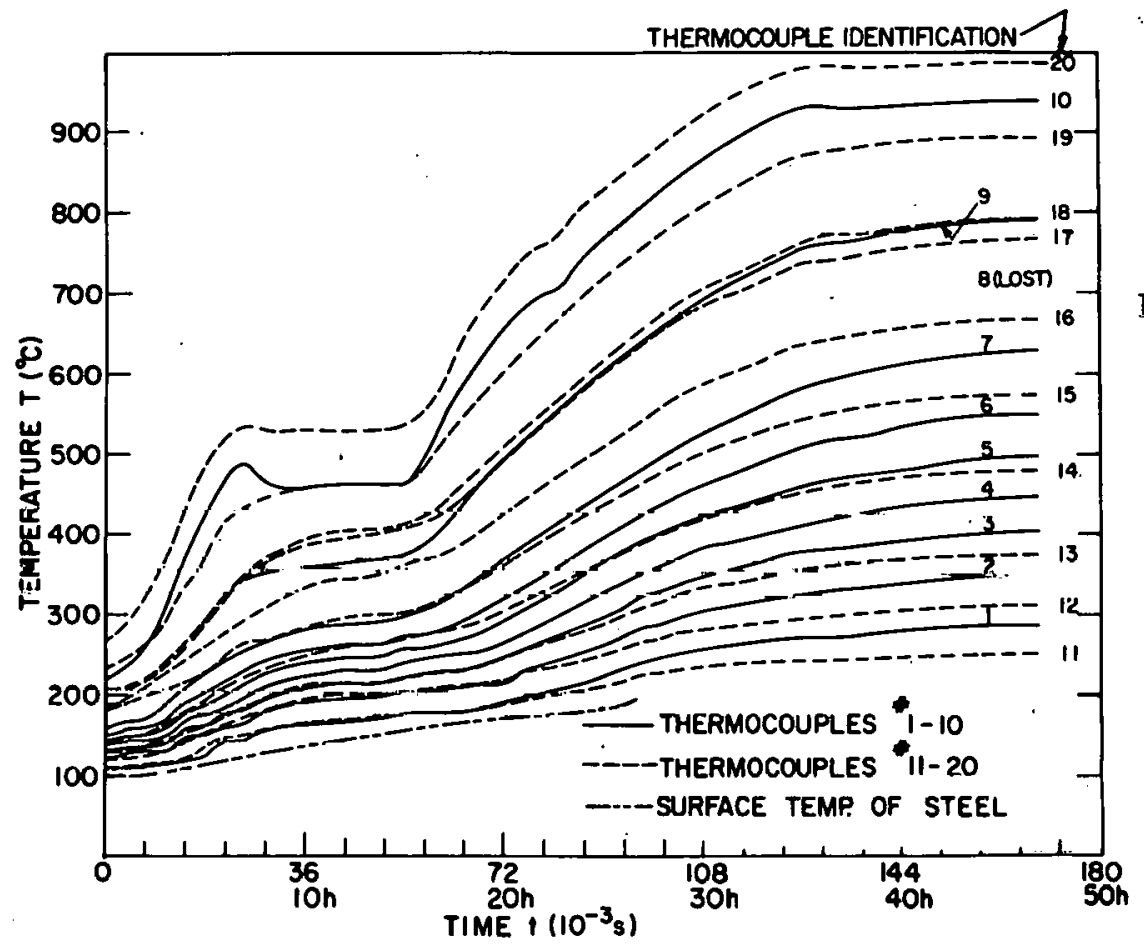

Fig. 27, Time-Temperature Plots for All Thermocouples at the Two Throughwall Locations. External surface tempcraturc is aloo ehown. Neg. No. MSD-63822.

Fig. 28. Temperature Distribution through the Refractory Wall for Steady-state Conditions $\left(930^{\circ} \mathrm{C}\right)$. Neg. No. MSD63829 .

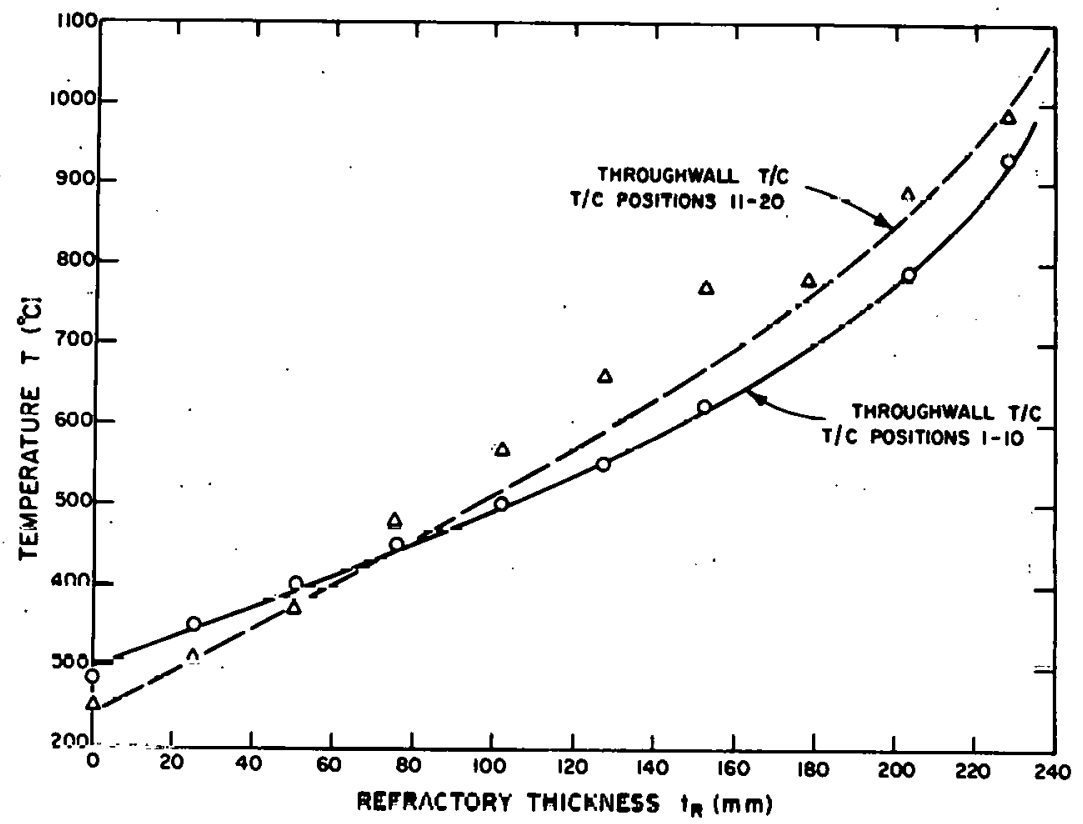

Task D -- Corrosion Behavior of Materials in Coal-conversion Processes (K. Natesan and 0. K. Chopra)

The objectives of this program are to (1) experimentally evaluate the high-temperature corrosion behavior of iron- and nickel-base alloys in gas environments with a wide range of oxygen, sulfur, and carbon potentials, (2) develop uniaxial tensile data on four selected commercial alloys upon exposure to simulated multicomponent gas environments, and (3) develop a systems approach, based upon available thermodynamic and kinetic information, 
for evaluating possible corrosion problems in different coal-conversion processes. Correlations will be developed that depict the corrosion behavior of materials as a function of process conditions, which will enable extrapolations and predictions of long-term performance of specific components.

To evaluate the corrosion problems anticipated in coal-gasification systems, it is necessary to establish the gas compositions as a function. of temperature and pressure. The reported gas compositions at various locations in different processes are analyzed at room temperature by means of a gas chromatography technique. Understanding of the corrosion behavior of materials upon exposure to complex multicomponent gas environments at elevated temperatures requires a judicious extrapolation of room-temperature composition to the temperatures of interest. For this purpose, a computer program based upon thermodynamic equilibria between various molecular gas species has been developed to characterize an environment that includes $\mathrm{CO}, \mathrm{CO}_{2}, \mathrm{H}_{2}, \mathrm{CH}_{4}, \mathrm{H}_{2} \mathrm{O}$, $\mathrm{H}_{2} \mathrm{~S}$, and $\mathrm{NH}_{3}$. The analysis is used to examine the gas environment as a function of temperature and pressure in different pilot-plant coal-gasification processes. The results are used to evaluate the stability of phases in specific alloys of interest, such as Types 304 and 310 stainless steel, Incoloy 800, and Inconel 671, in the process environments.

\section{Coal-gasification Processes}

At present, five gasification processes are under development for conversion of coal into high Btu pipeline-quality gas. These processes and their developers are HYGAS (Institute of Gas Technology), $\mathrm{CO}_{2}$-Acceptor (Consolidation Coal Company), Synthane (U. S. Bureau of Mines), Agglomerating Ash (BattelleUnion Carbide), and Bi-Gas (Bituminous Coal Research, Inc.). In general, the combustion gas composition in the different processes depends on the type of process and feedstock composition in addition to operating temperature and pressure. The gas mixtures usually consist of $\mathrm{CO}, \mathrm{CO}_{2}, \mathrm{H}_{2}, \mathrm{H}_{2} \mathrm{O}, \mathrm{CH}_{4}, \mathrm{H}_{2} \mathrm{~S}$, and $\mathrm{NH}_{3}$. The maximum operating temperatures and pressures and room-temperature compositions of the gas mixtures anticipated ${ }^{3}$ in different pilot-plant processes are listed in Table $V$. The compositions are based on the use of lowsulfur coal feedstock. In these processes, the operating pressures are almost constant; however, the temperatures vary over a wide range, e.g., the peak temperature at the coal burning regions of the gasifier is several hundred degrees higher than at the gas exit and primary cyclone regions of the system. Therefore, it is essential to establish the variation in the reaction potential of different gas species as a function of temperature before an assessment of the suitability of an alloy for specific applications can be made. For this purpose, the computer program 4 was used to evaluate the oxygen, sulfur, and carbon potentials as a function of temperature in the range of $800-1400 \mathrm{~K}$ for the gas environments listed in Table $\mathrm{V}$.

Figure 29 shows the variation of oxygen partial pressure $\left(\mathrm{PO}_{2}\right)$ as a function of temperature at the operating pressure for each of the five processes. The results indicate the oxygen partial pressure has a maximum variation of a factor of $\sim 30$ between the Bi-Gas and Battelle-Union Carbide processes. Figure 30 shows the calculated values for the sulfur partial pressure $\left(P_{2}\right)$ as a function of temperature for the five processes. The results indicate that the $\mathrm{P}_{S_{2}}$ values are almost the same in the Battelle-Union Carbide, Synthane, and HYGAS processes; however, the values for the $\mathrm{Bi}-\mathrm{Gas}$ and $\mathrm{CO}_{2}$-Acceptor 
TABLE V. Estimated Gas. Compositions (vo1\%) and Temperazure and Pressure Conditions in Varicus Coal-gasification ?rocesses with Low-sulfur Coal Feedstock ${ }^{a}$

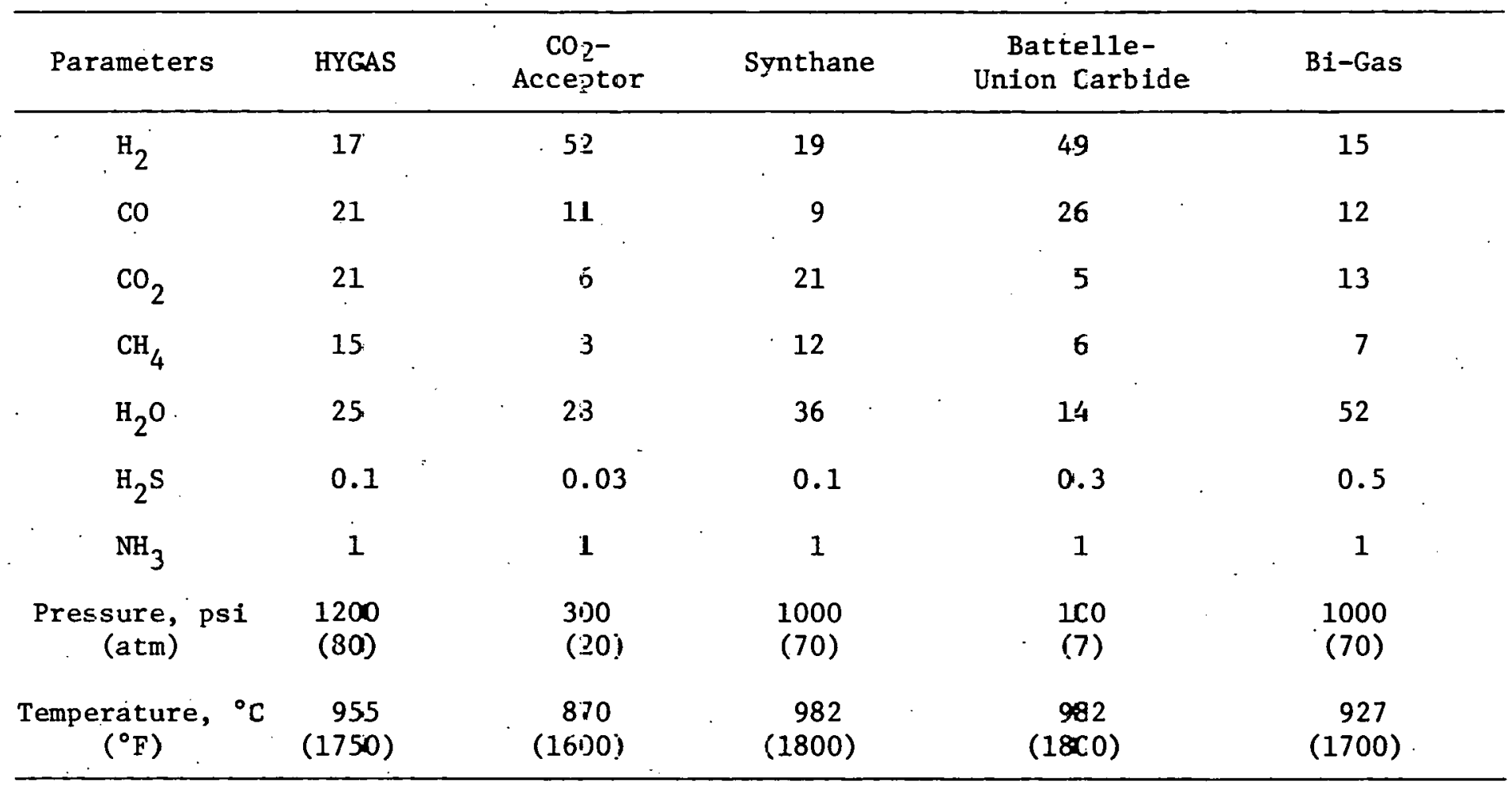

a From Ref. 3; conversion factor: 1 atm $=0.101356 \mathrm{MPa}$. 


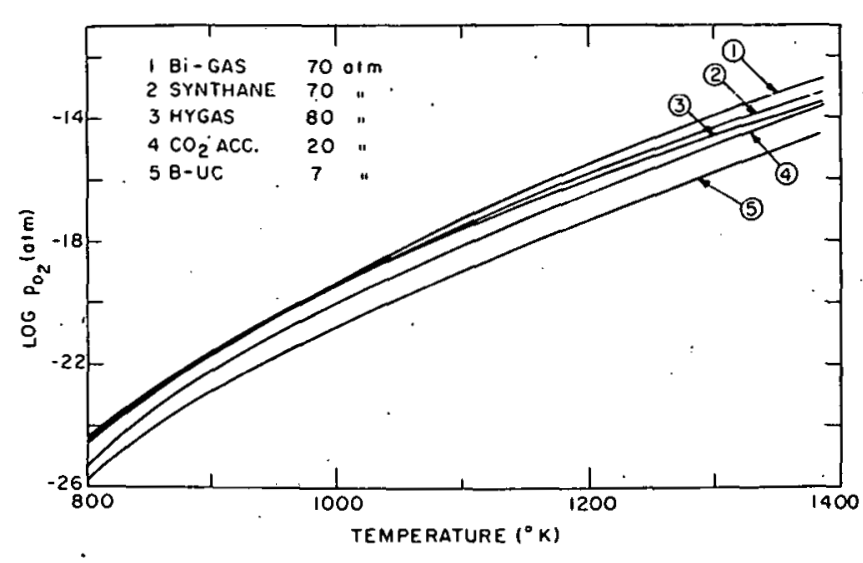

Fig. 29. Variation of Oxygen Partial Pressure as a Function of Temperature Calculated for Different Coalgasification Processes. Conversion factor: $1 \mathrm{~atm}=0.101356 \mathrm{MPa}$. Neg. No. ANL-306-76-179.

Fig. 30. Variation of Sulfur Partial Pressure as a Function of Temperature Calculated for Different Coal-gasification Processes. Conversion factor: 1 atm $=0.101356$ $\mathrm{MPa}$. Neg. No. ANL-306-76-180.

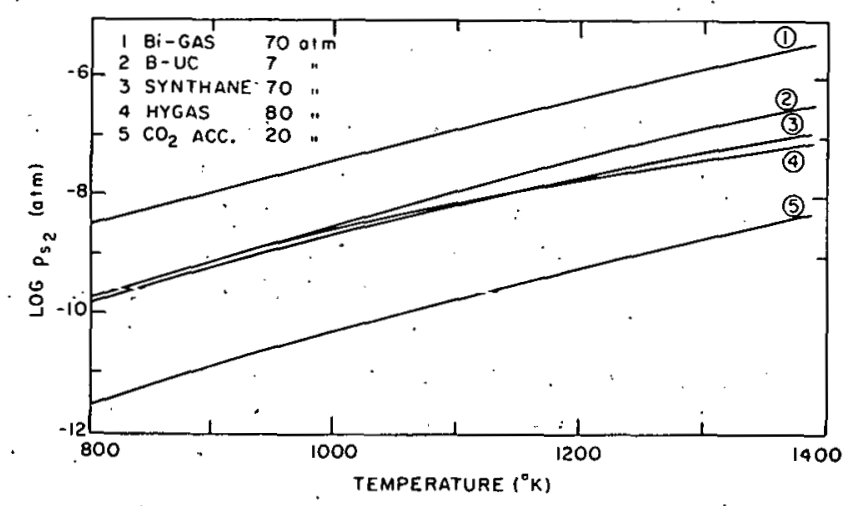

processes are factors of $\sim 30$ higher and lower, respectively. Figure 31 shows the calculated values for the carbon activity as a function of temperature for the five processes. The results indicate that in all the processes, the carbon activity values increase rapidly as the temperature decreases from 1400 to $1000 \mathrm{~K}$. To lend perspective to this diagram, one can consider Type 304 stainless steel, which, upon exposure to the $\mathrm{CO}_{2}$-Acceptor process environment, will undergo negligible carburization at $1400 \mathrm{~K}$ but will carburize to $\sim 1.5 \mathrm{wt} \%$ carbon at $1100 \mathrm{~K}$, on the basis of the available carbon activity-concentration

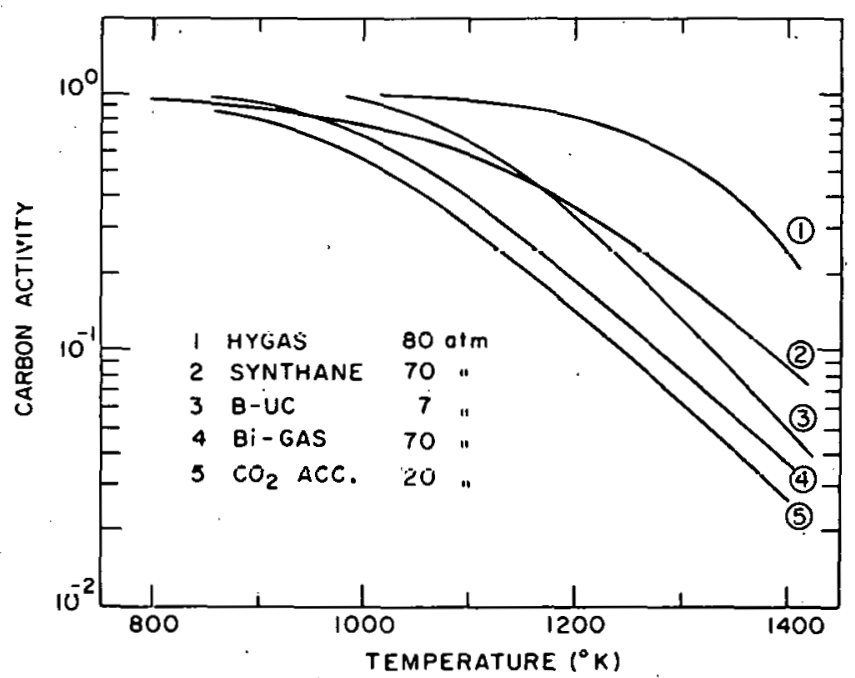

Fig. 31. Variation of Carbon Activity as a Function of Temperature Calculated for Different Coal-gasification Processes. Conversion factor: $1 \mathrm{~atm}=0.101356$ $\mathrm{MPa}$. Neg. No. ANL-306-76-181. 
data for the steel. 5 Under these conditions, the loss in mechanical properties of the material, and, in general, for all iron-base alloys, is a potential problem. It is evident from Figs. 29-31 that the processes can have a wide variation in gas composition, and, therefore, materials performance in the different processes is not expected to be the same, even for identical conditions of temperature and pressure.

\section{Alloy Behavior in Process Environments}

The principal alloys used in the elevated-temperature regions of the gasifiers are iron and nickel base with chromium as a major constituent. The oxidation data for $\mathrm{Fe}-\mathrm{Cr}$ and $\mathrm{Ni}-\mathrm{Cr}$ alloys show that chromium oxide will be thermodynamically stable even at low chromium concentrations in the alloy; however, a large chromium content in the alloy is required for the oxidation process to change from internal oxidation to formation of an external protective layer. The chromium concentration required for external scale formation is a function of temperature and oxygen potential in the environment, and these functional relationships are yet to be established. It has been reported that $20-25 \mathrm{wt} \%$ chromium in Ni-Cr alloys is necessary for satisfactory oxidation resistance at $900^{\circ} \mathrm{C}$ and $0.1 \mathrm{~atm}$ oxygen pressure. 6 Furthermore, in the presence of a sulfidizing environment, the alloy behavior is strongly dependent on the relative amounts of chromium oxide and chromium sulfides present in the material. Since the sulfide layers are not protective. in nature and have growth rates that are orders of magnitude larger than the oxide layers, the corrosion rates of these alloys may become prohibitively large. In the present report, we examine the stability of different phases in Type 304 stainless steel, Incoloy 800 , and Inconel 671 with the use of thermochemica1 diagrams ( $\mathrm{p}$ lots of 1 og $\mathrm{P}_{02}$. versus $\log \mathrm{P}_{\mathrm{S}_{2}}$ ) that were developed from the available thermodynamic data $7-10$ for various oxide, sulfide, and carbide phases. The thermodynamic information for the $\mathrm{Cr}-\mathrm{S}$ binary system is only available at $700^{\circ} \mathrm{C} .11$ Ao a rcoult, somc unccrtainty is associated with the stability regions of different chromium sulfides. Also, the chromium oxidechromium sulfide phase boundary is not well established over a wide range of temperatures. The chemical composition of the alloys used in the present study is 1isted in Table VI.

TABLE VI. Chemical Composition (wt\%) of Alloys Used in Present Work

\begin{tabular}{|c|c|c|c|c|c|c|c|c|}
\hline A11oy & $\mathrm{Fe}$ & $\mathrm{Cr}$ & $\mathrm{Ni}$ & $\mathrm{C}$ & $\mathrm{s}$ & $\mathrm{Mn}$ & Si & Other \\
\hline Type 304 sS & $\mathrm{Ba} 1^{\mathrm{a}}$ & 19 & 10 & 0.06 & - & 1.5 & 0.4 & - \\
\hline Incoloy $800^{b}$ & 46.0 & 21 & 32.5 & 0.05 & 0.008 & 0.75 & 0.35 & $0.38 \mathrm{AI}, 0.38 \mathrm{Ti}$ \\
\hline Inconel $671^{b}$ & - & 48 & 50 & 0.05 & - & - & - & $0.35 \mathrm{Ti}$ \\
\hline Type $310 \mathrm{ss}^{\mathrm{b}}$ & $\mathrm{Bal}^{\mathrm{a}}$ & 25 & 20 & 0.25 & - & 1.5 & 0.4 & - \\
\hline $\begin{array}{c}\text { U.S. Steel } \\
\text { Alloyb }\end{array}$ & $\mathrm{Ba1}^{\mathrm{a}}$ & 18.5 & 17.8 & 0.06 & $0: 011$ & 1.25 & 2.05 & - \\
\hline
\end{tabular}

${ }_{\mathrm{Bal}}$ indicates balance.

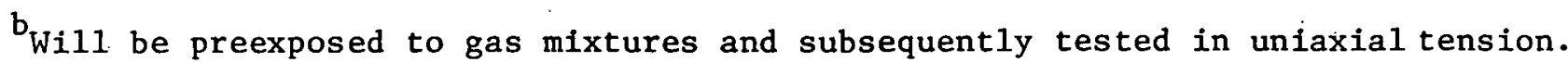


Figures 32-34 show the oxygen-sulfur thermochemical diagrams for Type 304 stainless steel, Incoloy 800 , and Inconel 671 , respectively, at temperatures of 1000,1200 , and $1400 \mathrm{~K}$. Also shown in these figures are the oxygen and sulfur partial pressures calculated from the gas environments listed in Table $\mathrm{V}$ for the different processes. The open symbols in these figures correspond to a total of $1 \mathrm{~atm}$, and the closed symbols correspond to the design pressures for the processes. Note that the effect of total pressure on the gas' composition decreases with an increase in temperature and becomes almost negligible at $1400 \mathrm{~K}$. The effect of an increase in the sulfur concentration of the coal feedstock (Appalachian coal rather than Western coals) is a shift in the process gas composition in the direction of increașing P $_{2}$.

Figures 32-34 show that all three alloys are prone to sulfidation at $1000 \mathrm{~K}$ upon exposure to the process gas environments. An increase in the chromium content of the alloy (from $10 \mathrm{wt} \%$ in Type 304 stainless steel to $48 \mathrm{wt} \%$ in Incone1 671) enlarges the stability region of chromium oxide; however, chromium sulfide formation in the subscale is unavoidable. Another important feature of the diagrams is that as the nickel content of the alloy increases (from $9 \mathrm{wt} \%$.in Type 304 stainless steel to $50 \mathrm{wt} \%$ in Incone 1671 ), the formation of nickel sulfide becomes a distinct possibility. The nickel sulfide, if formed, will be liquid at this temperature and can lead to enhanced corrosion rates for high-nickel alloys. As the temperature increases from 1000 to $1400 \mathrm{~K}$, the gas environment becomes less sulfidizing and the alloys will form an external oxide scale with some sulfides in the subscale. The analysis shows that, even though an increase in chromium content of the alloy is beneficial for application in coal-gasification processes, the nickel content will limit the alloy performance. The results indicate that an Fe$\mathrm{Cr}-\mathrm{Ni}$ alloy with approximately equal amounts of iron, chromium, and nickel will be more corrosion resistant than either high-iron or high-nickel alloys.

\section{Experimental Program}

The oxygen-sulfur thermochemical diagrams are used as a basis in the selection of complex gas environments for the experimental program. Since the complimentary corrosion program 12 at the Illinois Institute of Technology Research Institute involves an evaluation of materials upon exposure at fixed oxygen and carbon potentials, our program will investigate the materials behavior under conditions of different oxygen and carbon potentials at a fixed sulfur activity. The sulfur partial pressures in different experiments will range between $10^{-10}$ and $10^{-6}$ atm. For this purpose, $\mathrm{H}_{2}-\mathrm{H}_{2} \mathrm{~S}$ and $\mathrm{CO}-\mathrm{CO}_{2}-\mathrm{CH}_{4}$ gas mixtures were procured and the desired carbon, oxygen, and sulfur potentials were established by adjusting the relative flow rates of the gas mixtures. The details of the experiments and some of the results from this phase of the program were presented in an earlier report. 1

The second phase of the experimental program involves generation of uniaxial tensile data on four selected alloys upon exposure to the multicomponent gas environments. The composition of these alloys is listed in Table VI. The alloys have chromium and nickel in the range of $19-48$ wt\% and 18-50 wt\%, respectively. The experimental parameters such as gas composition, temperature, and pressure are listed in Table VII. The basic gas mixtures 

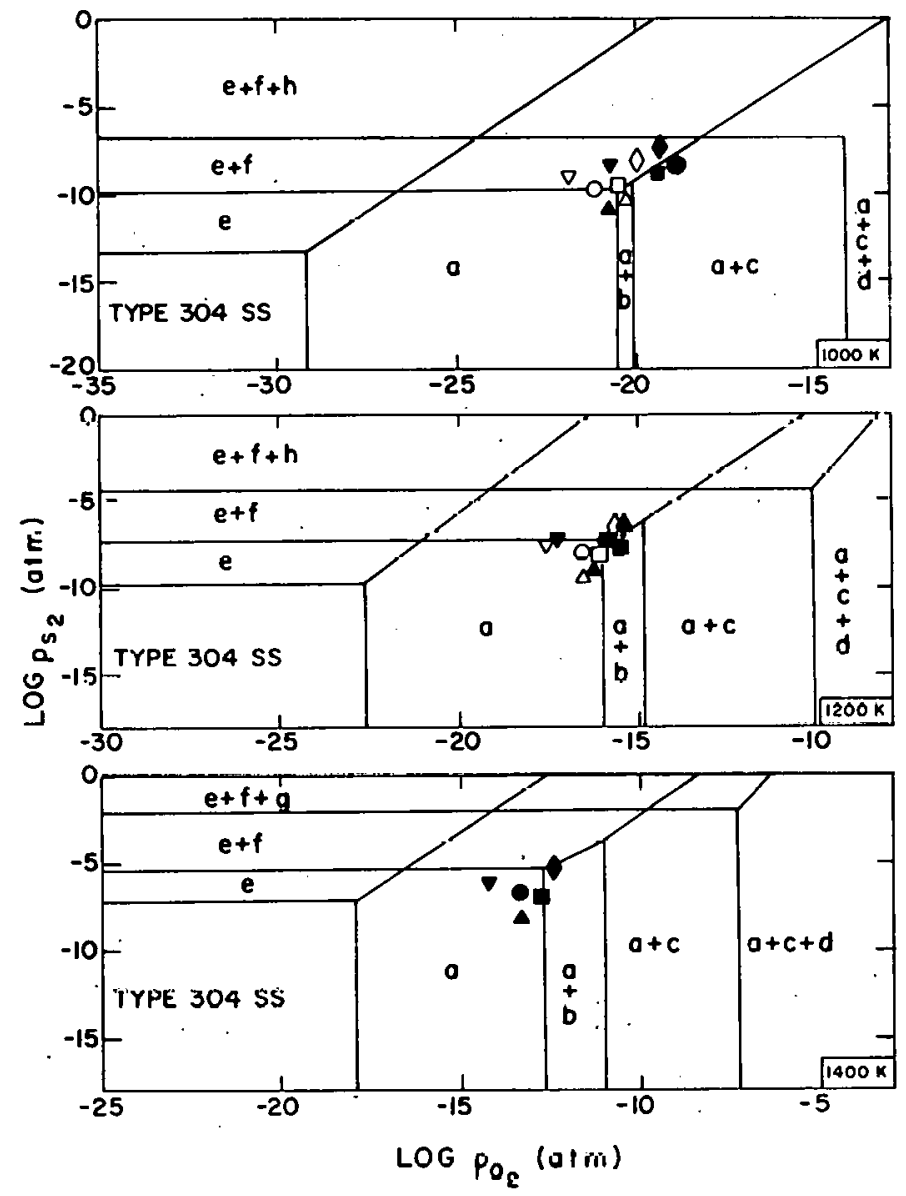
(a) $\mathrm{Cr}_{2} \mathrm{O}_{3}$ (s)
(b) $\mathrm{Fe}_{0.947} \mathrm{O}(\mathrm{s})$
(c) $\mathrm{Fe}_{3} \mathrm{O}_{4}(\mathrm{~s})$
(d) $\mathrm{NiO}$ (s)
(e) $\mathrm{CrS}(\mathrm{s})$
(f) $\mathrm{FeS}(\mathrm{s})$
(g) NiSy (l)
(h) Ni SULFIDE (s)

\begin{tabular}{|c|c|c|}
\hline PROCESS & $1 \mathrm{~atm}$ & \\
\hline HYOAS & 0 & 80 \\
\hline $\mathrm{CO}_{2}$ ACCEPTOR & $\Delta$ & 20 \\
\hline SYNTHANE & 0 & 70 \\
\hline BATTELLE-UC & $\nabla$ & 7 \\
\hline$B i-G A S$ & $\Delta$ & 70 \\
\hline
\end{tabular}

Fig. 32. Oxygen-Sulfur Thermochemical Diagram for Type 304 Stainless Steel at 1000, 1200, and $1400 \mathrm{~K}$. The gas environments calculated for the pilot-plant processes are indicated by different symbols. Neg. No. ANL-306-76183. 


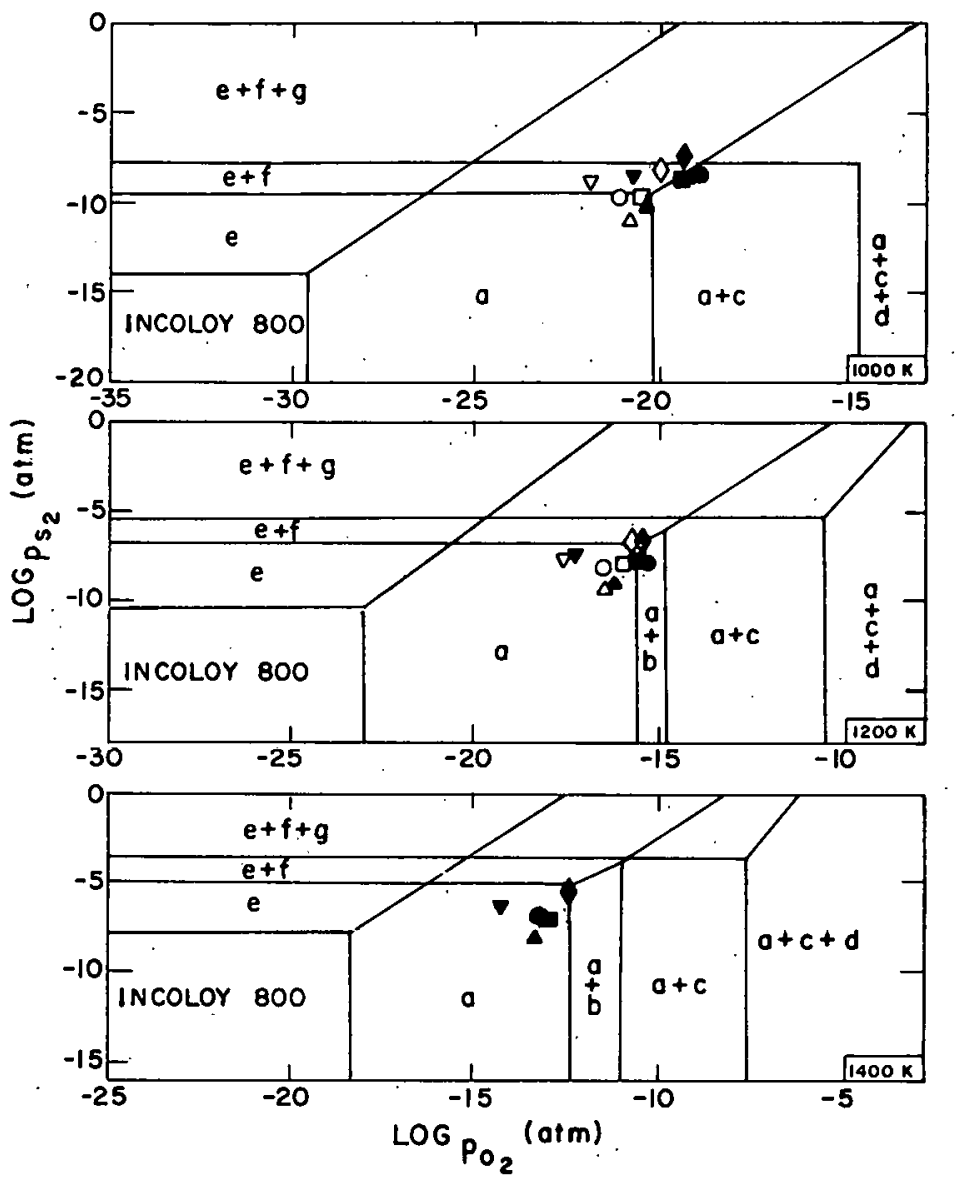
(a) $\mathrm{Cr}_{2} \mathrm{O}_{3}$ (s)
(b) $\mathrm{Fe}_{0.947} \mathrm{O}(\mathrm{s})$
(c) $\mathrm{Fe}_{3} \mathrm{O}_{4}(\mathrm{~s})$
(d) $\mathrm{NiO}$ (s)
(e) $\operatorname{CrS}(s)$
(f) $\mathrm{FeS}$ (s)
(g) NiSy (l)
(h) Ni SULFIDE (s)

\begin{tabular}{|c|c|c|}
\hline PROCESS & 1 atm & \\
\hline HYGAS & 0 & 80 \\
\hline $\mathrm{CO}_{2}$.ACCEPTOR & $\Delta$ & 20 \\
\hline SYNTHANE & 口 & 70 \\
\hline BAT TELLE - UC & $\because \nabla$ & 7 \\
\hline$B i-G A S$ & $\Delta$ & 70 \\
\hline
\end{tabular}

Fig. 33. Oxygen-Sulfur Thermochemical Diagram for Incoloy 800 at 1000,1200 , and $1400 \mathrm{~K}$. The gas environments calculated for the pilot-plant processes are indicated by different symbols. Neg. No. ANL-306-76-182. 


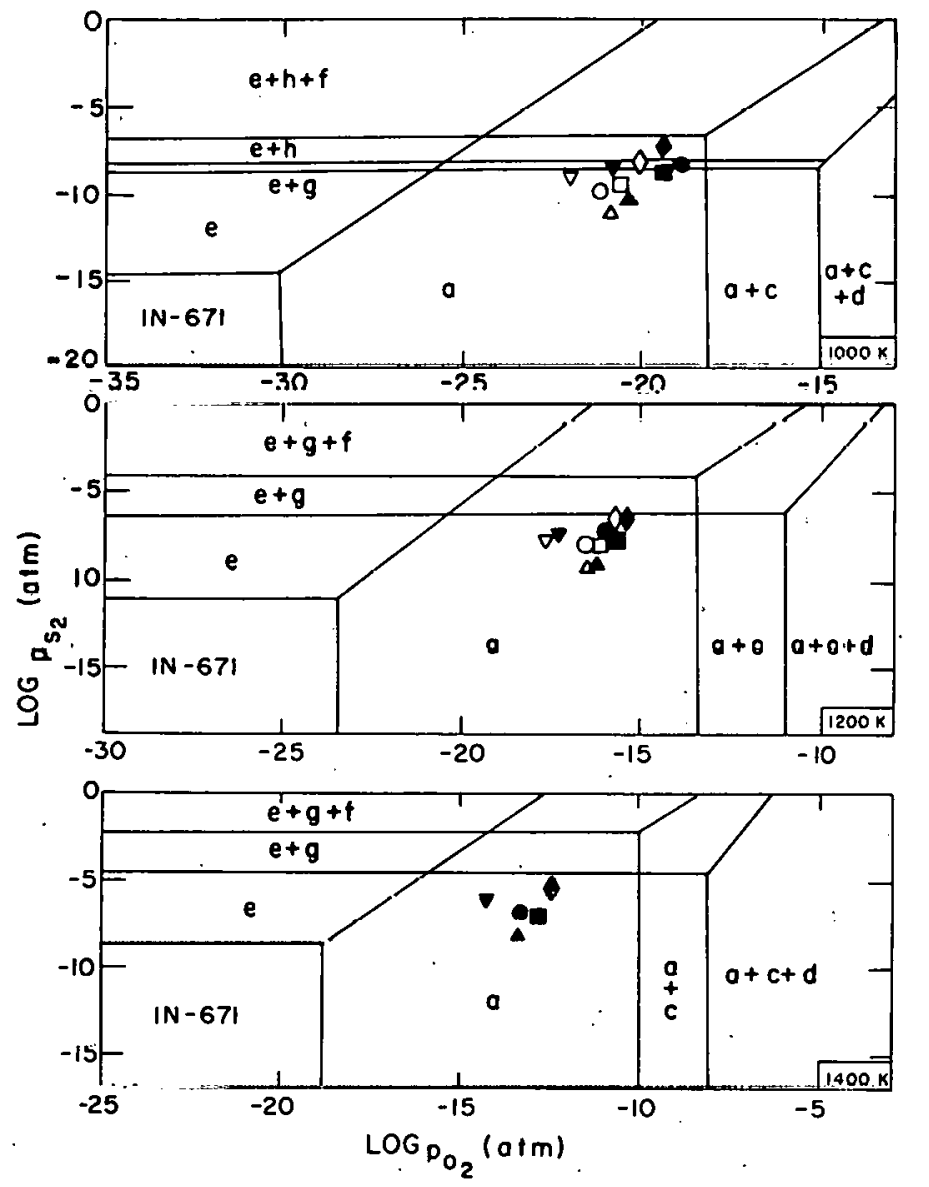
(a) $\mathrm{Cr}_{2} \mathrm{O}_{3}(\mathrm{~s})$
(b) $\mathrm{Fe}_{0.947 \mathrm{O}(\mathrm{s})}$
(c) $\mathrm{Fe}_{3} \mathrm{O}_{4}(\mathrm{~s})$
(d) $\mathrm{NiO}$ (s)
(e) $\operatorname{crs}(s)$
(f) $\mathrm{FeS}(\mathrm{s})$
(g) NiSy (l)
(h) NI SULFIDE (s)

$\begin{array}{lcr}\quad \text { PROCESS } & 1 \mathrm{alm} & (P) .0 \mathrm{~lm} \\ \text { HYGAS } & 0 & 80 \\ \mathrm{CO}_{2} \text {.ACCEPTOR } & \Delta & 20 . \\ \text { SYNTHANE } & 0 & 70 . \\ \text { BATTELLE-UC } & \nabla & 7 \\ \text { Bi-GAS } & 0 & 70\end{array}$

Fig. 34: Oxygen-Sulfur Thermochemical Diagram for Inconel 671 at 1000,1200 , and $1400 \mathrm{~K}$. The gas environments calculated for the pilot-plant processes are indicated by different symbols. Neg. No. ANL-306-76-184. 
TABLE VII. Experimental Parameters Proposed for Preexposure of Mechanical Test Specimens.

A. Gas Environment

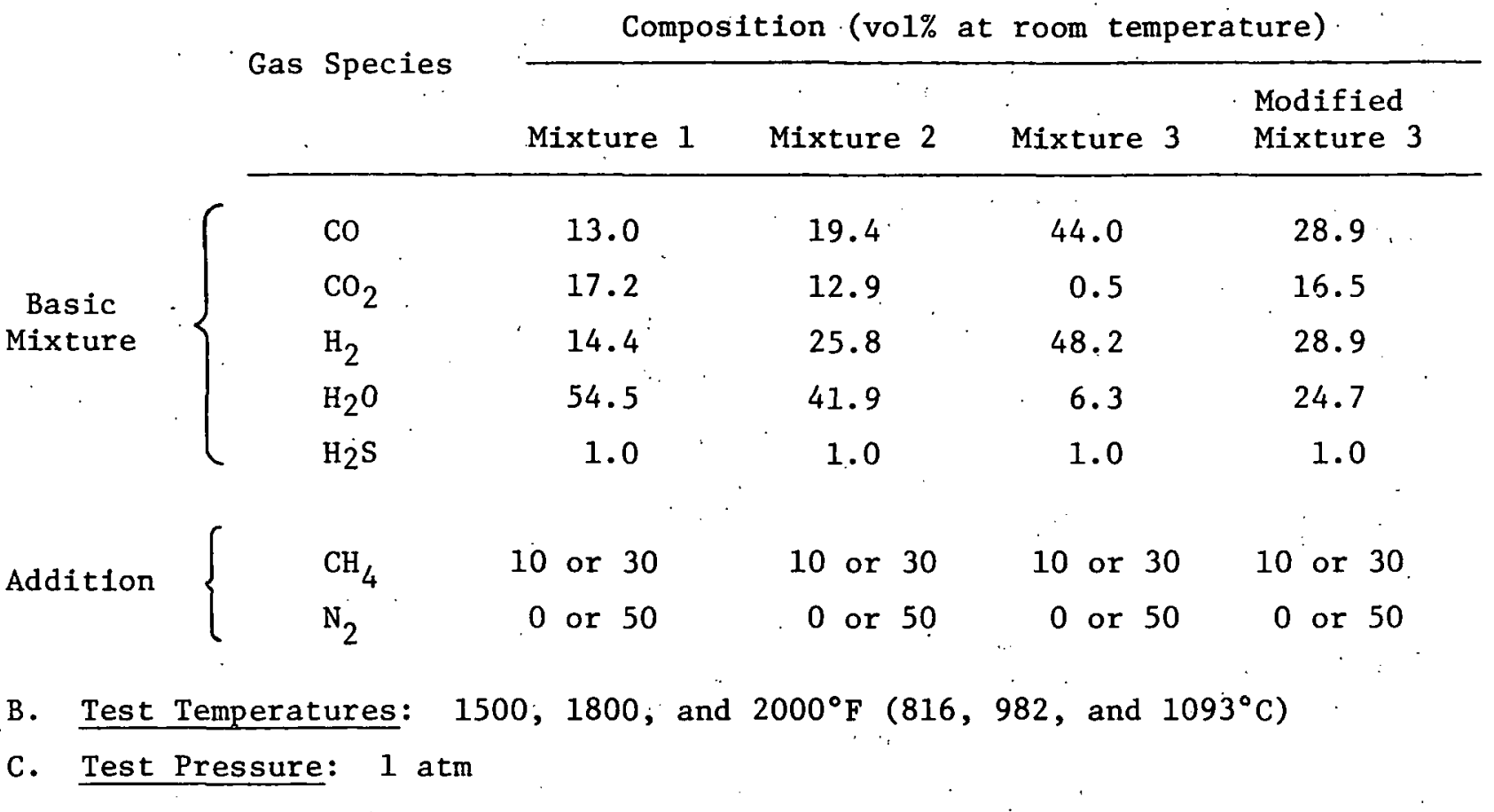

include $\mathrm{CO}, \mathrm{CO}_{2}, \mathrm{H}_{2}, \mathrm{H}_{2} \mathrm{O}$, and $\mathrm{H}_{2} \mathrm{~S}$. The additions to the basic mixtures are $\mathrm{CH}_{4}$ and $\mathrm{N}_{2}$. The test temperatures are 1500,1800 , and $2000^{\circ} \mathrm{F}(816,982$, and $\left.1093^{\circ} \mathrm{C}\right)$. The tests at Argonne National Laboratory will be conducted at $1 \mathrm{~atm}$, and the Battelle program will involve pressures of 34,68 , and $102 \mathrm{~atm}$.

Table VIII lists the oxygen, sulfur, and carbon potentials calculated using the computer program under different proposed experimental conditions. The results show that the effect of increasing the methane content of the gas mixture is to decrease the oxygen and sulfur potentials and increase the carbon activity. The effect of increasing the total pressure of the system is to increase the carbon, oxygen, and sulfur potentials. The increase in carbon activity is much more pronounced when going from 1 to $34 \mathrm{~atm}$ than at higher pressures. It appears, that proposed gas mixture 3 is not best suited for the experimental program because this mixture yields oxygen and sulfur potentials essentially the same as the others but the carbon potential is extremely large and can lead to a significant carbon deposit. As a result, an alternate gas mixture has been selected, which is also listed in Table VII. The oxygen, carbon, and sulfur potentials that will be established by this gas mixture are being calculated as a function of temperature and pressure.

The thermodynamic stability of different phases that will form in materials upon exposure to the gas mixtures 1isted in Table VII was also evaluated using the computer program. The results are presented in Figs. 35 and 36 as $\log \mathrm{P}_{2}$ versus $\log \mathrm{P}_{\mathrm{S}_{2}}$ thermochemical diagrams for $U$. S. Steel 18-18-2 alloy and Inconel 671 at 1089 and $1366 \mathrm{~K}$, respective1y. These two 
TABLE VIII. Calculated Oxygen, SulEur, and Carbon Potentials for Gas Mixtures 1 and 2 in Table VII

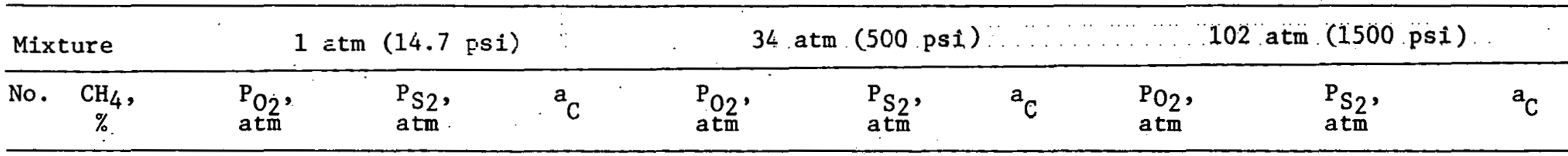

$1500^{\circ} \mathrm{F}\left(816^{\circ} \mathrm{C}\right)$

$\begin{array}{lcccccccccc}1 & 10 & 7.99 \times 10^{-19} & 1.21 \times 10^{-7} & 0.021 & 1.82 \times 10^{-18} & 2.32 \times 10^{-7} & 0.357 & 4.75 \times 10^{-18} & 5.24 \times 10^{-7} & 0.463 \\ & 30 & 2.51 \times 10^{-20} & 1.70 \times 10^{-8} & 0.199 & 4.41 \times 19-19 & 7.88 \times 10^{-8} & 0.922 & 1.59 \times 10^{-18} & 2.08 \times 10^{-7} & 0.959 \\ 2 & 10 & 2.67 \times 10^{-19} & 3.17 \times 10^{-8} & 0.047 & 1.05 \times 10^{-18} & 2.18 \times 10^{-7} & 0.544 & 3.14 \times 10^{-18} & 5.38 \times 10^{-7} & 0.651 \\ & 30 & - & - & - & 3.47 \times 10^{-19} & 8.30 \times 10^{-3} & 1.0 & 1.31 \times 10^{-18} & 2.18 \times 10^{-7} & 1.0\end{array}$

$1800^{\circ} \mathrm{F} \cdot\left(982^{\circ} \mathrm{C}\right)$

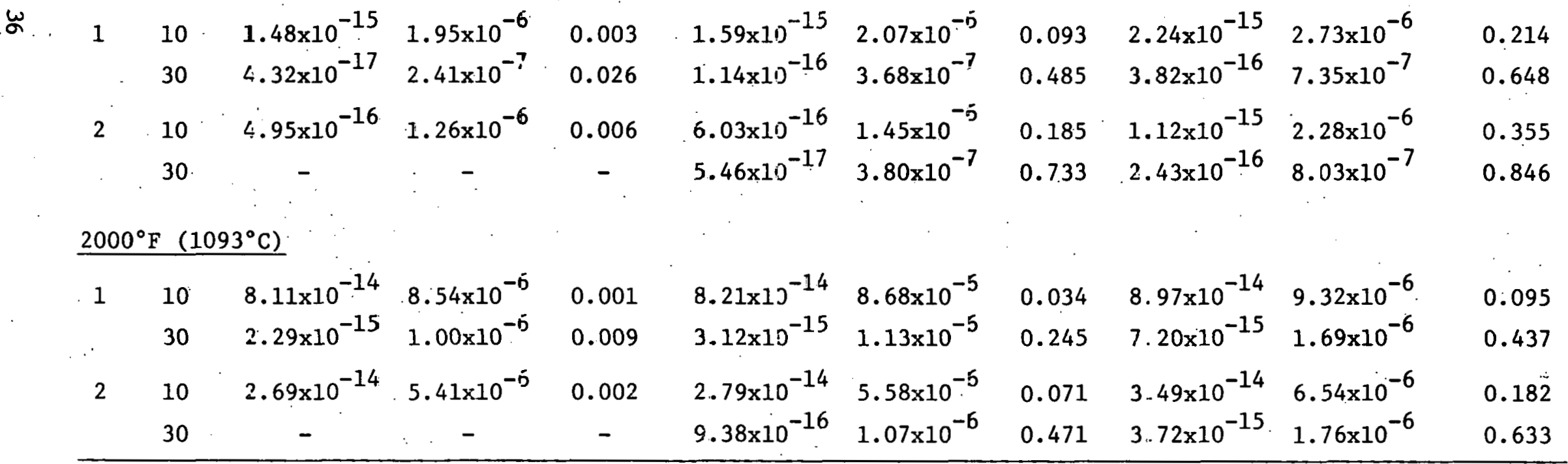

${ }^{a}{ }_{C}=$ carbon activity based upon graphite standard state. 

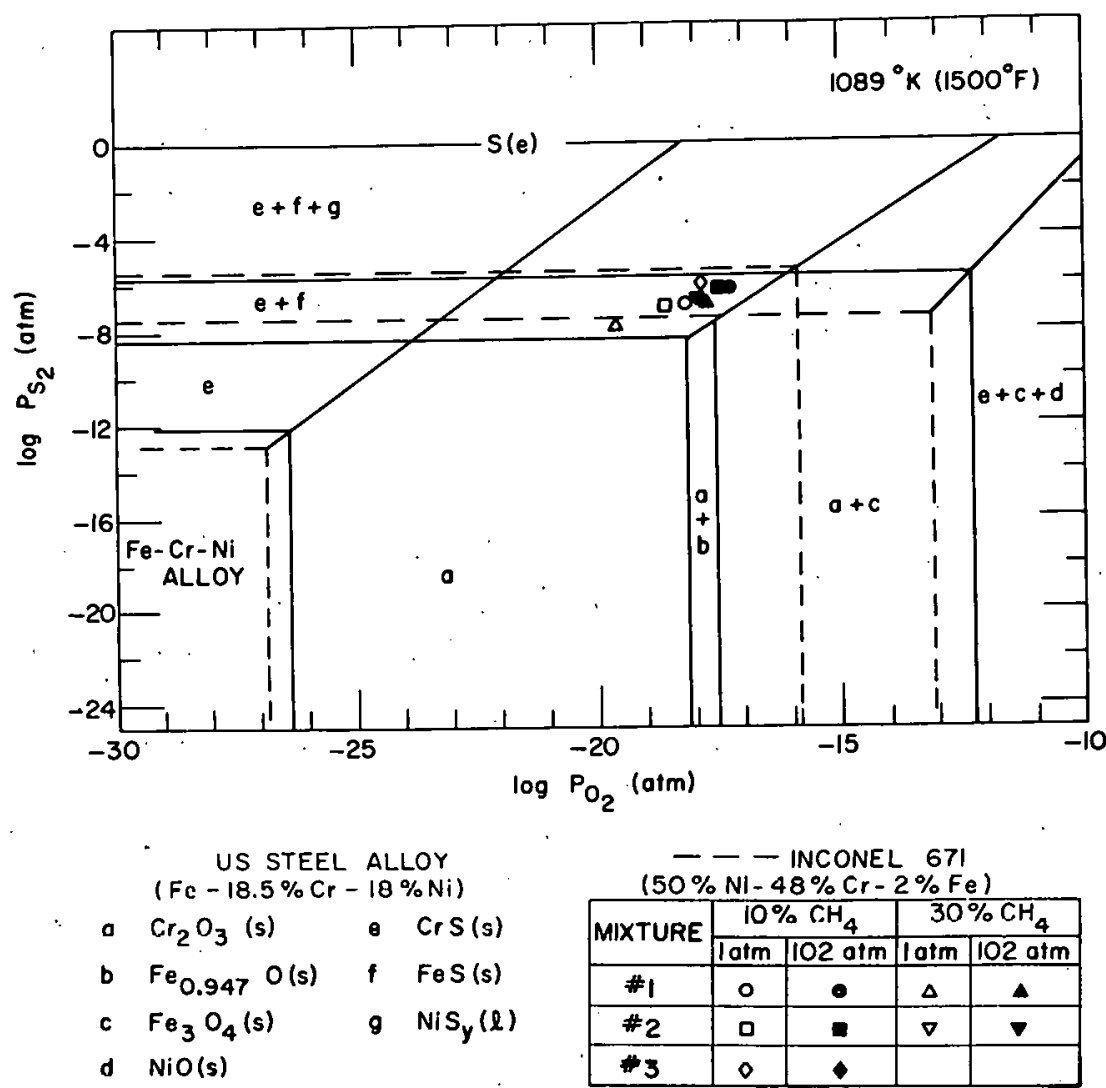

- - INCONEL 67I $(50 \% \mathrm{NI}-48 \% \mathrm{Cr}-2 \% \mathrm{Fe})$

\begin{tabular}{|c|c|c|c|c|}
\hline \multirow{2}{*}{ MIXTURE } & \multicolumn{2}{|c|}{$10 \% \mathrm{CH}_{4}$} & \multicolumn{2}{|c|}{$30 \% \mathrm{CH}_{4}$} \\
\cline { 2 - 5 } & latm & 102 alm & lotm & $102 \mathrm{otm}$ \\
\hline \# & 0 & $\bullet$ & $\Delta$ & $\Delta$ \\
\hline 2 & 0 & & $\nabla$ & $\nabla$ \\
\hline 3 & 0 & $\bullet$ & & \\
\hline
\end{tabular}

Fig. 35. Thermodynamic Stability of Different Phases in U. S. Steel Alloy (Fe-18.5 wt\% Cr$18 \mathrm{wt} \% \mathrm{Ni}$ ) and Incone1 671 (50 wt\% Ni-48 wt\% $\mathrm{Cr}-2 \mathrm{wt} \% \mathrm{Fe})$ at $1089 \mathrm{~K}$ $\left(1500^{\circ} \mathrm{F}\right)$. The gas environments proposed in the experimental program are indicated by open $\left(10 \% \mathrm{CH}_{4}\right)$ and closed $\left(30 \% \mathrm{CH}_{4}\right)$ symbols. Neg. No. MSD63757.

Fig. 36. Thermodynamic Stability of Different Phases in U. S. Steel Alloy (Fe-18.5 wt\% $\mathrm{Cr}-$ $18 \mathrm{wt} \% \mathrm{Ni}$ ) and Inconel671 (50 wt\% Ni-48 wt\% $\mathrm{Cr}-2 \mathrm{wt} \% \mathrm{Fe})$ at $1366 \mathrm{~K}$ $\left(2000^{\circ} \mathrm{F}\right)$. The gas environments proposed in the experimental program are indicated by open $\left(10 \% \mathrm{CH}_{4}\right)$ and closed $\left(30 \% \mathrm{CH}_{4}\right)$ symbols. Neg. No. MSD63758 .

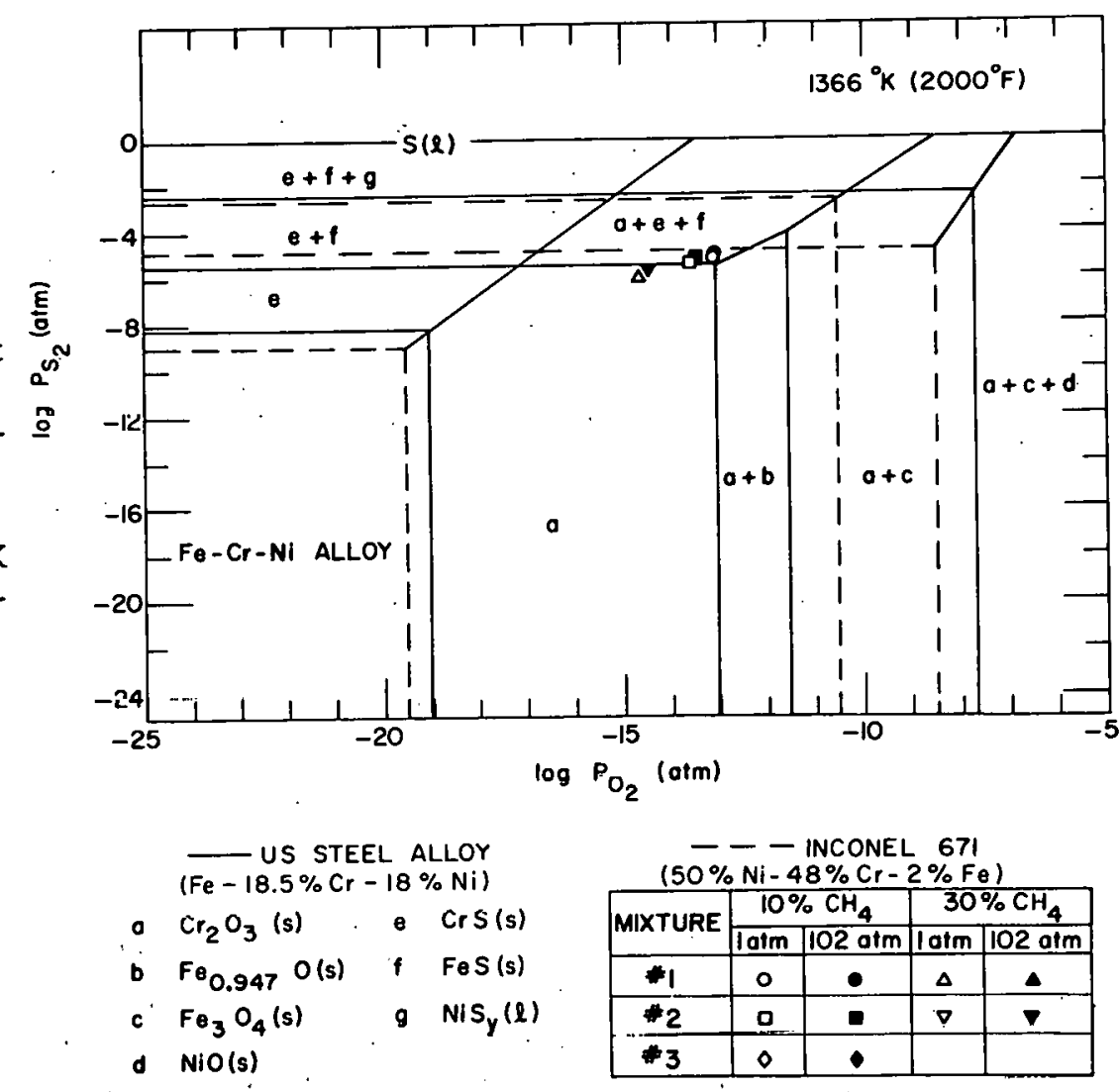


a1loys were chosen for evaluation of the effect of chromium content. The expected phases in these two alloys under the different experimental conditions proposed are listed in Table IX. The calculations show that the selected gas mixtures will result in a predominantly chromium-rich oxide scale with chromium sulfide and in some instances iron sulfide in the subscale. Furthermore, formation of liquid nickel sulfide is a distinct possiblity in Incone 1671 , expecially at low temperatures. The results also indicate that the system pressure has little effect on the type of phases formed but can have an influence on the amount of different phases and the locations (external scale or internal subscale) at which these phases are formed.

The construction of a corrosion test rig that will be used for exposure of mechanical test specimens is completed. A schematic of the rig and details of the apparatus were reported earlfer. 13 Preliminary corrosion experiments were conducted in this apparatus by expusure of the four selected alloys for $25 \mathrm{~h}$ in an environment that included $\mathrm{CO}, \mathrm{CO}_{2}, \mathrm{CH}_{4}, \mathrm{H}_{2}, \mathrm{H}_{2} \mathrm{O}$, and $\mathrm{H}_{2} \mathrm{~S}$ at $816^{\circ} \mathrm{C}$. The composition of the gas mixture and the oxygen, sulfur, and carbon. potentials established in the experiment are listed in Table $X$.

Using optical metallography, the samples were examined after exposure to the gas environment, and the phases present were identifled using a scanning-electron microscope equipped with an energy-dispersive x-ray analyzer. Figures 37-40 show the optical micrographs of the cross sections of specimens of U. S. Steel 18-18-2 alloy, Type 310 stainless stee1, Incoloy 800, and Inconel 671, respectively. The scale regions in all four alloys were identified as chromium-rich oxide phase. The alloys also showed pronounced internal oxidation and some internal sulfidation. In advance of these fronts, carburization was observed.

Figures $41-43^{\prime}$ are $x$-ray photographs that show the specimen image, metallic element (chromium, nickel, and iron) diatribution, and sulfur distribution in the scale/alioy interface regions of the samples Incolny 800 , Type 310 stainless steel, aud linconel 671 , 10upoctively. The photopraphs clearly indicate the absence of sulfur in the scale region, which confirms the presence of a chromium-rich oxide phase in these layers. The results in Figs. 41-43 also show that the dark particles in the interior of the alloy specimens are sulfides of chromium, which indicates the occurrence of internal sulfidation in these alloys upon exposure to the gas environment. Additinnal experiments are being conducted to establish the stability of the oxide layers in these alloys as a function of gas composition and temperature, subsequent to which mechanical test specimens of these materials will be exposed to the selected environments.

Task E -- Erosion Behavior of Materials in Coal-conversion Processes

During this quarter a critical review of the available analytical models for erosion behavior was conducted. It is helpful to divide the available models into two classes: (1) those that are interpretative, 1.e., models which can be used to extrapolate limited experimental data but contain parameters that can be determined only by actual erosion tests, and (2) those that are predictive, i.e., models which predict erosion rates on the basis of mechanical properties determined in simpler tests (e.g., uniaxial tension 
TABLE IX. Phases Expected under Different Experimental Conditions Proposed

Gas Mixture

Number $\underset{\%}{\mathrm{CF}_{4}^{-},}$

U. S. Steel A1loy

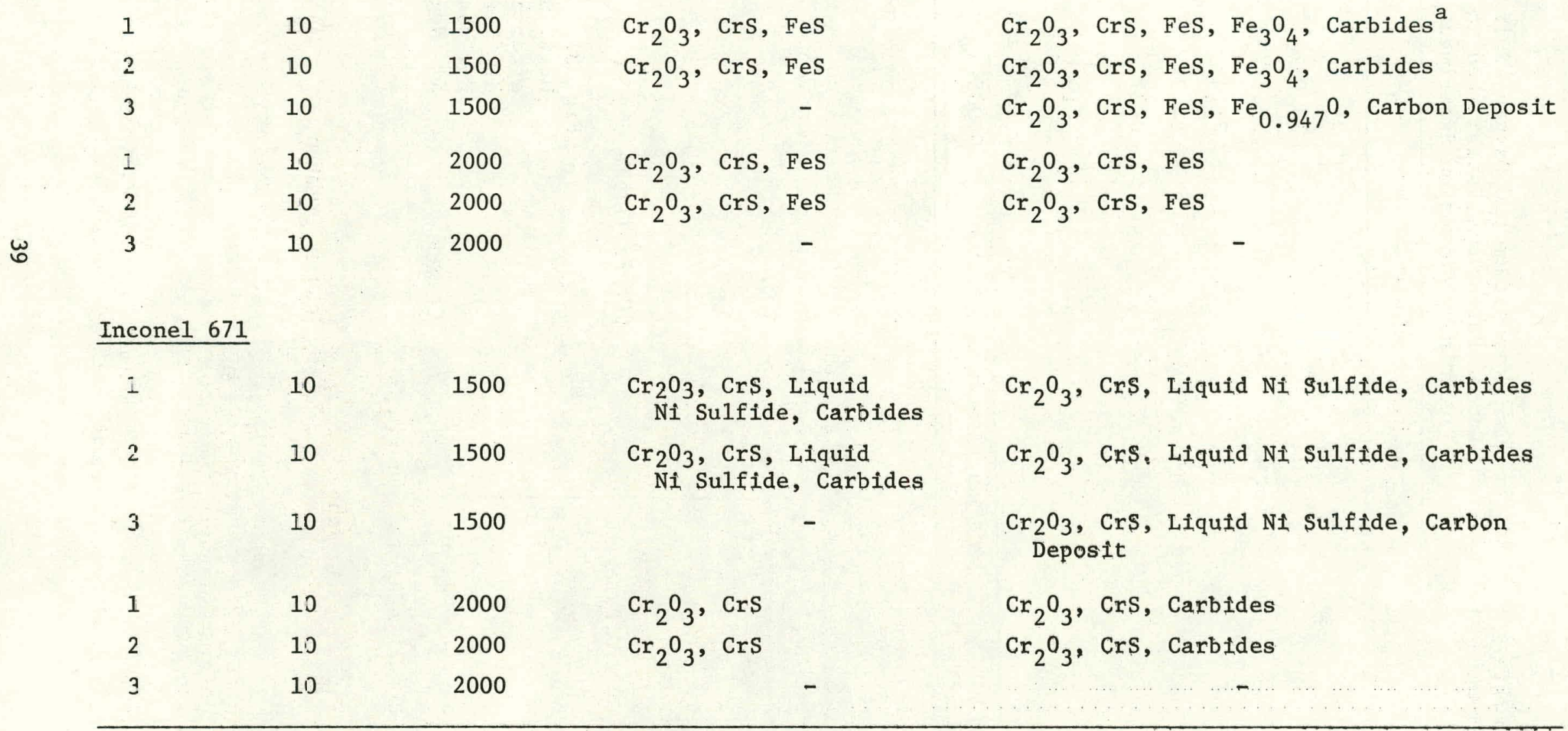

a Type of carbides depends on the kinetics of the carbide reactions.
Expected Phases

1 atm 102 atm


TABLE X. Gas Composition and Oxygen, Sulfur, and Carbon Potentials Established in the Preliminary Corrosion Experiment

\begin{tabular}{lc}
\hline Gas Species & Vo1\% \\
\hline $\mathrm{CO}$ & 34.1 \\
$\mathrm{CO}_{2}$ & 14.9 \\
$\mathrm{CH}_{4}$ & 5.3 \\
$\mathrm{H}_{2}$ & 21.3 \\
$\mathrm{H}_{2} \mathrm{O}$ & 24.0 \\
$\mathrm{H}_{2} \mathrm{~S}$ & 0.37 \\
$\mathrm{P}_{\mathrm{O}_{2}}=$ & $2 \times 10^{-19} \mathrm{~atm}$ \\
$\mathrm{P}_{\mathrm{S}_{2}}=$ & $2.5 \times 10^{-8} \mathrm{~atm}$ \\
$\mathrm{a}_{\mathrm{C}}=$ & 0.085 \\
\hline
\end{tabular}

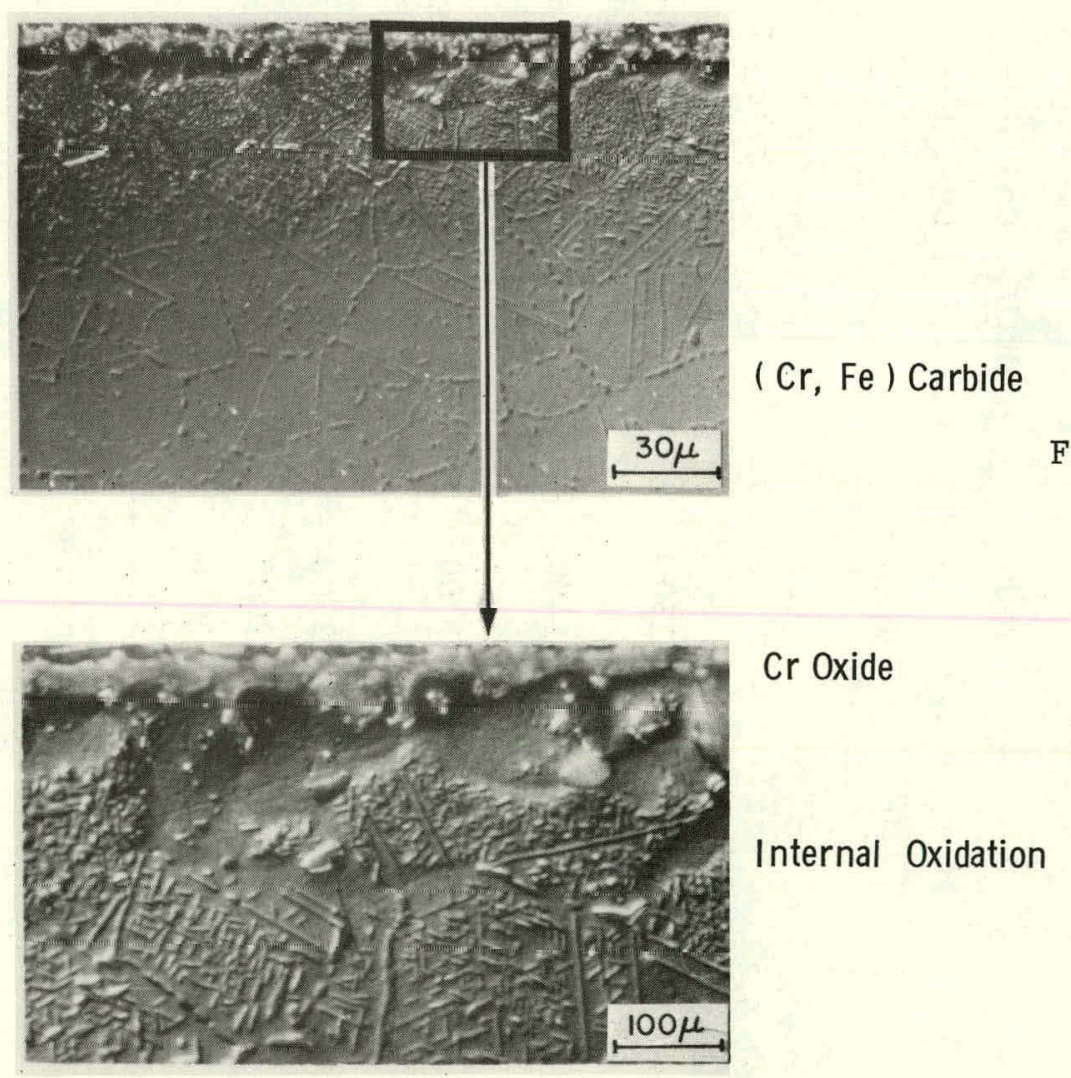

Fig. 37. Optical Micrograph of U. S. Stee1 18-18-2 Alloy after a 25-h Fxposure at $816^{\circ} \mathrm{C}\left(1500^{\circ} \mathrm{F}\right)$ to the Gas Environment Listed in Table X. Neg. No. MSD-63761. 


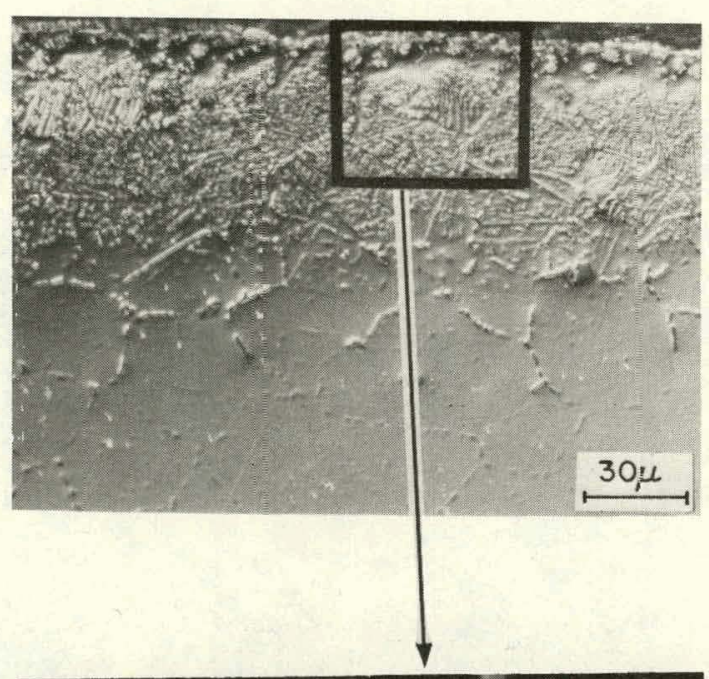

( $\mathrm{Cr}, \mathrm{Fe}$ ) Carbide

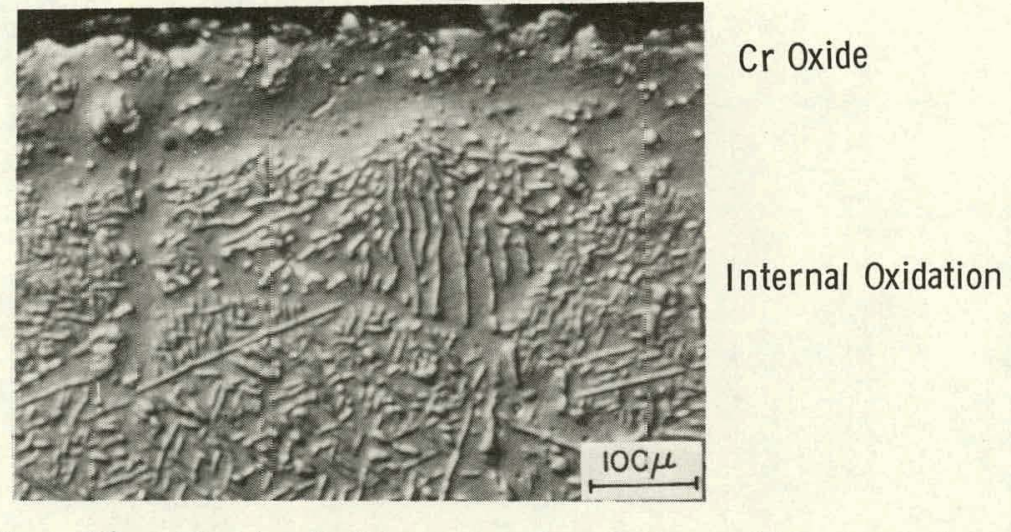

Fig. 38. Optical Micrograph of Type 310 Stainless Steel after a $25-\mathrm{h}$ Exposure a $=816^{\circ} \mathrm{C}\left(1500^{\circ} \mathrm{F}\right)$ to the Gas Environment Listed in Table X. Neg. No. MSD-637б3.

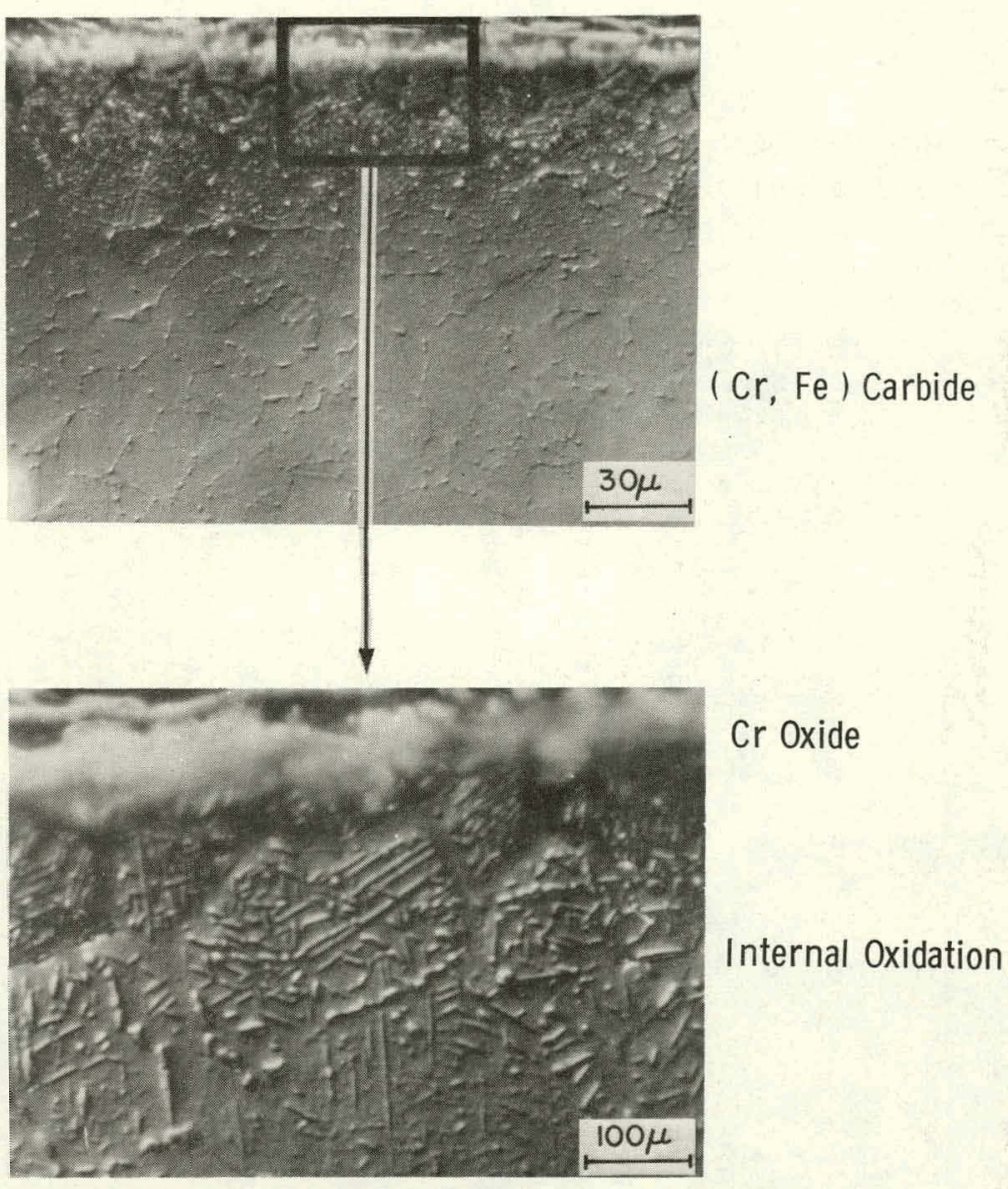

Fig. 39. Optical Micrograph of Incoloy 800 after a $25-\mathrm{h}$ Exposure at $816^{\circ} \mathrm{C}\left(1500^{\circ} \mathrm{F}\right)$ to the Gas Environment Listed in Table X. Neg. No. MSDMSD-63762. 


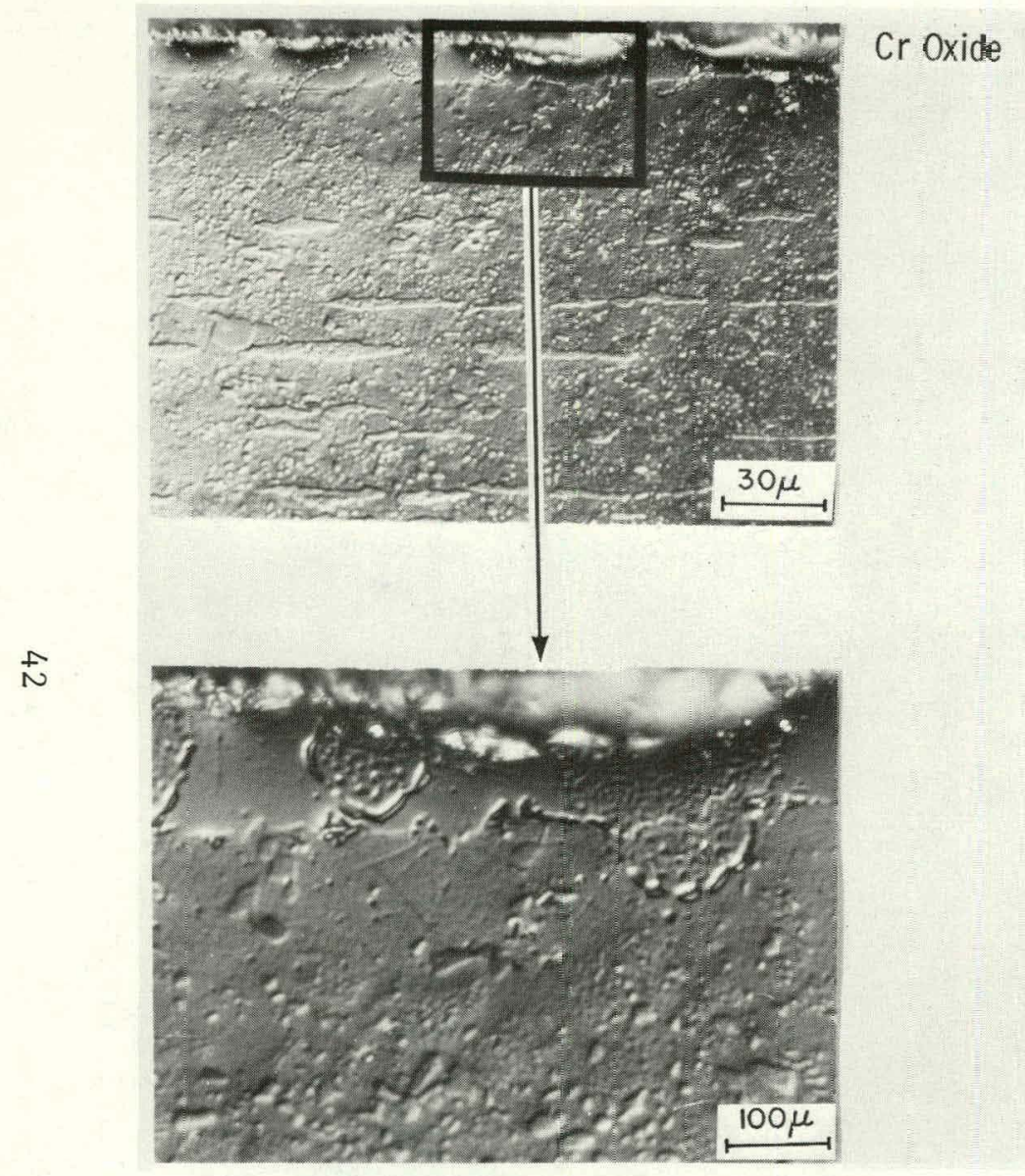

Fig. 40. Optical Mizrograph of Inconel 671 after a 25 -h Exposure at $816^{\circ} \mathrm{C}\left(1500^{\circ} \mathrm{F}\right)$ to the Gas Environment Listed in Table $\mathrm{X}$. Neg. No. MSD-63765.
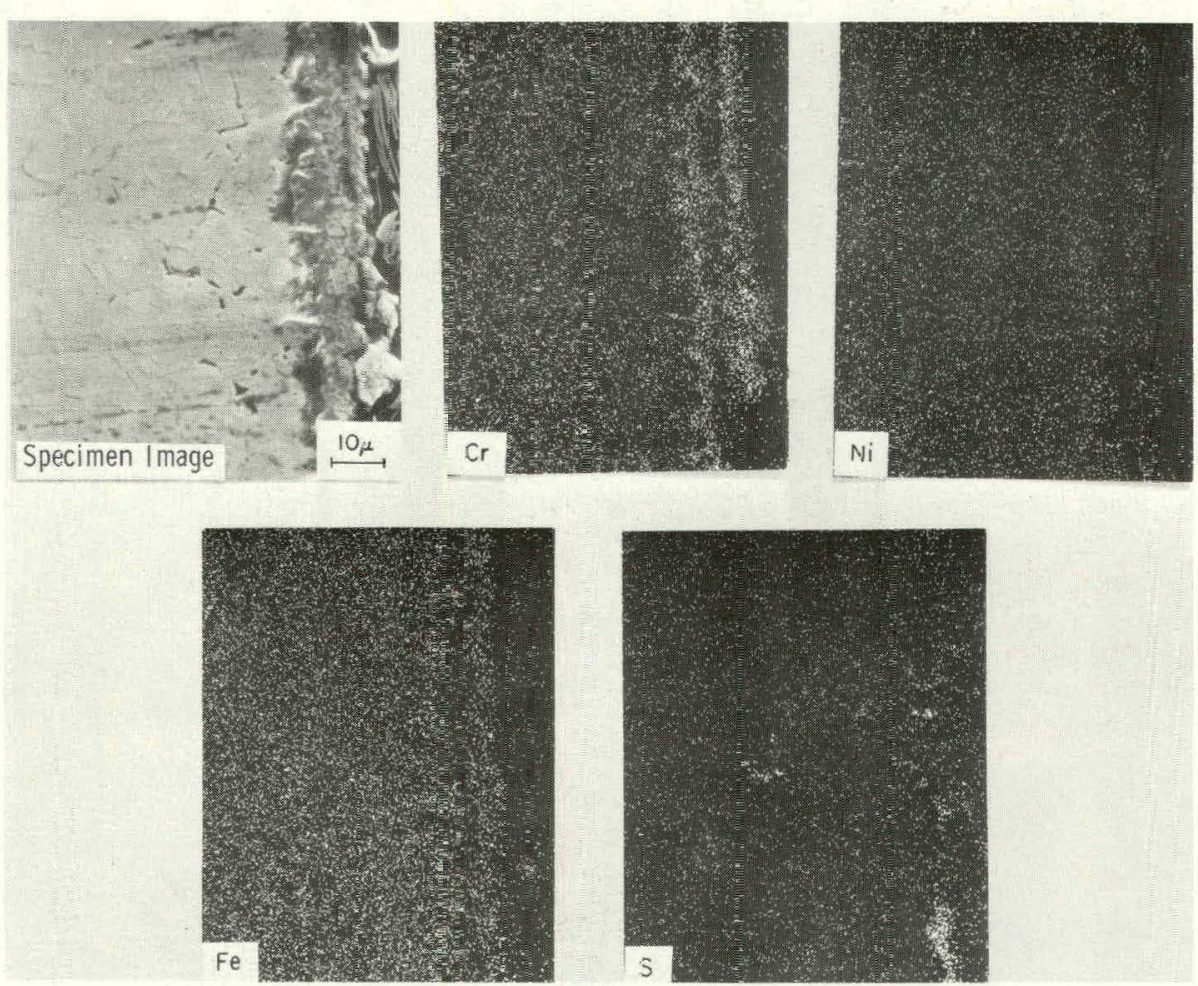

Fig. 41. X-ray Photograph and $\mathrm{Cr}, \mathrm{Ni}, \mathrm{Fe}$, and S Distribution in Incoloy 800 Specinen Shown in Fig. 39. In the distribution pictures, the light region indicates a high concentration of the respective elements. Neg. No. MSD-63760. 


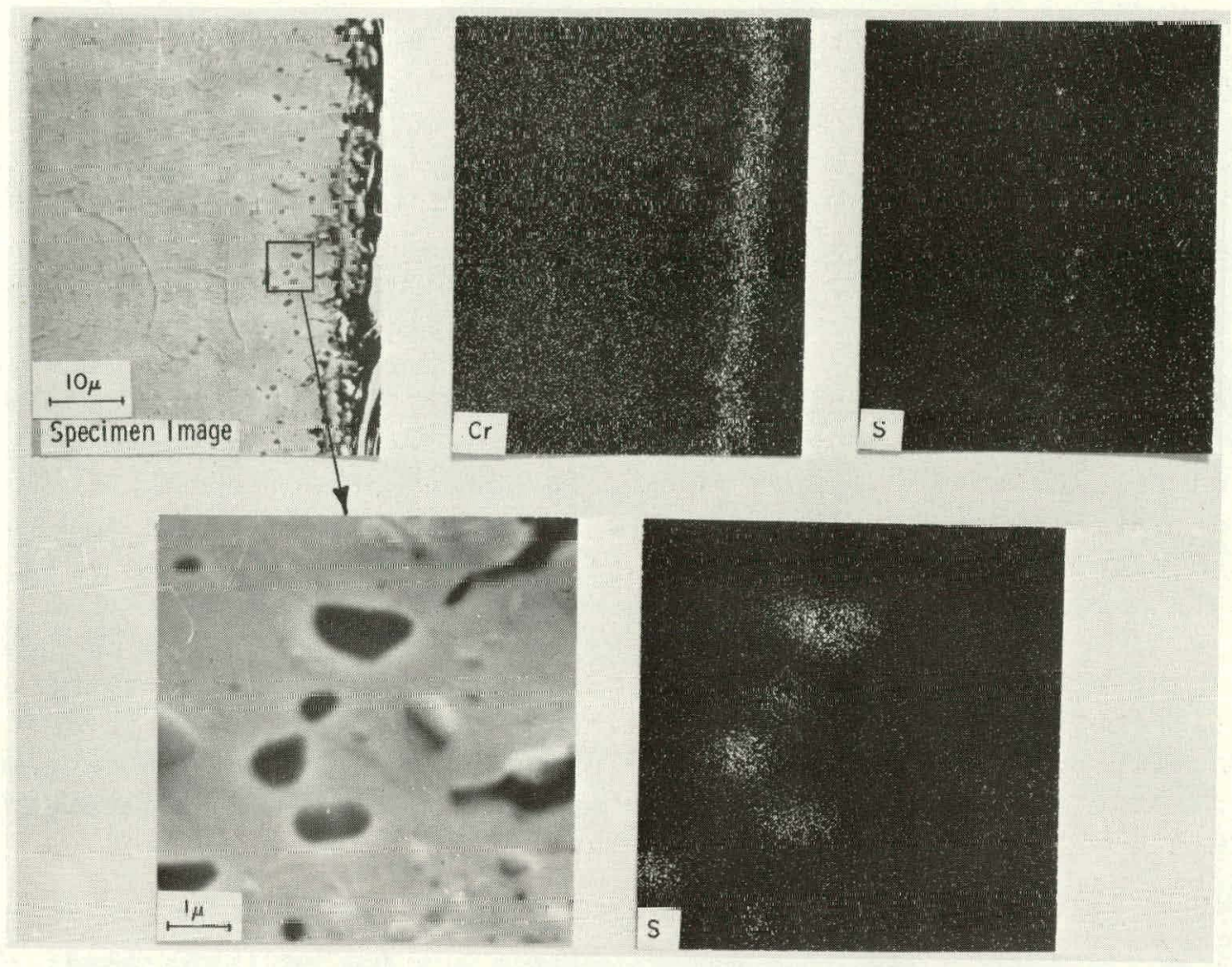

Fig. 12. X-ray Photograph and $\mathrm{Cr}$ and $\mathrm{S}$ Distribution in Type 310 Stainless Steel specimen Shown in Fig. 38. In the distribution pictures, the light region indicates a high concentration of the respective elements. Neg. No. MSD-63764.
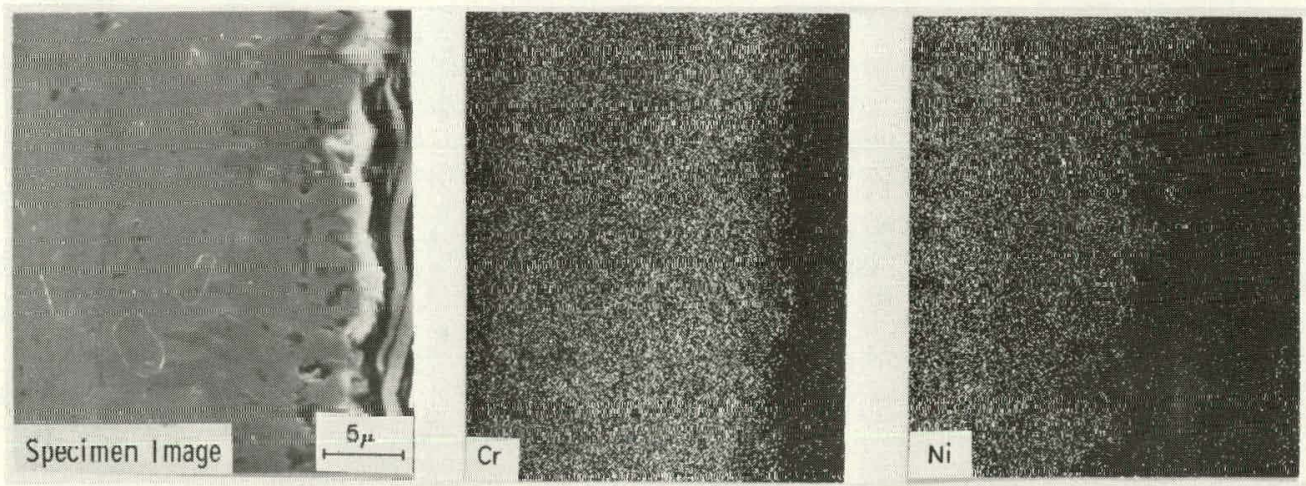

Fig. 43. X-ray Photograph and $\mathrm{Cr}$ and $\mathrm{Ni}$ Distribution in Inconel 671 Specimen Shown in Fig. 40. In the distribution pictures, the light region indicates a high concentration of the respective elements. Neg. No. MSD-63759. 
tests). Among the predictive models are those of Finnie, 14 Mamoun, 15, 16 and Jennings et a1.17 Among the interpretative models are those of Bitter 18,19 and Neilson and Gilchrist.20 Although interpretative models are useful, erosion tests are expensive and time consuming, and predictive models that can at least give rough estimates of erosion behavior are highly desirable.

The model developed by Finnie, 14 which assumes that erosive wear is due to mechanical cutting by the impacting particles, predicts no erosion at a11 for $90^{\circ}$ impact angles. To remedy this deficiency, Mamoun ${ }^{15}$ developed a model which assumes that wear at high angles of impact is due to plastic fatigue and failure of a surface layer. Before reviewing the basic assumptions and results of the latter model, it should be noted that the mechanism of failure at high angles of impact is still not well understood, even in a qualitative manner. In Ref. 14, Finnie briefly summarizes the proposed mechanisms and reviews the (1imited) evidence available.

Three basic relations are required for an estimate of the erosion rate: (1) the volume of materlal which undergues lasge plastic deformations as a function of, for example, particle mass and velocity, (2) the magnitude of the plastic strains involved as a function of the impact parameters, and (3) a relation between the number of impacts to failure and the magnitude of the plastic strain/impact.

To find the volume of material that undergoes large plastic deformations, Mamoun 15,16 uses the analysis of Andrews. 21 The geometry of impact is shown schematically in Fig. 44, where L is the depth of penetration of the particle into the surface and $a$ is the radius of the projected area of contact between the particle and the surface. Andrews 21 shows that

$$
\mathrm{L}^{2} \simeq \frac{1 / 2 \mathrm{mV}^{2}}{6 \pi \mathrm{RY}}
$$

wliere $\mathrm{m}, \mathrm{R}$, and $\mathrm{V}$ arc the mass, radius, and velocity, respertively, of the impacting particle and $Y$ is the yield stress of the surface. The derivation of the pressure between the particle and surface is $\simeq 3 Y$ and is uniform over the area of contact. More sophisticated analyses and experiments show that the assumptions are quite reasonable. The work done is equal to the intlal kinetic energy of the particle

$$
F L=\left(\pi a^{2}\right)(3 Y) L=1 / 2 \mathrm{mv}^{2},
$$

where $\mathrm{F}$ is the total contact force.

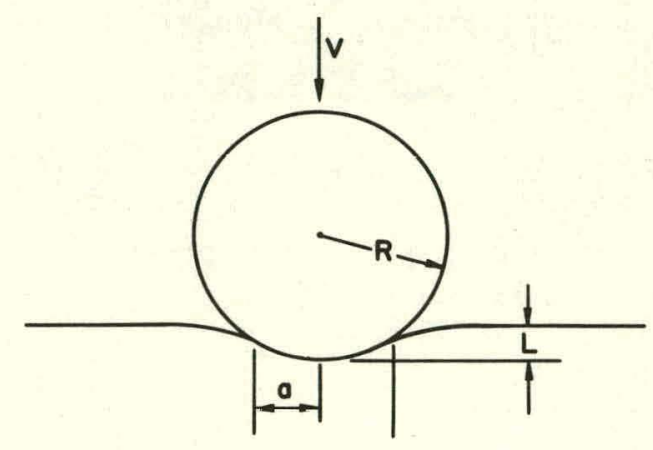

Fig. 44. Geometry of Impact. Neg. No. MSD63816. 
From the geometry of Fig. 44 it is clear that

$$
\mathrm{a}^{2}=2 \mathrm{RL}-\mathrm{L}^{2} \simeq 2 \mathrm{RL},
$$

since L $\ll$ R. Combining Eqs. 2 and 3 yields Eq. 1. Mamoun estimates the volume $V_{p}$ of the region that undergoes severe plastic deformation as

$$
\mathrm{V}_{\mathrm{p}} \simeq \pi \mathrm{a}^{2} \mathrm{~L} \simeq 2 \pi R L^{2}
$$

The plastic strain in this region can be expressed by the empirical

formula

$$
\varepsilon_{\mathrm{p}} \simeq 0.2\left(\frac{\mathrm{a}}{\mathrm{R}}\right)
$$

or

$$
\varepsilon_{\mathrm{p}} \simeq 0.4\left(\frac{\mathrm{L}}{2 \mathrm{R}}\right)^{1 / 2}
$$

using Eq. 3. Equation 5, from Tabor, ${ }^{22}$ is based on experimental measurements of the plastic strain distributions under a hard indentor.

On the basis of considerable experimental data for a wide variety of structural alloys, Manson and Hirschberg ${ }^{23}$ have proposed that for low-cycle fatigue the fatigue life $\mathrm{N}_{f}$ can be related to the plastic strain range $\Delta \varepsilon_{p}$ by the equation

$$
\mathrm{N}_{\mathrm{f}}=\left(\frac{\Delta \varepsilon \mathrm{p}}{\mathrm{I}}\right)^{1 / \mathrm{k}},
$$

where $\mathrm{k}$ and $\mathrm{I}$ are material constants. For most structural materials $\mathrm{k} \simeq-0.5$.

In the erosion case, $\mathrm{N}_{\mathrm{f}}$ can be interpreted as the number of collisions required to impact the same site and cause the plastically deformed volume of material surrounding that site to fail. Thus, using Eq. 4 we find that the volume loss $Q$ for a single impact is

$$
Q=\frac{V_{p}}{N_{f}}=\frac{2 \pi R L^{2}}{N_{f}}
$$

Eliminating $\mathrm{N}_{\mathrm{f}}$ and using Eqs. 6 and 7 yie1ds

$$
Q \sim I^{1 / k}{ }_{R}^{(2 k+1) / 2 k} L^{(4 k-I) / 2 k} \text {, }
$$

where the proporlionality constant depends only on k. Substituting Eq. 1 into Eq. 9 finally gives the desired relation between the erosion rate $Q$ and the dynamics of the impacting particle:

$$
Q \sim I^{1 / k} R^{3 / 4 k}\left(\frac{1 / 2 \mathrm{mV}^{2}}{\mathrm{Y}}\right)^{(4 \mathrm{k}-1) / 4 k}
$$


where again the constant of proportionality depends only on $k$. Erosion data are usually reported in dimensionless terms as the ratio $\mathrm{W}^{*}$ of the mass of material removed to the mass of the impacting particles. From Eq. 10

$$
W^{*}=\frac{\rho Q}{m}=\alpha(k) \rho I^{1 / k} \rho_{p}^{-1 / 4 K}\left(\frac{1}{Y}\right)^{\frac{4 k-1}{4 k}} v^{\frac{4 k-1}{4 k}} \text {, }
$$

where $\rho$ is the density of the material, $\rho_{p}$ is the density of the particle, and the constant of proportionality $\alpha(k)$ depends only on $k$. Since $k \simeq-0.5$ in most cases, it is consistent with the order of the approximations involved to assume a constant value for $\alpha(k)$ of $\alpha(-0.5)$, in which case

$$
W^{*}=2.5 \times 10^{-?} \cap I^{1 / k} o_{p}^{-1 / 4 k} \mathrm{Y}^{\frac{1-4 k}{2 k}} V^{\frac{4 k-1}{2 k}} \text {. }
$$

Some physical insight into the bellavior predicted by Eq. 12. can be obtained by noting that $I \sim \varepsilon_{f}$, where $\varepsilon_{f}$ is the strain to failure in uniaxial tension, and $\mathrm{k} \simeq 0.5$; then

$$
\mathrm{W} *\left(1 / \varepsilon_{\mathrm{f}}\right)^{2}(1 / \mathrm{Y})^{3 / 2} \mathrm{~V}^{3}
$$

Equation 13 indicates that an interaction exists between hardness (i.e., Y) and ductility (i.e., $\varepsilon_{f}$ ). The model developed by Mamoun ${ }^{15}$ predicts a stronger dependence on velocity $\left(\sim V^{3}\right)$ than the models presented in Refs. 14, 17, and 18.

When attempting to assess the validity of the assumptions used in the deve1npment of Eq. 10, it is useful to examine the order of magnitude of the plastic deformation involved in a typical particle impact. For a 50- $\mathrm{m} \mathrm{Al}_{2} \mathrm{O}_{3}$ particle with a velocity of $30 \mathrm{~m} / \mathrm{s}$ impacting onto a l'ype 304 stainless stee1 surface, Eqs. 1 and 2 provide estimates of the plaslic-zune dimenoione: $\mathrm{L} \simeq 1 \mu \mathrm{m}$ and $\mathrm{a} \simeq 7 \mu \mathrm{m}$; for a $500-\mu \mathrm{m}$ particle at the same speed the plasticzone size is still small: $\mathrm{L} \sim 10 \mu \mathrm{m}$ and $\mathrm{a} \sim 70 \mu \mathrm{m}$. Since grain sizes for a Type 304 stainless steel surface are of the order of $50 \mu \mathrm{m}$, the plastic-zone size associated with impact occurs on a scale comparable to the grain size at these relatively low speeds for small particles. However, Eqs. 1 and 5 are based upon plasticity theories developed to describe the bulk behavior of polycrystalline materials. Similarly, the fatigue damage law, Eq. 7, was developed to describe the behavior of materials in macroscopic bending and torsion experiments. Thus, it is difficult to justify, a priori, the application of these results to describe behavior on a scale comparable to the grain size.

Despite this caveat, the crucial test of Eq. 12 is how well it predicts actual erosion behavior. Most of the erosion data in the literature are for much higher speeds $(100-400 \mathrm{~m} / \mathrm{s})$ than are of interest in coal gasification, and at these higher speeds different mechanisms of material removal may be acting. Table XI summarizes the velocity dependence observed in the literature for high-speed erosion tests. 
TABLE XI. Particle Velocity Dependence $\left(\mathrm{V}^{\mathrm{n}}\right)$ for High-velocity Erosive Wear

\begin{tabular}{|c|c|c|c|}
\hline Test Type & $\begin{array}{c}\text { Impact } \\
\text { Angle, deg }\end{array}$ & $\mathrm{n}$ & Reference \\
\hline $\begin{array}{l}\text { Air Blast, } 60 \text {-mesh } \\
\text { SiC Grit on Steel, } \\
\text { Cu, Al }\end{array}$ & 20 & 2.4 & 24 \\
\hline $\begin{array}{l}\text { Air Blast, } 180 \text {-mesh } \\
\text { SiC Grit on Steel }\end{array}$ & 20 & $2.4-2.7$ & 24 \\
\hline $\begin{array}{l}\text { Air Blast, } \mathrm{SiC}>100 \\
\mu \mathrm{m} \text { on Steel, } \mathrm{Cu}, \mathrm{A} 1\end{array}$ & 30 & 3.0 & 24 \\
\hline $\begin{array}{l}\text { Air Blast, SiC Grit } \\
\text { on Al, Cu, Steel }\end{array}$ & 20 & 2.9 & 25 \\
\hline $\begin{array}{l}\text { Whirling Arm, Quartz } \\
\text { Grit }>125 \mu \mathrm{m} \text { on } 11 \% \\
\text { Cr-Steel }\end{array}$ & 90 & 2.3 & 26 \\
\hline $\begin{array}{l}\text { Single Particle, } \\
2.3-\mathrm{mm} \text { Steel Shot } \\
\text { on Aluminum Alloy }\end{array}$ & $\begin{array}{l}20 \\
90\end{array}$ & $\begin{array}{l}2.8 \\
2.2\end{array}$ & 27 \\
\hline $\begin{array}{l}\text { Single Particle, } \\
\text { 9.5-mm Steel Shot } \\
\text { on Mild Steel }\end{array}$ & 30 & 2.9 & 28 \\
\hline $\begin{array}{l}\text { Air Blast, } 0.8-\mathrm{mm} \\
\text { Cast Iron Shot on } \\
\text { Stee1 }\end{array}$ & $\begin{array}{l}30 \\
90\end{array}$ & $\begin{array}{l}2.9 \\
2.1\end{array}$ & 29 \\
\hline
\end{tabular}

In the two cases (Refs. 27 and 29) for which direct comparisons between low- and high-angle impacts are available the agreement is superior at low angles. Note, however, that at a $20^{\circ}$ impingement angle the normal component of velocity $(\sim 40 \mathrm{~m} / \mathrm{s})$ is more typical of the speeds encountered in coal-gasification systems. Thus, the available data for high-velocity erosive wear at least suggests that in the range of normal velocities encountered in coal-gasification systems the velocity dependence predicted by the model is quite reasonable.

A more direct comparison of the theory ${ }^{15}$ with experiment is possible using data generated by the Natinnal Bureau of Standards (NBS). ${ }^{30}$ The1r experiments were conducted with $90^{\circ}$ impingement angles and at the lower speeds characteristic of coal-gasification systems. The NBS studies on a number of alloys indicate that at room temperature erosion is proportional to velocity in the range of $\mathrm{V}^{2.5}$ to $\mathrm{V}^{3}$, which is in agreement with the velocity dependence predicted by the theory. Experimental data 30 on erosive wear of Type 310 stainless steel at room temperature by $150-\mu m$ (100 mesh) SiC particles are shown in Fig. 45 along with the corresponding theoretical curve obtained from 


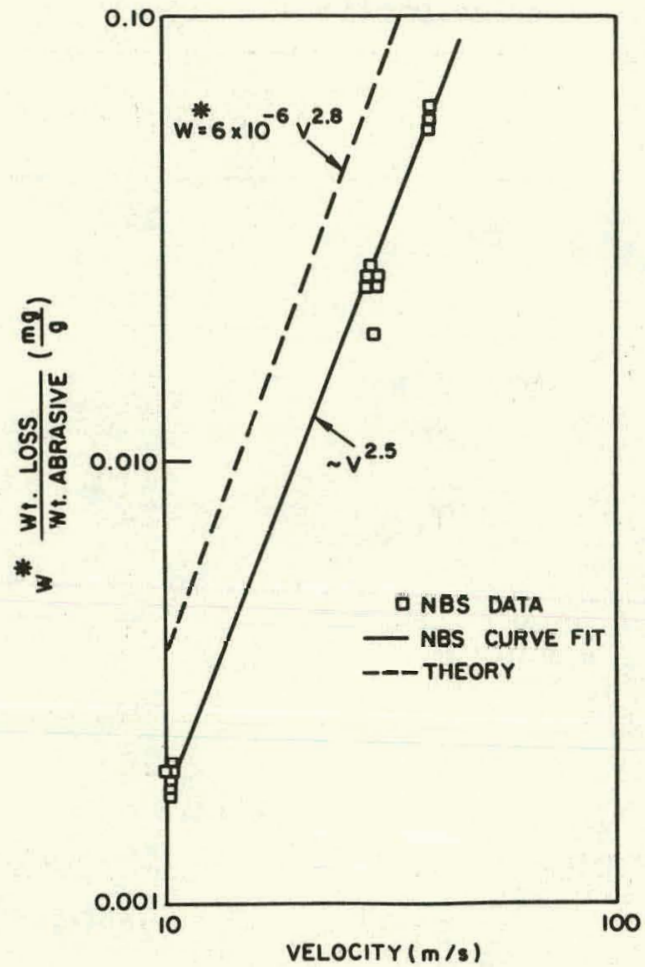

Fig. 45. Erosive Wear as a Function of Velocity for Typc 310 Stainless Steel. Neg. No. MST-63815.
Eq. 12. The NBS data on the erosion of Type 304 stainless steel at room temperature by $\mathrm{Al}_{2} \mathrm{O}_{3}$ particles are presented in $\mathrm{Fig} .46$ with the corresponding curve from Eq. 12. When computing the theorectical results, the proper value for yield stress is the saturation value of the cyclic-hardening stress; in the calculations provided in the present report, this value has been approximated as $0.75 \sigma_{\text {ULT }}$, where oULT is the ultimate tensile strength at the appropriate temperature.

The agreement with the available data at room temperature is good. Equation 12 indicates that the relative eroston tale is independent of parlicle sizc. This is consistent with experimental observations for particles over $100 \mu \mathrm{m} ;{ }^{14}$ however, a particlesize effect has been observed for smaller particles 14 and is evident from the NBS data on Type 304 stainless steel. Fortunately, wear rates decrease with particle size tor the smaller particles. The reasons for this size effect are not clear. It may be a physical size effect in that impacted regions below a certain size show an increase in yield strength.

The agreement at higher temperatures is not satisfactory. In general, the model predicls that crosion rates increase with increasing temperature. The data from $\mathrm{NBS}^{30}$ indicate that this is not necessarily the case. Studies on a number of alloys shnw that, for small, 5- $\mu \mathrm{m}, \mathrm{Al}_{2} \mathrm{O}_{3}$ particles at $\mathrm{V}=30 \mathrm{~m} / \mathrm{s}$, erosion rates decreased as the temperature was increased from 25 to $500^{\circ} \mathrm{C}$; for the larger, $50-\mu \mathrm{m}, \mathrm{Al}_{2} \mathrm{O}_{3}$ particles, the erosion rates in general increased with temperature, but not in all cases. Since the tests were conducted at a $45^{\circ}$ impingement angle, a quantitative comparison cannot be made between theory and experiment.

The discrepancy is apparently due to oxide formation on the surface. After testing specimens at $500^{\circ} \mathrm{C}$ for $2 \mathrm{~min}$, the $\mathrm{NBS}^{30}$ observed film thicknesses that ranged from 0.5 to $2 \mu \mathrm{m}$, depending on the alloy. This oxide film offers considerable protection, at leasl from small purlicles. Additional tests are required to determine whether the theory is adequate for larger particles, where the oxide film is relatively less effective.

Task F -- Component Performance and Failure Analysis (S. Dany Zuk, G. M. DrageZ, M. D. Gorman, W. J. Shack, and W. A. Eillingson)

The activity during this quarter involved examination of failed components from the Synthane pilot plant (weld-neck flange and ball-valve stem), HYGAS pilot plant [ $\mathrm{N}_{2}$ purge line (322 1ine) and thermocouple protection tube], 


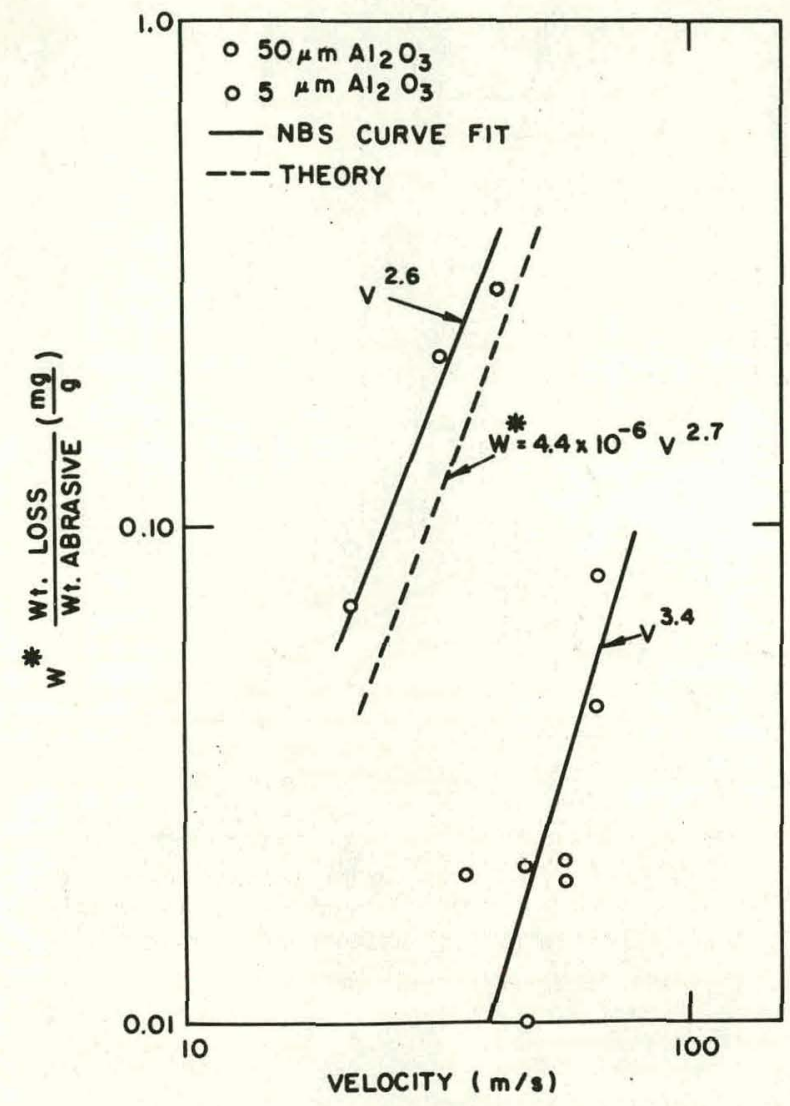

Fig. 46. Erosive Wear as a Function of Velocity for Type 304 Stainless Stee1. Neg. No. MSD-63814. and Grand Forks Energy Research Center (GFERC) (gate valve). A final report of the results from the investigation of the weld-neck flange has been issued, and a final report of the ball-valve stem failure is in preparation. The results from the investigations of the other components have been communicated to HYGAS and GFERC personnel, and final reports will be issued in the coming quarter. A summary of these analyses is presented below. Also, a final report, "Analysis of the HYGAS Ash Agglomerting Gasifier Internal Cyclone Dipleg Failure," has been issued (December 1976). This failure was described in a previous quarterly report. 31 Work is continuing on failure analysis of components from the HYGAS pilot plant, Morgantown Energy Research Center, and GFERC.

\section{Synthane Weld-neck Flange}

The Synthane high Btu coa1conversion pilot plant was shut down after the discovery of a leaking crack in a Type 304 stainless steel weldneck flange that is part of a preheat line of the gasifier. The flange was exposed to $\sim 2.9$ Ms of operation at 4.3

MPa steam and $399^{\circ} \mathrm{C}$. Several nonleaking intergranular cracks were also found at the inside diamter (ID) surface of the weld neck. The cracks are believed to be due to intergranular stress corrosion and the effects of aqueous chlorides; the chlorides were present in city water that was used to backfill the loop seal. One crack had penetrated through to the outside diameter (OD). 'The cracks may have initiated in the heat-affected zone associated with the butt weld between the weld-neck flange and preheat piping. This hypothesis was not verified, however, since the weld was not available for analysis. The piping system in which this failure occurred is used to carry oxygen and steam and is subjected to flue gas during start-up of the gasifier. An isometric drawing of the preheat piping is shown in Fig. 47. The water-loop seal, steam and $\mathrm{O}_{2}$ inlet, and distributor cone are also shown. Butt welds are indicated by dots, and the weld-neck flange (A) that had developed cracks is near the top of the figure.

Samples of the cracked regions were prepared for metallographic analysis. Figure 48 shows an isometric drawing and photograph of the weldneck flange. Metallography revealed precipitates at the grain boundaries and the occurrence of slip and precipitation on slip planes. This indicated that plastic deformation in excess of that expected under normal operating conditiuns liad occurred and the examined region of the weld-neck flange had been 


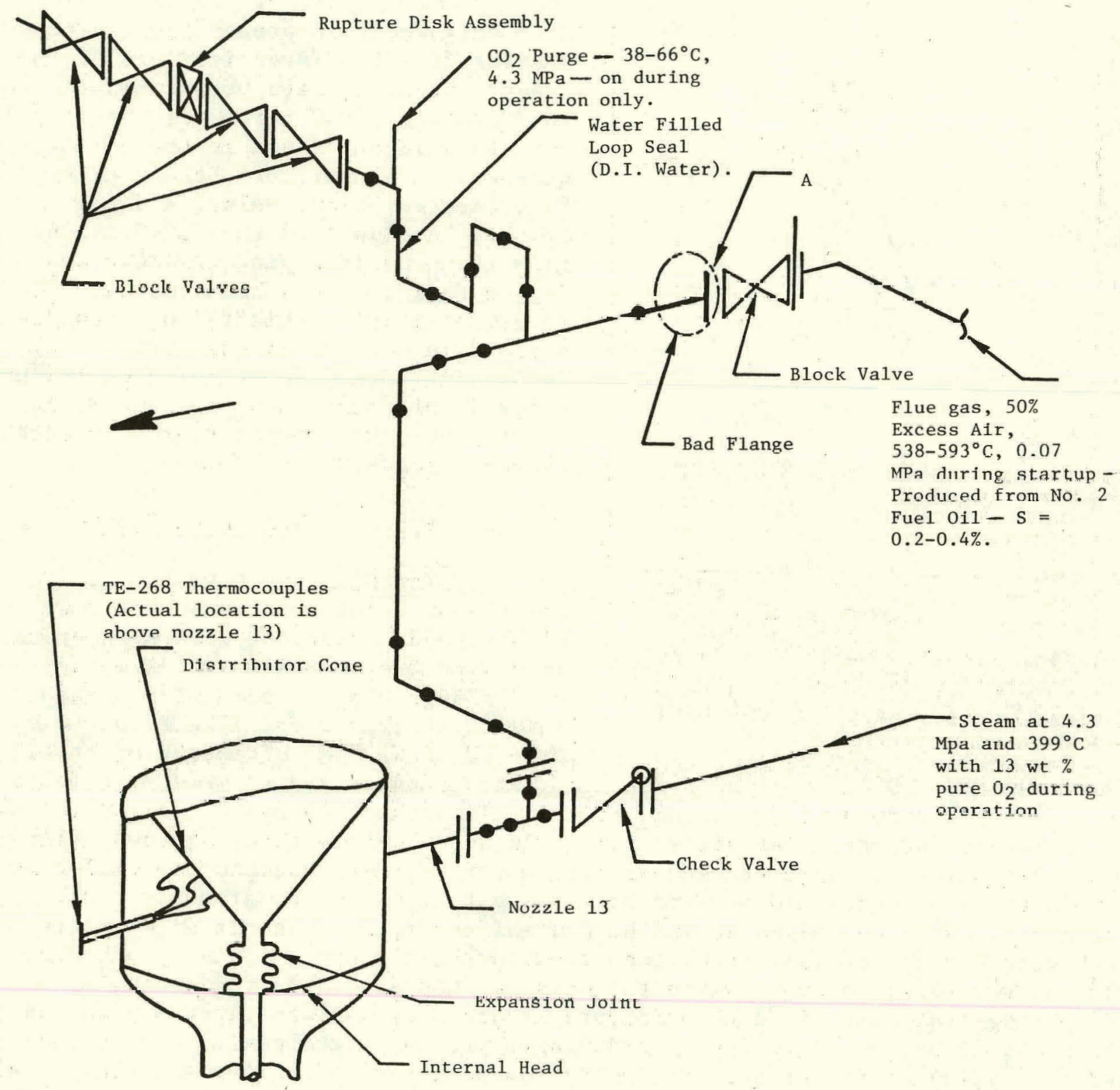

Fig. 47. Isometric Drawing of the Preheat Line. The cracked flange "A" is shown at the top center. The distributor cone is shown at the lower left. Butt welds are indicated by dots. Neg. No. MSD63862 . 


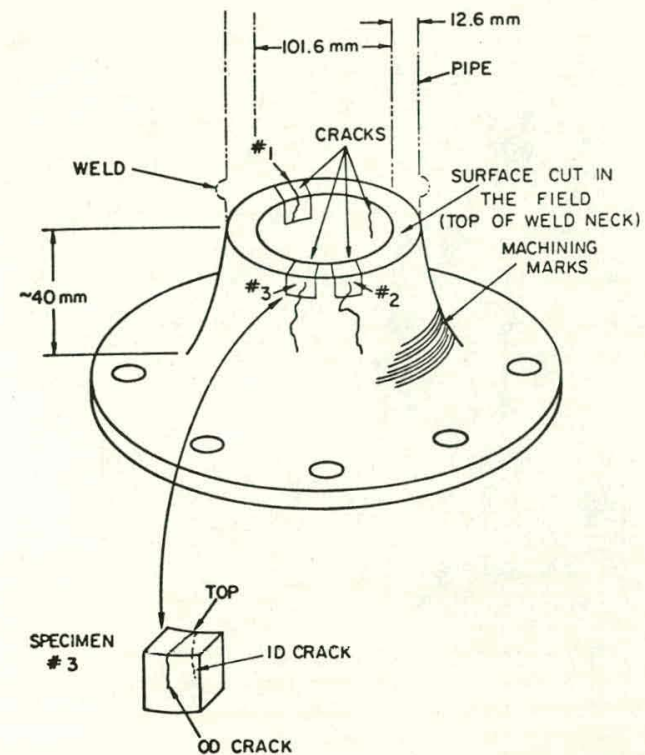

(a)

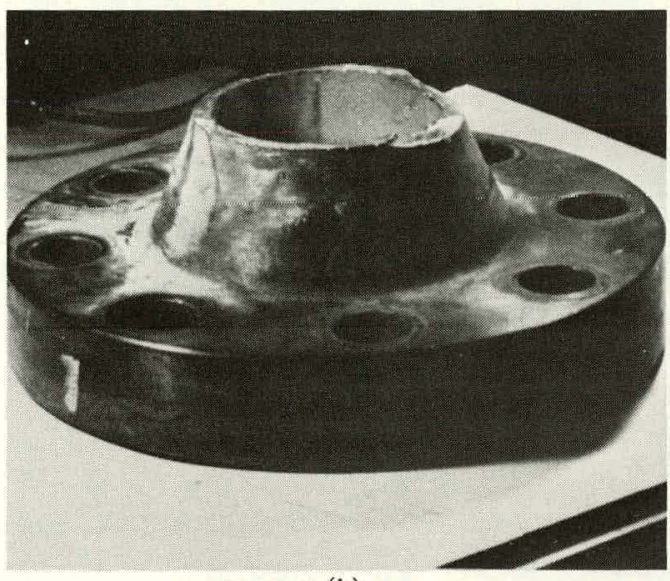

(b)

Fig. 48. Isometric Drawing and Photograph of the Weld-neck Flange. The three cracks examined are indicated. Neg. No. MSD-63861. cold worked prior to a heat treatment. Radiography failed to reveal any cracks in the weld-neck region. Dye penetrant was used successfully to pinpoint one leaking crack on the $O D$ and record the extent of two additional cracks on the ID surface.

The cracked Type 304 stainless steel weld-neck flange was replaced by Synthane-Lummus personnel, and the loop seal has been filled with deionized water. It was recommended that the preheat piping system be replaced, but, if this is not practical, close monitoring for additional cracks (by visual inspection) should be continued. If additional problems are encountered with the replaced weld-neck flanges, the weld and heat-affected zone should be preserved for analysis. Spotcheck Formula B Penetrant should not be used in the field since it contains chlorides. Zyglo dye penetrant is recommended.

\section{Synthane EBV Ba11-valve Stem Failure}

A ball valve (Type 440C stainless steel) at the exit port of the pressurized feed hopper (Fig. 49) in the Synthane pilot plant failed by separation of the valve stem from the valve body. The failure was mechanical in nature and was due to surface defects that increased the stresses at the junction between the valve shoulder and stem. The radius of curvature between these components significantly increased the stresses. Figure 50 shows the ball valve, fractured valve stem, and top and bottom ball-valve seats. The ball valve in this figure was oriented to be in the open position. A crack initiated and propagated until $215 \%$ of the cross-

sectional area was traversed. The failure was completed by brittle fracture in a shear mode with sume bending moment. Calculations showed that the motor drive used to operate the valve could not have sheared the stem if the surface defects wcre not presenl.

Analysis by SEM showed that silicon-, calcium-, and titanium-rich precipitates are wedged in the surface oxide at the fracture surface. It is not known how these precipitates participated in the fracture mechanism. Striations oriented along the longitudinal axis were observed on the polished face of the valve $8 t c m$. These strlations were filled with precipitates that are rich in chromium and iron. 


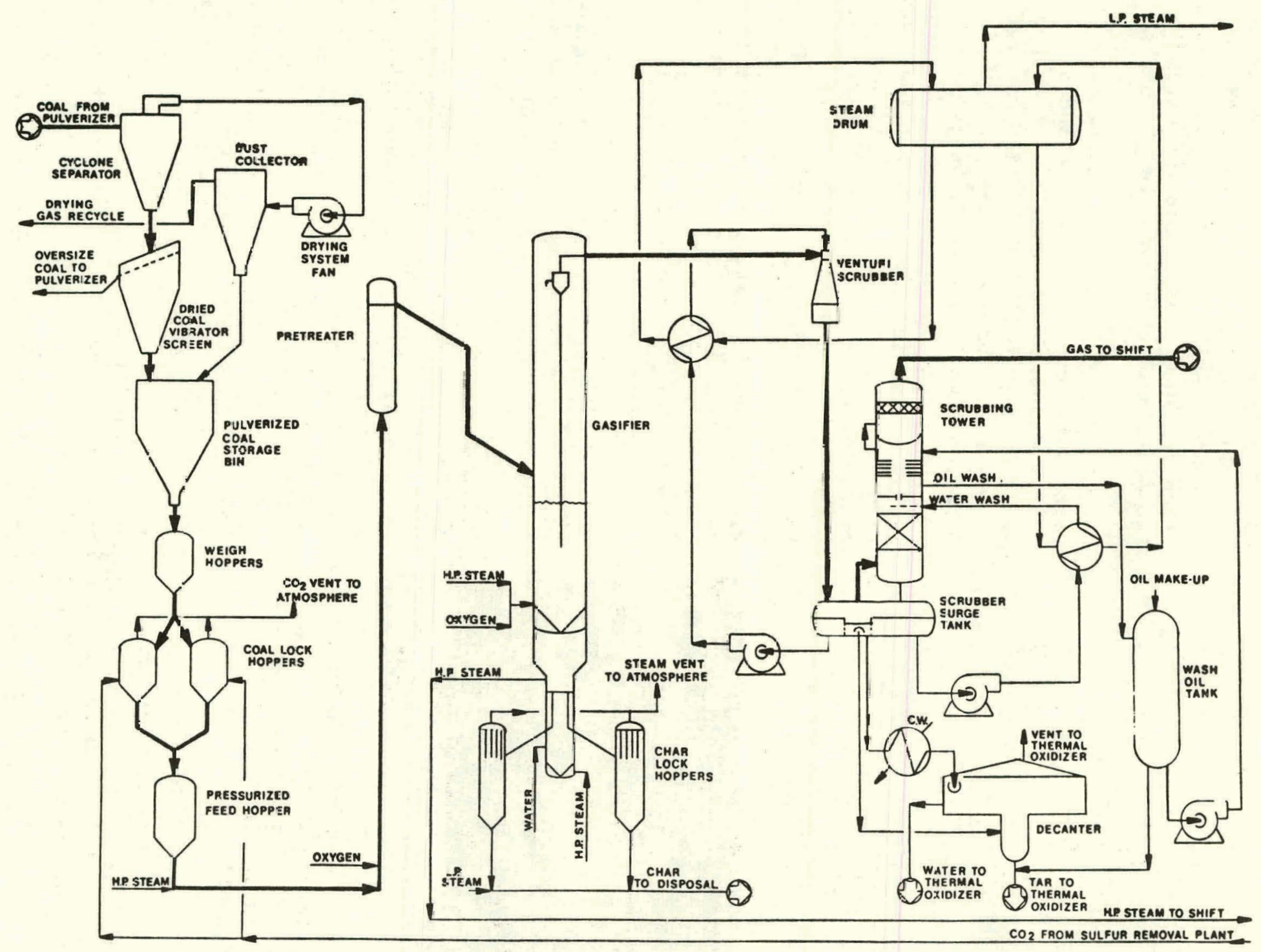

Fig. 49. Synthane Coal-yasification Pilot-plant Process. Neg. No. MSD-63863. 


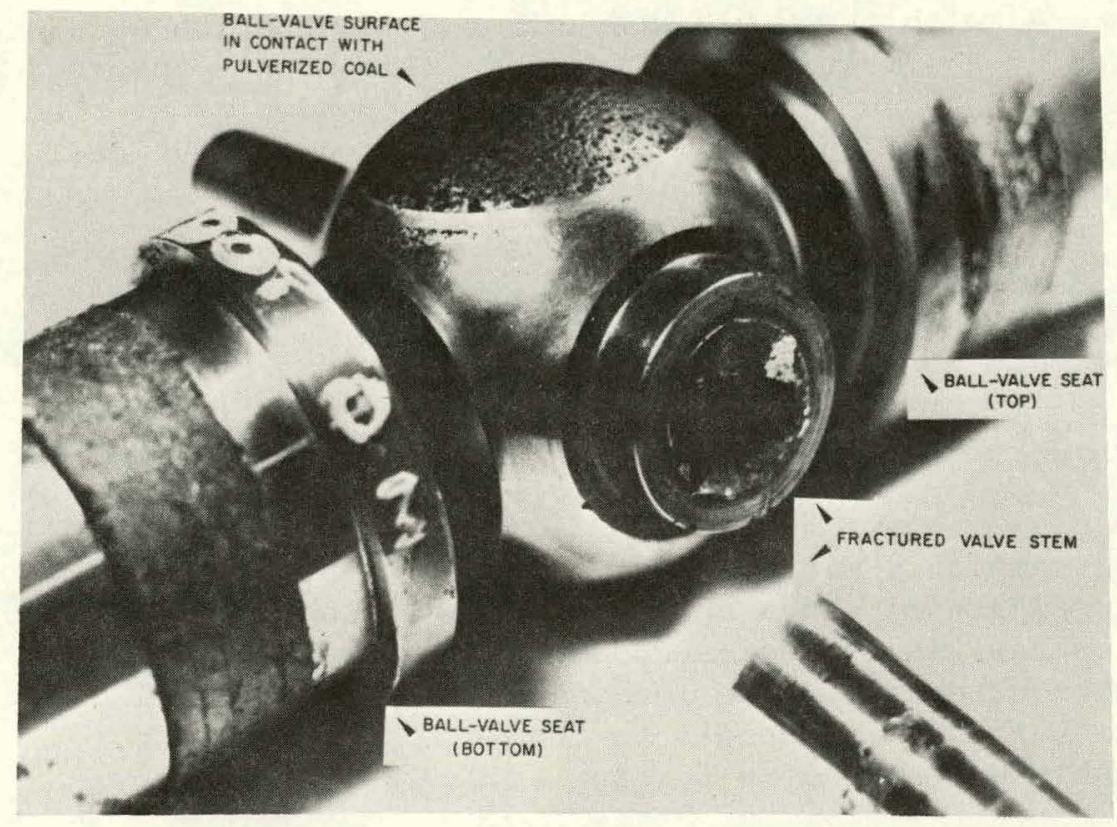

Fig. 50. Ball Valve, Fractured Valve Stem, and Top and Bottom Ball-valve Seats. Neg. No. MSD-63859.

Pitting was observed on surfaces that were in contact with the coal feed. This pitting is believed to be chemical in nature and is not related to the failure.

It was recommended that a more careful quality control of the surface finish and preparation should be initiated to minimize crack initiation due to surface flaws. A beveled interface between the valve stem and body would reduce the stress concentration and the possiblity of crack initiation.

\section{HYGAS $\mathrm{N}_{2}$ Purge Line (322 Line)}

A nitrogen purge line (Type 316 stainless steel) from the 322 line of the HYGAS pilot plant fractured in a brittle manner along the grain boundaries. This purge line transports process gas in the bottom zone (steam-oxygen) of the gasifier.

The grain boundaries were found to be embrittled by chrome sulfides, and three distinct layered phases, rich in sulfur, lined the ID surface of the tube that had been exposed to the bottom zone $\left(\sim 760-870^{\circ} \mathrm{C}\right)$. Also, significant amounts of silicon were located at the grain boundaries. Wet chemical methods have shown that the innermost phase at the ID contains $~ 11-2$ wt\% sulfur. This result is quite surprising since the $O D$ of the tube does not contain such a large quantity of sulfur. At present, the point in the process at which the sulfur may have entered the tube is not known.

\section{HYGAS Thermocouple Protection Tube Failure}

A thermocouple protection tube (Type 310 stainless steel) from the Ash Aglomerating Gasifier of the HYGAS plant failed by melting and shorting of the thermocouple wires. The melting occurred near the end of the tube that was inside the gasifier. This behavior is similar to that of a failure reported previously.13 The melted zone contained $24.0 \mathrm{wt} \%$ sulfur, which is 
exceedingly high when compared with the 0.012 wt\% sulfur concentration obtained from a section not affected by the melting. Sulfur and silicon were observed by electron-microprobe analysis to be located in the grain boundaries of the bulk material near the melted zone. The cause of failure was excessive deviation from specified process temperatures.

\section{GFERC Cracked Gate Valve}

A gate valve used in the steam-generating system of the GFERC coa1gasification pilot plant failed by fracture of the valve plug guide. The valve was in service from 1958 to 1965 and was used again in the reactivation tests of April 1976.

The failure was mechanical, with a crack originating at the inside surface nf the guide lip. Figure 51 shows a pholugraph and schematic of the fracture surface. The crack origin is indicated along with shear $\perp i p$, beach marks, and crack-propagation direction. The loading was apparently well distributed, although the crack grew more rapidly to the left of the figure. Crack initiation was probably a result of a forging or surface defect.

The valve has been replaced, and it is recommended that the guide surfaces be inspected periodically for surface detects.
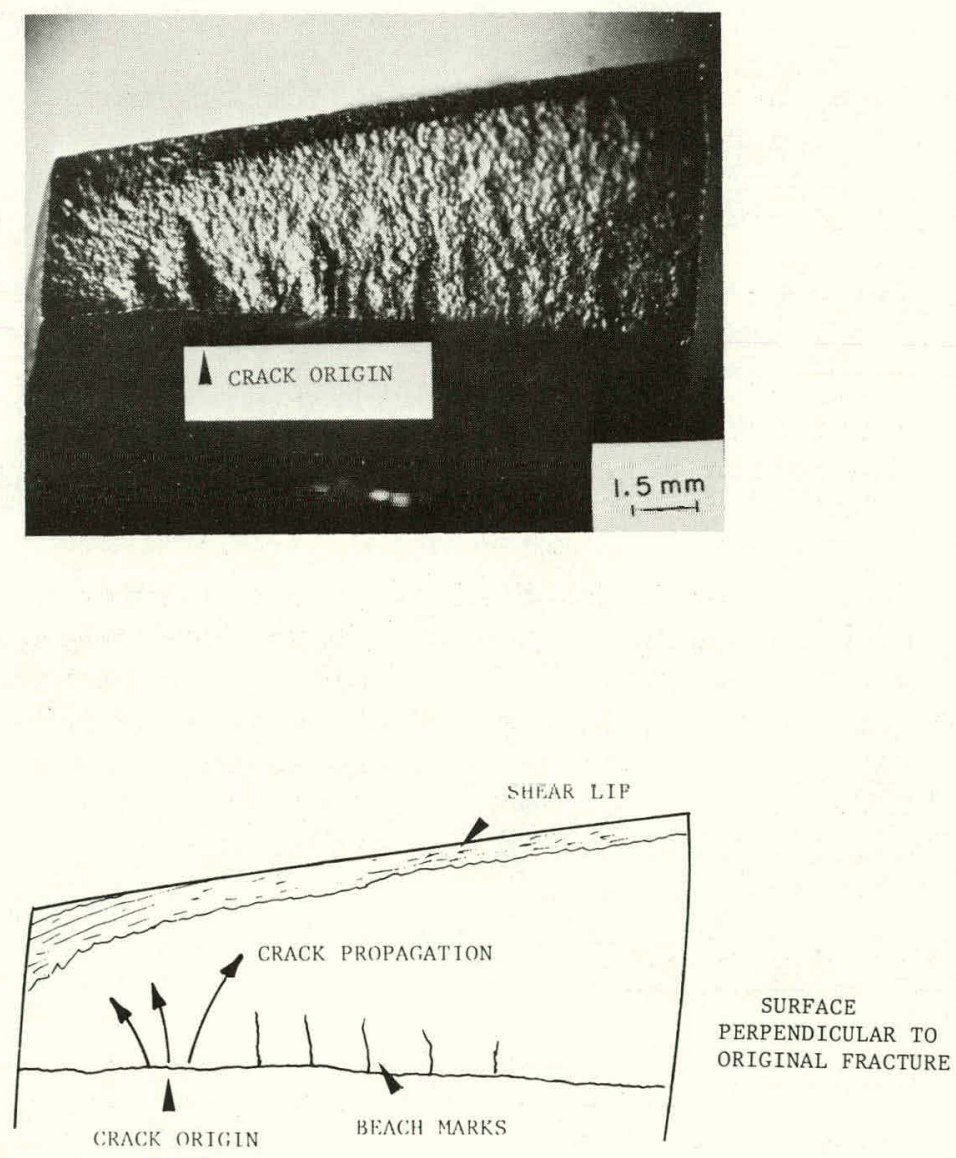

Fig. 51. Photograph and Schemat1c of Fracture Surfare of Gate-valve Guide. Neg. No. MSD-63860. 


\section{REFERENCES}

1. Materials Science Division Coal Technology Eighth Quarterly Report, JulySeptember, 1976, Argonne National Laboratory, ANL-76-125.

2. AGA Thermovision 750 Operating Manual, Publication 556.408, AGA Infrared Systems, 1973.

3. A. 'J. MacNab, Workshop on Materials Problems and Research Opportunities in Coal Conversion, Vol. II, Ohio State University, Columbus, Ohio, April 16-18, 1974, p. 33 .

4. K. Natesan, "High-temperature Corrosion," Proc. Conf. on Prevention of Failures in. Coal-conversion Systems, Battelle-Columbus Laboratories, Columbus, Ohio, April 21-23, 1976, to be published.

5. K. Natesan and T. F. Kassner, Met. Trans. 4, 2557 (1973).

6. C. S. Giggins and F. S. Pettit, Trans. Met. Soc. AIME 245, 2495 (1969).

7. J. P. Coughlin, U. S. Burealu of Mines Bulletin 542 (1954).

8. K. K. Kelley, U. S. Bureau of Mines Bulletin 601 (1962).

9. 0. Kubaschewski and E. Evans, Metallurgical Thermochemistry, ButterworthSpringer Ltd., London, 1956.

10. J. F. Elliott and M. Gleiser, Thermochemistry for Steelmaking, Vol. 1, Addison-Wesley Publishing Company, Reading, Mass., 1960.

11. D. J. Young, W. W. Smeltzer, and J. S. Kirkaldy, J. Electrochem. Soc. 120 1221 (1973).

12. M. A. H. Howes, "Selection of Materials Used in Coal-gasification Plants," Seventh Synthetic Pipeline Gas Symposium, Proceedings, October 1975, Chicago, American Gas Association, ERDA, and International Gas Union, p. 31 .

13. Materials Science Division Coal Technology Sixth Quarterly Report, January-March, 1976, Argonne National Laboratory, ANL-76-60.

14. I. Finnie, Wear 19, 81-90 (1972).

15. Materials Science Division Coal Technology Second Quarterly Report, January-March, 1975, Argonne National Laboratory.

16. Materials Science Division Coal Technology Third Quarterly Report, April-June, 1975, Argonne National Laboratory.

17. W. H. Jennings, W. J. Head, and C. R. Manning, Jr., Wear 40, 93-112 (1976).

18. J. G. A. Bitter, Wear 6 , 5-21 (1963). 
19. J. G. A. Bitter WEAR $\underline{6}, 169-190$ (1963).

20. J. H. Neilson and A. Gilchrist, Wear 11, 111-122 (1968).

21. J. P. Andrews, Phil. Mag. 9, 593-599 (1930).

22. D. Tabor, The Hardness of Metals, Oxford University Press, London, 1950.

23. S. S. Manson and M. H. Hirschberg, "Fatigue Behavior In Strain Cycling in the Low- and Intermediate-cycle Range," in Fatigue -- An Interdisciplinary Approach, Syracuse University Press, Syracuse, New York, 1964.

21. F, T.. Sheldon, J. Basic Eng. (I'rans. ASME Ser. D) 92, 619-623 (1970) .

25. G. L. Sheldon and I. F1nule, J. Eng. Ind. (Irans. ASME Ser. B) 89, 387-395 (1966).

26. G. P. Tilley and W. Sage, Wear 16, 447-488 (1970).

27. G. L. Sheldon and Ashok Kanhere, Wear 21, 195-209 (1972).

28. I. M. Hutchings, R. E. Winter, and J. E. Field, Proc. Roy. Soc. Lond. A 348, 379-392 (1976).

29. I. Kleis, Wear 13 , 199-215 (1969).

30. Material Research for Clean Utilization of Coal, Quarter1y Progress Report, July 1976, National Bureau of Standards. 


\section{Distribution of ANL-77-5}

\section{Internal:}

E. G. Pewitt

A. D. Tevebaugh

B. R. T. Frost

R. W. Weeks (6)

M. F. Adams

O. K. Chopra

S. Danyluk

D. R. Diercks

W. A. Ellingson (6)

$\mathrm{J}$. Fischer

K. J. Reimann
A. A. Jonke

T. F. Kassner

C. R. Kennedy

A. B. Krisciunas

K. Natesan

J. L. Nivens

R. B. Poeppel

W. J. Shack

ANL Contract Copy

ANL Libraries (5)

TIS Files (6)

\section{External:}

ERDA-TIC, for distribution per UC-90h (231)

Manager, ERDA-CH

Chief, Chicago Patent Group

President, Argonne Universities Association

Materials Science Division Review Committee:

R. W. Balluffi, Cornell Univ.

S. Doniach, Stanford Univ.

H. L. Falkenberry, Tennessee Valley Authority

C. Laird, Univ. Pennsyl.vania

D. Lazarus, Univ. Illinois

M. T. Simnad, General Atomic

A. R. C. Westwood, Martin Marietta Laboratories

V. F. Zackay, Univ. California, Berkeley

R. R. Adams, Battelle Columbus Laboratories

W. G. Bair, Inst. of Gas Technology

W. Bakker, USERDA/FE

S. Carson, CE Lummus Co.; Bruceton, $\mathrm{Pa}$.

A. Conn, Amoco Oil Co., Naperville, Ill.

W. C. Corder, Battelle Columbus Laboratories

M. Crowley, Standard Oil of Indiana, Naperville, Ill,

J. Flagg, Universal Oil Products Co., Des Plaines, Ill.

E. Fox, Stearns-Roger Corp., Homer City, $\mathrm{Pa}$.

H. E. Franke 1, USERDA/FE

D. Glaser, Stearns Roger Corp., Denver

H. Heysteck, Tuscaloosa Metallurgy Research Center, University, Ala.

V. Hill, IIT Research Inst.

D. Hull, Philips Petroleum Co., Homer City, Pa.

H. Leavenworth, U. S. Bureau of Mines, Washington

R. Lewis, Synthane Pilot Plant, USERDA/FE, Pittsburgh

G. Long, Northern Illinois las Co., Aurora

R. M. Lundberg, Commonwealth Edison Co., Chicago

A. L. Plumley, Combustion Engineering Power Systems, Windsor

A. Schaeffer, Metals Properties Council, New York

S. J. Schneider, National Bureau of Standards

J. R. Schorr, Battelle Columbus Laboratories

J. Stevensnn, Rolla Mctallurgy Research Center

J. Sudbury, Consolidated Coal Co., Library, Pa. 
C. Whitten, Peabody Coal Co., Columbia, Tenn.

F. Woods, Albany Metallurgy Research Center

A. V. Levey, Lawrence Berkeley Laboratory

J. M. O'Donnell, The Lummus Co., Bloomfield, N. J.

R. I. Jaffee, Electric Power Research Institute

D. L. Keairns, Westinghouse Research Labs.

S. M. Gaitonde, Commonwealth Edison Co., Maywood, I11.

E. M. Anderson; The Babcock \& Wilcox Company. 